

\section{EDITORIAL POLICY}

Papers must be submitted with the understanding that they have not been published elsewhere (except in the form of an abstract or as part of a published lecture, review, or thesis) and are not currently under consideration by another journal published or any other publisher. The submitting (Corresponding) author is responsible for ensuring that the article's publication has been approved by all the other coauthors. It is also the authors' responsibility to ensure that the articles coming from a particular institution are submitted with the approval of the necessary institution. Only an acknowledgment from the editorial office officially establishes the date of receipt. It is a condition for submission of a paper that the authors permit editing of the paper for readability. All enquiries concerning the publication of accepted papers should be addressed to nadipelly.j@tau.edu.gy.

\section{EDITORIAL TEAM}

Chief Patron:

Dr. A. Anand, Vice Chancellor, TAU, Guyana.

Executive Editor: Dr. Jagan Nadipelly, Faculty of Medicine - Pharmacology, TAU, Guyana.

Managing Editor: Dr. Pendru Raghunath, Asso. Prof. of Microbiology, TAU, Guyana.

\section{PEER REVIEWERS}

Dr. S. Esakki Muthu, Professor and HOD, Premedical Department, TAU, Guyana.

Dr. Edna D Cuaresma, Asso. Prof., Clinical Sciences, TAU, Guyana.

Mr. Dave C. Paguntalan, Asst. Prof., Nursing Sciences, TAU, Guyana.

Dr. Nagesh Venkatasubbareddy, Asst Prof., Pharmacology, TAU, Guyana.

Dr. Sankalan Sarkar, Asst. Prof. of Physiology, TAU, Guyana.

Dr. Rajini Kurup, Asst Prof., Microbiology, Uni. of Guyana, Guyana.

Dr. V. Bhuvarahamurthy, Professor and Head Department of Medical Biochemistry

University of Madras IBMS, Taramani, Chennai.

\section{PRINCIPAL CONTACT INFORMATION}

Dr. Pendru Raghunath,

Managing Editor, TIJBMS,

Associate Professor of Microbiology,

Texila American University (TAU), George Town, Guyana, South America,

E-mail: pendru.r@tau.edu.gy

Skype: pendru.r@tau.edu.gy 


\section{ABOUT PLAGIARISM}

Plagiarism is the use or close imitation of the language and ideas of another author and representation of them as one's own original work. Duplicate publication, sometimes called self-plagiarism, occurs when an author reuses substantial parts of his or her own published work without providing the appropriate references. This can range from getting an identical paper published in multiple journals, where authors add small amounts of new data to a previous paper.

Plagiarism can be said to have clearly occurred when large chunks of text have been cut and pasted. Such manuscripts would not be considered for publication in TIJBMS Journal. But minor plagiarism without dishonest intent is relatively frequent, for example when an author reuses parts of an introduction from an earlier paper. The editors will judge any case of which they become aware (either by their own knowledge of and reading about the literature, or when alerted by referees) on its own merits.

The paper containing the plagiarism will be obviously returned back to the author's for review, but we earnestly request the authors to avoid submitting plagiarized. 


\section{DISCLAIMER}

Texila International Journal of Basic Medical Science's (TIJBMS) make every effort to ensure the accuracy of all the information (the "Content") contained in its publications. However, the TIJBMS and its agents make no representations or warranties whatsoever as to the accuracy, completeness or suitability for any purpose of the Content and disclaim all such representations and warranties whether express or implied to the maximum extent permitted by law. Any views expressed in this publication are the views of the authors and are not necessarily the views of the Editor's or Texila International Journal of Basic Medical Science's. 


\section{TABLE OF CONTENT}

1 Does the Flipped Classroom Method Enhance the Learning of Undergraduate

Medical Students: A Review

Arulsamy Anand

2 Elements that Establish a Healthy Doctor Patient Relationship

Kim Near

3 Occurrence, Molecular Characterisation and Antibiogram of Water Quality Indicator Bacteria (Pseudomonas Aeruginosa and Enterobacter Aerogenes) in Water Samples from Klang River

Abisola Mercy Olowofeso

4 Tranexamic Acid: Implementing a Clinical Guideline for its use in a Moderate Resource Setting

Hemchand Jhagru

5 Characterization of Selected Medicinal Plants of Mamanwa Tribe in Caraga, Philippines

Levitah C. Mapatac 


\title{
Does the Flipped Classroom Method Enhance the Learning of Undergraduate Medical Students: A Review
}

\author{
Article by Arulsamy Anand \\ Vice Chancellor, Texila American University, East Bank Demerara, Guyana \\ Email:vc@tau.edu.gy
}

\begin{abstract}
Objective: There has been a remarkable transformation in medical education, more so with the advent of technology into education and also because of the certain regulatory bodies' requirements. One among the transformation is the flipped classroom method. More and more schools have started to use flipped classroom $(F C)$ teaching approach in an effort to enhance student's active engagement in learning. The aim of this review is to examine the efficacy of the FC model over traditional lecture methods

Methods: A literature search was conducted using the major electronic databases on researches published from 2016 to 2018. Peer-reviewed papers were screened and reviewed according to explicit inclusion criteria. A total of 426 study were sourced and out of which only 18 were chosen for the review and analysis based on the inclusion and exclusion criteria

Results: Out of the 18 study chosen study 10 of them explicitly stated that the flipped classroom approach in health professions education yields a significant improvement in student learning compared with traditional teaching methods, however 8 studies stated that FC did not have significant advantages over the lecture methods rather reported more burden and pressure than those from the traditional lectures

Conclusion: Flipped classroom teaching and learning pedagogy is one of the effective ways of enhancing student engagement and learning, however, this would be more effective only if students are motivated and as such FC does not seem to address the less motivated and thereby engagement of the students is likely to be the same as in other traditional methods
\end{abstract}

Keywords: flipped classroom, learning methods. Lecture-based, student's engagement.

\section{Introduction}

The flipped classroom is an innovative pedagogical approach that focuses on learner-centered instruction.[8] FC is the result of assigning didactic material to learners before class time while using the face-to-face time for more active learning strategies such as reflection, group projects, or discussions. Core elements of an FC include assigned pre-class content, formative assessment, working on learning gaps, developing competency, and the teachers' role as a guide on the side. Studies show that video lectures slightly outperform in-person lectures, with interactive online videos doing even better. Online homework is just as effective as paper-and-pencil homework. According to Tucker (2012), students utilize the time in class to work through problems, advance concepts and engage in collaborative learning. Research also shows that using class time for active learning versus lecture provides opportunities for greater teacher-to-student mentoring, peer-to-peer collaboration and crossdisciplinary engagement. [8]

Ideally, Teachers who use the 'flipped classroom approach' reverse the role of school work and homework; they achieve this by either recording their lectures or using already available video lectures from the internet. Students gain access to their subject videos through Learning Management System prior to the classes, and they watch these lectures and prepare for their classes outside the classroom. During the class hour, normally called as, In Class Session [ICS], the teacher administers reef polling to assess the students' knowledge on the topic. During the ICS the teacher ideally administers 10 or more questions through reef polling, and the teacher gets to see the results instantaneously. In the event of the majority of students not getting the correct answer, the students will be split into small groups for discussion on the topics where they have not scored correctly. In case if the students further need 
clarification on the topics then the teacher would conduct a focused mini-lecture for about 10 to 12 minutes.

The flipped classroom has been gaining popularity in recent years. In theory, flipping the classroom appears sound: passive learning activities such as unidirectional lectures are pushed to outside class hours in the form of videos, and precious class time is spent on active learning activities.[13] But does using the flipped classroom approach in medical schools really enhance students learning? Most of the researches cite a positive perception of the students on flipped classroom methods, however, this does not necessarily imply that this instructional approach will significantly enhance student's engagement and improve learning. There are also several barriers to implementing the flipped classroom, which includes access to resources, time, technical support, teacher beliefs, teacher readiness, overall support, and leadership. Technology drawbacks are always a factor when choosing to use technology as a truly integral part of learning. Technology failure - power, software crashes, and Internet connectivity — will inevitably occur from time to time. Teachers must consider back up plans when issues arise. Another fear of some educators is that the increasing use of computers in the classroom threatens to decrease the intimacy between students and teachers, and with it, teacher morale. [19]

The uncertainty about the effectiveness of the flipped classroom approach over the traditional lecture method provided the impetus for the current review. We opted to study the efficacy of flipped classrooms with traditional classrooms because the latter is still widely used in medical schools worldwide.

\section{Methods}

Articles from the various digital database were sourced, 426 related articles were identified from Pubmed, Biomed Central and Google scholar. The articles were chosen only from 2016 to 2018 so as to obtain a more recent perspective.

\section{Eligibility criteria}

To examine the possible effects of the flipped classroom on student achievement, a review was done on eligible articles. The eligibility criteria are as follows:

Inclusion: The objectives of the studies should be primarily focused on the efficacy of the FC model over traditional lecture-based.

Exclusion: The articles were excluded if the study was not conducted on undergraduate medical education and if the data was incomplete.

\section{Study selection and data extraction}

The title and the abstract of various studies from the initial search were screened in order to derive a primary set of full articles for the proposed final review. Further, the author verified the relevance of the full article and came into a conclusion to include the article for the final review. To extract the data, the author looked for information including authors of the study, publication year, location in which the study was conducted, subject topic, participant sample, study design, and details of the flipped classroom implementation such as the uses of video lectures and in-class session activities. To reach consensus, the discrepancies between the extracted data of the two researchers were reviewed, discussed, and resolved prior to data entry and analysis.

The initial search strategies yielded 426 original candidate articles, but after abstract review, 28 articles remained eligible for inclusion. Among the common reasons for article exclusion were the following: the learners described were not medical students and did not focus on the efficacy of the FC in enhancing the learning. After reviewing full texts, an additional 10 studies were excluded for reasons including lack of program evaluation, nonmedical student learners, and insufficient characteristics of the flipped classroom approach (Figure 1). As a result, 18 articles were selected for inclusion in this review. 


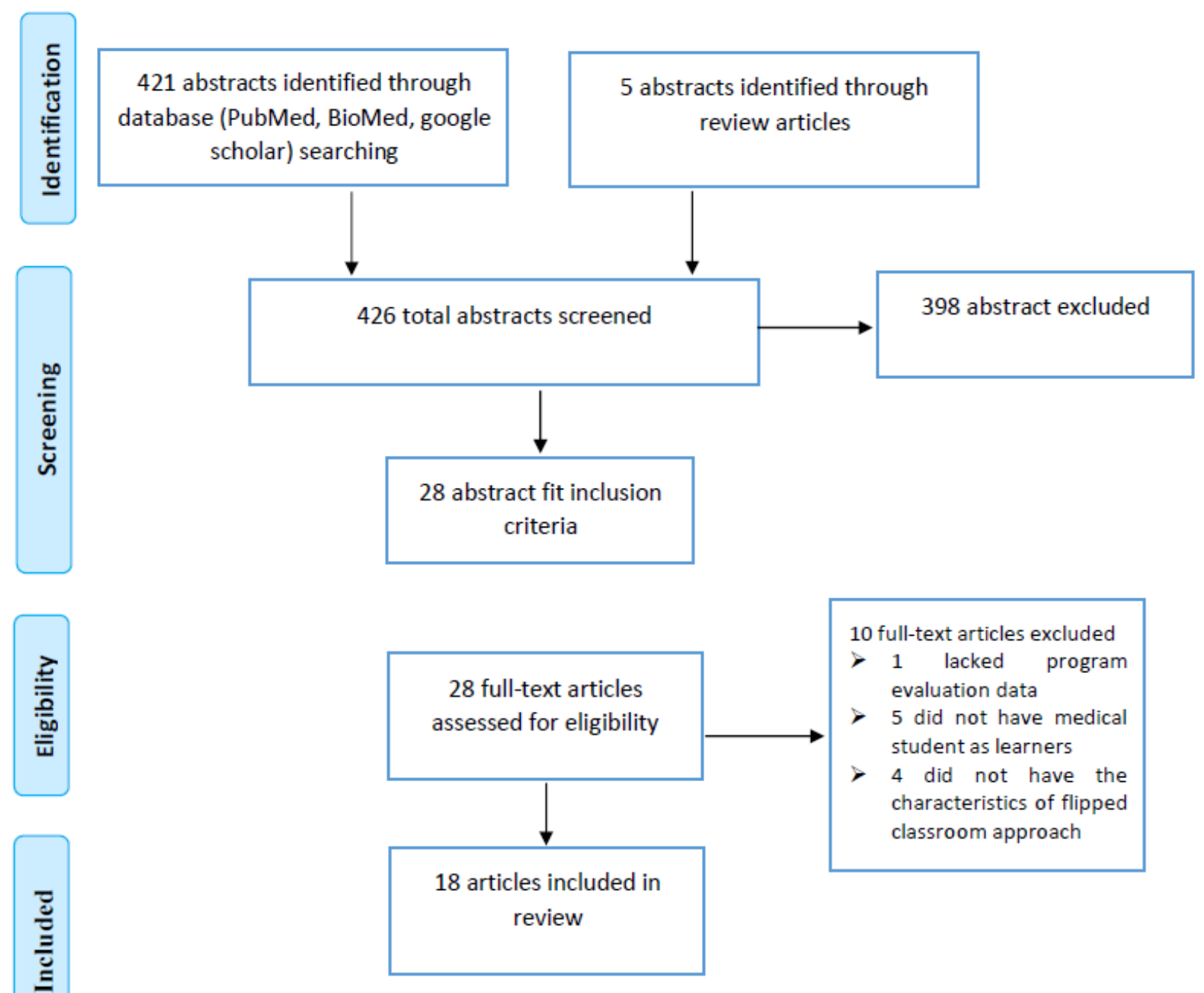

Figure 1. Search process by data source, stage, and yield

\section{Results}

Out of the 18 articles reviewed 55\% of the study found FC to be advantageous and enhanced learning. The following are the findings

1. The findings reveal that the FC is a promising teaching approach to increase learners' motivation and engagement. The most frequently reported advantage of the flipped classroom is the improvement of student learning performance [1]

2. In addition, the flipped classroom approach was proven to be more effective when instructors used quizzes at the start of each in-class session. More respondents reported they preferred flipped to traditional classrooms. [9]

3. Current evidence suggests that the flipped classroom approach in health professions education yields a significant improvement in student learning compared with traditional teaching methods. [9]

4. It was observed from the responses of the students of a particular survey, that flipped learning is helpful for the interaction and collaboration in the classroom

5. The FC method is associated with greater academic achievement than the lecture-based approach for higher-level learning outcomes, which has become more obvious in recent years.

6. A study was done with ophthalmology students, comparing the effectiveness of the flipped classroom and the traditional lecture-based approach. More students in the flipped group agreed that FC helped to promote their learning motivation, improve their understanding of the course materials, and enhance their communication skill and clinical thinking. Students from the flipped 
group performed better on the posttest over the ocular trauma-related questions when compared to those from the traditional group. [20]

7. The redesigned course, which integrates the flipped classroom approach, improved student test performance and perceptions of the learning experience during the first year of implementation.

8. This study provides evidence that the Inverted Classroom Method of teaching clinical microbiology can replace the traditional method without loss of student performance. Respondent perceptions of the inverted classroom were positive, with students favoring the flexibility

9. In conclusion, medical students have generally expressed strong satisfaction with early applications of the FC to undergraduate medical education, and generally, prefer this method to lecture-based instruction.

10.Flipped classroom teaching and learning pedagogy is an effective way of enhancing student engagement and active learning. Thus, this pedagogy can be used as an effective tool in medical schools.

Eight out of the eighteen reviews did not find it to be advantages nor did they find it better than the traditional lecture methods, their results are given below

1. We found a number of challenges in the flipped classroom model. The majority of these are related to out-of-class activities, such as much reported inadequate student preparation prior to class.

2. More students agreed that FC helped to promote their learning motivation, improve their understanding of the course materials, and enhance their communication skill and clinical thinking. However, students in the FC did not show a preference for this method of teaching, and also reported more burden and pressure than those from the traditional lectures.

3. Some students have expressed concerns with the FC and noted that suboptimal student preparation and insufficient direction and structure during active learning sessions may limit the studentcentered benefits.

4. Our findings also reveal that in general, students resist learning the topics on their own outside the classroom in the FC Model. Instead, they prefer learning the topics from the instructor inside the class. The problems encountered in this model can be categorized into three main titles: Motivation, Content, and Learning. As reported by our participants, in a new learning environment, students who are typically willing to put effort into learning tend to have difficulty getting motivated. The students studying outside the classroom stated they experienced problems regarding the difficulty of the contents and insufficiency of the resources. Among the other problems were lack of time to study outside the class, difficulty in understanding the topics, and learning difficulty. [4]

5. Studies suggest the lack of strong evidence for the effectiveness of FCs in promoting knowledge acquisition above and beyond the traditional learning methods.

6. Competency assessment after simulation-based training in ACLS undergone by senior medical students randomly assigned to flipped and traditional classrooms showed no statistical difference in competency between the two groups.

7. Meta-analyses revealed that the FC had significantly better outcomes than the lecture-based method in examination scores (post-intervention and pre-post-change) and course grades, but not in objective structured clinical examination scores. [6]

8. The FC method is associated with greater academic achievement than the lecture-based approach for higher-level learning outcomes, which has become more obvious in recent years. However, results should be interpreted with caution because of the high methodological diversity, statistical heterogeneity, and risk of bias in the studies used. Future studies should have high methodological rigor, a standardized FC format and utilize assessment tools evaluating higher cognitive learning and behavior change to further examine differences between FC and Lecture-Based learning.

\section{Discussion}

Benjamin Franklin once stated, "Tell me and I forget, teach me and I may remember, involve me and I learn." Franklin's quote embodies the core of the flipped classroom concept. As the call for innovative teaching-learning methods becomes stronger, the use of the flipped classroom approach is becoming increasingly popular in health professions education. However, there has not been any detailed review 
published that specifically examines the effect of flipped classroom versus traditional classroom on student learning. This study examined the findings of comparative articles through analysis in order to summarize the overall effects of teaching with the flipped classroom approach. We focused specifically on a set of flipped classroom studies in which pre-recorded videos were provided before face-to-face class meetings. The findings reveal that the most frequently reported advantage of the flipped classroom is the improvement of student learning performance. Students recognized the benefits of being able to revisit the online resource (in this case, the video) pre-lecture. They indicated that they found the 'pause' and 'rewind' functions in the video recording very useful in helping them revisit points in the lecture, something which is not possible to do so in a lecture delivered in a conventional way. Participating in the lecture's active learning activities (e.g. group discussions and brainstorming activities) was beneficial to learning new concepts. [15] We also found a number of challenges in this model. The majority of these are related to out-of-class activities, such as much reported inadequate student preparation prior to class. Although students generally perceive that FC approaches can improve their learning and knowledge, this has not been conclusively shown via performances on assessment tools, which may be related to caveats with the assessment tools used. [16] Flipped classroom also places a huge burden of learning the concepts on students, whereas previously it was the responsibility of teachers to ensure that the learning process is happening. In their research, Chen Hsieh et al. (2017) pointed out that many students had difficulties adapting to the FC Model since it is a new approach. Most of the students stated that the course included heavily-loaded requirements, and they did not have time to watch the videos outside the class. Not all students have the same grasping power. Through FC, students would depend heavily on self-directed learning. This undermines the opportunity to discuss and clarify doubts with the lecturer. While the flipped classroom method poses a lot of advantages, it does have a few shortcomings, as were discussed. Considering medical schools, in particular, the flipped classroom method must be used with caution. In medical school, students will be faced with the task of covering vast material, which is hard enough to do with didactic lectures. In such a scenario, employing FC, which relies mostly on SDL (self-directed learning) would be cumbersome and futile for the students. Hence, we would suggest that a hybrid of lectures and FC be used in the course, where the larger and more important topics are covered with lectures, and smaller, more basic topics are handled by students themselves. This will ensure that students don't miss out on understanding important topics, and are not overburdened with a responsibility beyond their capability. At the same time, they can experience the FC method and move forward as they feel comfortable.

\section{Limitations of the study}

One of the major limitations of this review is that the long terms benefits and shortcomings of flipped classroom were not considered. The real impact of the flipped classroom can only be understood through long term implementation and subsequent monitoring of the students' academic performances.

\section{Conclusion}

One of the common challenges in the medical education is to actively engage students in learning activities and the medical education transformers have always been coming up with various innovations like Problem Based Learning, Team-Based Learning, Blended Learning, Web-Based Learning, Selfdirected Learning, Small Group Discussion and Flipped Classroom teaching. The FC seems to be a promising teaching approach to increase learners' motivation and engagement and currently adopted by many schools, however, as known, there is no single comprehensive method that would suit all learners, teachers, and institution. In the opinion of the author, the flipped classroom concept should be part of the entire educational package, used in conjunction with other modes of instruction.

There could be many new methods in teaching and many newer approaches to teaching and learning and they can never replace or become better than the traditional lecture method, which has existed for centuries and will exist for centuries, at least at the undergraduate levels. 
DOI: 10.21522/TIJBMS.2016.04.01.Art001

ISSN: $2519-500 \mathrm{X}$

\section{Disclaimer}

This disclaimer informs readers that the views, thoughts, and opinions expressed in the text belong solely to the author, and not necessarily to the author's employer, organization, committee or other group or individual.

\section{References}

[1]. Akçayır, G. and Akçayır, M., 2018. The flipped classroom: A review of its advantages and challenges. Computers \& Education, 126, pp.334-345.

[2]. Burnham, K.D. and Mascenik, J., 2018. Comparison of student performance and perceptions of a traditional lecture course versus an inverted classroom format for clinical microbiology. Journal of Chiropractic Education, 32(2), pp.90-97.

[3]. Cab1, E., 2018. The Impact of the Flipped Classroom Model on Students' Academic Achievement. International Review of Research in Open and Distributed Learning, 19(3).

[4]. Chen Hsieh, J.S., Wu, W.C.V. and Marek, M.W., 2017. Using the flipped classroom to enhance EFL learning. Computer Assisted Language Learning, 30(1-2), pp.1-21.

[5]. Chen, F., Lui, A.M. and Martinelli, S.M., 2017. A systematic review of the effectiveness of flipped classrooms in medical education. Medical education, 51(6), pp.585-597.

[6]. Chen, K.S., Monrouxe, L., Lu, Y.H., Jenq, C.C., Chang, Y.J., Chang, Y.C. and Chai, P.Y.C., 2018. Academic outcomes of flipped classroom learning: a meta-analysis. Medical education, 52(9), pp.910-924

[7]. DeLozier, S.J. and Rhodes, M.G., 2017. Flipped classrooms: a review of key ideas and recommendations for practice. Educational Psychology Review, 29(1), pp.141-151.

[8]. Gilboy, M.B., Heinerichs, S. and Pazzaglia, G., 2015. Enhancing student engagement using the flipped classroom. Journal of nutrition education and behavior, 47(1), pp.109-114.

[9]. Hew, K.F. and Lo, C.K., 2018. Flipped classroom improves student learning in health professions education: a meta-analysis. BMC medical education, 18(1), p.38.

[10]. Jung, H., An, J. and Park, K.H., 2018. Analysis of satisfaction and academic achievement of medical students in a flipped class. Korean journal of medical education, 30(2), p.101.

[11]. Koo, C.L., Demps, E.L., Farris, C., Bowman, J.D., Panahi, L. and Boyle, P., 2016. Impact of flipped classroom design on student performance and perceptions in a pharmacotherapy course. American journal of pharmaceutical education, 80(2), p.33.

[12]. Larry Hurtubise, Elissa Hall, Leah Sheridan and Heeyoung Han (2015) The Flipped Classroom in Medical Education: Engaging Students to Build Competency Journal of Medical Education and Curricular Development [13]. Mok, H.N., 2014. Teaching tip: The flipped classroom. Journal of Information Systems Education, 25(1), p.7.

[14]. Moraros, J., Islam, A., Yu, S., Banow, R. and Schindelka, B., 2015. Flipping for success: evaluating the effectiveness of a novel teaching approach in a graduate level setting. BMC medical education, 15(1), p.27.

[15]. Musib, M.K. (2014). Student perceptions of the impact of using the flipped classroom approach for an introductory-level multidisciplinary module. CDTL Brief, 17(2), 15-20

[16]. Ramnanan, C.J. and Pound, L.D., 2017. Advances in medical education and practice: student perceptions of the flipped classroom. Advances in medical education and practice, 8, p.63.

[17]. Riddell, J., Jhun, P., Fung, C.C., Comes, J., Sawtelle, S., Tabatabai, R., Joseph, D., Shoenberger, J., Chen, E., Fee, C. and Swadron, S.P., 2017. Does the Flipped Classroom Improve Learning in Graduate Medical Education?. Journal of Graduate Medical Education, 9(4), pp.491-496.

[18]. Rotellar, C. and Cain, J., 2016. Research, perspectives, and recommendations on implementing the flipped classroom. American journal of pharmaceutical education, 80(2), p.34.

[19]. Snowden, K.E., 2012. Teacher perceptions of the flipped classroom: Using video lectures online to replace traditional in-class lectures (pp. 1-71). Denton, TX: University of North Texas.

[20]. Tang, F., Chen, C., Zhu, Y., Zuo, C., Zhong, Y., Wang, N., Zhou, L., Zou, Y. and Liang, D., 2017. Comparison between flipped classroom and lecture-based classroom in ophthalmology clerkship. Medical education online, 22(1), p.1395679.

[21]. Tucker, B. (2012). The flipped classroom. Education Next,12(1), 82-83. 
Texila International Journal of Basic Medical Sciences Volume 4, Issue 1, Jun 2019

[22]. Tusa, N., Sointu, E., Kastarinen, H., Valtonen, T., Kaasinen, A., Hirsto, L., Saarelainen, M., Mäkitalo, K. and Mäntyselkä, P., 2018. Medical certificate education: controlled study between lectures and flipped classroom. BMC medical education, 18(1), p.243. 


\title{
Elements that Establish a Healthy Doctor Patient Relationship
}

\author{
Article by Kim Near ${ }^{1}$, Sayanth Raj $^{1}$, Niharika Anand ${ }^{1}$ \\ ${ }^{1} M D$, Texila American University, Guyana, South America
}

\begin{abstract}
Background: The doctor patient relationship is the keystone of our health care system. But in modern medicine, there is very little credit given to this relationship. The degradation of the doctor patient relationship has led to unsatisfied patients, frustrated doctors and overall diminution in the quality of health care.

Objective: The aim of this study is to emphasize the importance of a good doctor patient relationship.

Method: The present study, upon review of several articles, discusses the components of a good doctor patient relationship, and summarizes it into five major categories. From the articles researched, below are a comprehension of the collective information gathered and presented in a redefined, organised manner.

Conclusions: The five main categories discussed include: First impressions, mannerisms, communication skills, professionalism qualities, and collaborative decision making. The study also talks about how these five components are integrated, and how it effects the doctor patient relationship, leading to better therapeutic outcomes in patients and long-term job satisfaction in doctors.
\end{abstract}

Keywords: doctor patient relationship, first impressions, mannerisms, communication skills, professionalism qualities, collaborative decision.

\section{Introduction}

The doctor-patient relationship is a central part of health care and the practice of medicine. It forms one of the foundations of contemporary medical ethics. Since the time of Hippocrates, this special relationship has received much philosophical and literary attention. Since then, medicine has come a long way in recognizing the effect and importance of this relationship. However, despite emphasis on the need for curricula that foster patient-centred attitudes among medical students, data suggest that students in later years of medical school have attitudes that are more doctor-centred or paternalistic compared to students in earlier years. (Paul Haidet et al, 2002).

A doctor's communication and interpersonal skills encompass the ability to gather information in order to facilitate accurate diagnosis, counsel appropriately, give therapeutic instructions, and establish caring relationships with patients. These are the core clinical skills in the practice of medicine, with the ultimate goal of achieving the best outcome and patient satisfaction, which are essential for the effective delivery of health care. The ultimate objective of any doctor-patient communication is to improve the patient's health and medical care. The Balint Society, founded in the UK in 1969, is a supportive and collaborative medical organization of clinicians and teachers who emphasize the importance of the use of emotion and personal understanding in the doctor's work and the therapeutic potential of the doctorpatient relationship. Nonetheless, the worrying fact remains that with the rapid modernisation of health care, these principles are less focused upon. (Mechanic D et al).

According to a study in the journal BMJ Open, patients whose doctors listen to and respect them are more likely to disclose important information, stick with treatment regimens and get important health screenings. As the authors noted, "the weight of evidence across different areas of health care indicates that patient experience is clinically important."

Doctors tend to overestimate their abilities in communication. Studies on doctor-patient communication have demonstrated patient discontent even when many doctors considered the communication adequate or even excellent. Tongue et al reported that $75 \%$ of the orthopaedic surgeons surveyed believed that they communicated satisfactorily with their patients, but only $21 \%$ of the patients reported satisfactory communication with their doctors. 
Effective doctor-patient communication is determined by the doctors' "bedside manner," which patients judge as a major indicator of their doctors' general competence.

According to a study published in the journal Health Services Research, the relationship between a physician and their patient is the key to high patient engagement. Some major aspects include:

- The quality of the patient-physician relationship - especially how well the doctor communicates in the office.

- The amount of respect and fairness patients felt they received.

- The frequency of patient-physician communication outside of the office (through email or phone).

The study found that patient communication was one of the most critical elements of success: for every one unit increase in the quality of interpersonal exchanges, patients reported a 10 unit increase in their overall engagement levels.

Good doctor-patient communication has the potential to help regulate patients' emotions, facilitate comprehension of medical information, and allow for better identification of patients' needs, perceptions, and expectations. (Kelly JM et al, 2014) Patients' agreement with the doctor about the nature of the treatment and need for follow-up is strongly associated with their recovery. (Levinson $W$ et al).

A good doctor patient relationship is not only crucial for the patient, but also beneficial for the doctor. Satisfied patients are less likely to lodge formal complaints or initiate malpractice complaints. Satisfied patients are advantageous for doctors in terms of greater job satisfaction, less work-related stress, and reduced burnout.

In the modern word of healthcare, everyone is more inclined to focus on the academic side of medicine. Even while choosing a medical school, students tend to select the school which have a greater academic reputation. Hence, medical schools side-line the importance of the other aspects of working in healthcare, such as communication skills, empathy, and doctor patient relationships. The lack of social and communication skills in a doctor had caused a rift between professionals and patients, leading to withholding of information, mistrust from both ends, and ultimately, misdiagnosis and inappropriate treatment. All this is a vicious cycle, which does not help anybody. The few opportunities that are presented to upcoming doctors to hone their social and communication skills are also not holistic.

In this article, we aim to tackle these problems and emphasize the need and importance of a good doctor patient relationship. We will also discuss the components that effect this relationship and provide a holistic approach to establishing this relationship.

\section{Methods}

Various articles were derived from open source journals through Pubmed, Research Gate and Google Scholar. These articles were intensely reviewed by the authors and consolidated below. This review is a narrative review, where selected studies are compared and summarized on the basis of the author's experience, existing theories and models. Results are based on a qualitative rather than a quantitative level. All article relevant to the topic were considered for review. Inclusion criteria include articles that present evidence-based views and are published in an indexed journal. Articles which are based on theory, and thereby lacking any statistical evidence were excluded.

\section{Results}

The benefits of building a good patient doctor relationship ensures good trust, open communication, collaboration as well as good adherence to advice and medical treatment that the doctor is being advised to the patient (Woolf Steven et al, 1999) In addition this helps build loyalty as well as many referrals from the patient where they are much more likely to return and recommend their families and friends to see the doctor, which increases the doctor's demand (Emanuel EJ et al, 1992).

Alternatively, a bad patient doctor relationship will result in the patient being closed off and not revealing all of the information that they may not think is relevant, as well as less adherences to intervention and treatment recommended by the doctor (Cathy Charles et al, 1999). In addition, it creates a poor satisfaction as well as a higher rate of being sued. The patient is also more likely to not return for a follow up appointment and find another doctor (Woolf Steven et al, 1999). 
However, the characteristics of a good patient doctor relationship comprise of many components and many factors (The Social Medicine Reader). This article will collaborate the different research components into a simplified digestible manner.

From the articles researched, below are a comprehension of the collective information gathered, presented in a redefined organised manner. In doing so the topics discussed are summarised into five main categories, which also comprise of many sub categories. The five main categories discussed include: First impressions, mannerisms, communication skills, professionalism qualities, and collaborative decision making.

It should be pointed out that some of attributes and skills mentioned in the sub categories overlap into other categories and to ensure the most accurate and reliable information presented, there will be some cross overs to not limit the information presented as well as ensuring the most accurate collection of research to be presented in a well-rounded comprehensive manner (Emanuel EJ et al, 1999).

\section{First impression}

With first impression, this refers to how a patient views the doctor the first time they see the doctor (Karen Sue, 2011). The first encounter of the patient with the doctor instantly forms an impression about the doctor's professionalism, credibility's, and abilities which shape how well the patient will decide to interact with the doctor as well as trust their advice and follow the doctor's advice (Mary Klein Buller, 1987).

This is one of the fastest ways for a doctor to generate a good lasting impression which helps build a healthy doctor patient relationship and establish trust, open communication and adherence to the recommendations by the doctor (Shakaib U Rehman et al, 2005).

Alternatively, a bad first impression, although can be changed over time in some cases, with a lot of work, it sometimes is also impossible to recover especially when there are a lot of competition doctors in the community (Karen Sue, 2011).

First impression is generally believed to be the first time someone sees you, in this case being the first time the patient sees the doctor although this is true, it actually starts before this with the very first time the patient gets any exposure to the doctor (Carol Teutsh). This includes things like how professional and simple it is to navigate on the doctor's website and find useful information, how welcoming, pleasant, the appearance of the secretary and friendly the secretary is when the patient tries to call to make an appointment or how the secretary greats the patient when they first step into the office, how pleasant, organised and well put the building and the office is when the patient walks in, how appealing and attractive the decorations are (Shakaib U Rehman et al, 2005). Each exposure has the potential to either help the patient take the initiative to continue to make an appointment and follow through with the meeting, right through to how they interact and trust the doctor and their advice, too even deciding if they will not make an appointment and find another doctor (Shakaib U Rehman et al, 2005).

The first contact of the patient with the doctor is also important and the components that make this up include, if the doctor smiles or greats the patient in a friendly welcoming manner using good eye contact and eye contact, the vocal projection, vocal tone and the manner in which the doctor speaks to create report as well as directing the patient about the process of the appointment. The attire of the doctor and their appearance makes an impression and the office layout and appearance (Karen Sue, 2011).

When all of these components are achieved effectively the patient is much more likely to have a good first impression, which leads to them feeling more comfortable about the process, it helps them to open up and communicate more freely, as well as having a higher chance that the patient will trust and adhere to any advice and recommendations the doctor makes, which includes running test, making follow up appointments and adhering to any medical prescription plan that was set (Mary Klein Buller et al, 1987).

\section{Mannerisms and traits}

Another component of a good patient doctor is mannerism and traits of the person's involved (Piyush Ranjan et al, 2015). As mentioned above this can apply to the secretary or any other staff that is working 
for the doctor that the patient comes into contact with, however this will be describing the useful aspects of the mannerism and traits for a doctor (Raj Arora et al, 2004).

Beneficial mannerisms of a doctor include professionalism, how well the doctor is culturally aware of the patients' background, being polite and courteous, showing empathy and compassion when needed, being respectful to the patient, being open minded and non-judgemental when the patient disclose information, how effective the doctor is in establish trust and how supportive and understanding the doctor is of the patient's condition, choices and background story (Mary Klein Buller et al, 1987)

These characteristics can be worked on and improved, which in turn build a better foundation for establishing a healthy patient doctor relationship. It especially has a big impact on how willing the patient is in disclosing information and trusting that the doctor will keep their medical history confidential, as well as establishing a healthy patient's impression of the doctor's ability to help (Piyush Ranjan et al, 2015).

\section{Communication skills}

Communication skill makes a big component of establishing a good patient doctor relationship. Communication skills in this case is describing the doctor's ability to effectively communicate their thoughts, opinions and recommendations to the patient (Raj Arora et al, 2004). It comprises of many aspects, some of which are also components mentioned above which are also used to establish a good mannerism, like showing empathy, having good cultural awareness (Barbara M Korsch et al, 1968). However, this section will detail all of the aspects that are intimately linked with effective communication skills.

The first component is the verbal skills, which includes using language that the patient understands, speaking clearly and slowly with appropriate vocal tones to portray the message as well as showing appropriate emotions that is suitable for the situation (M Simpson et al, 1991).

Listening skills is another key component (M Simpson et al, 1991). This includes giving the patient time to talk and not cutting in, and understanding the important aspects that the patient informs the doctor (Barbara M Korsch et al, 1968).

Closely related to listening and communication skills are body language awareness and control, which includes body posture and position as well as facial expressions and subtle movements, which help to portray the doctor's emotions like empathy and cultural politeness, and establish compassion for the patient as well as showing an invested interest to helping the patient, which also builds on the trust and patient doctor relationship. It is also important for the doctor to be able to recognise the body language of the patient, such as recognising if they are open or if the patient is closed off and reserved or protective, as these are signs that show how the patient is feeling, which helps the doctor to understand why and through effective communication shills the emotional barriers can be uncovered and barriers of ineffective or unopen communication can be overcome (M Simpson et al, 1991).

Empathy is important in the medical field as patients are telling the doctors their deepest worries which they may not even feel comfortable telling their partners, hence it is important for the doctor to be able to express empathy in the correct time of the conversation, which is done through vocal tone, pace and body language and facial expressions addressed previously (Roger W Squier, 1990)

In terms of structure for gathering information and directing the appointment, the CalgaryCambridge guideline gives a good structure for the flow of the meeting, where it is focused on providing structure which helps creates efficiency and build a professional impression for the patient, as well as reducing the risk of leaving out anything important, and it also helps build a good patient doctor relationship (Suzanne M. Kurtz, 2002).

Additional helpful techniques for communication skills is to group information being given as well as asking similar questions together to help the doctor express what he needs to the patient as well as allowing the patient to better comprehend the process. An effective way of doing this is to physically say, we will be discussing $\mathrm{x}$ numbers of points, which are and then follow up and list the topics, and then using signpost, to mark the end and start of each topic. An example of this could be, I now want to ask about your family history, and proceed to ask relating questions about the family history (Suzanne 
M. Kurtz, 2002). This also give the patient awareness of what's to come and they can be ready and hence more likely to be open with the process.

To ensure that there is no communication misunderstanding, it is a good technique for the doctor to summarise what they learn from the interaction, which could be done at the end of the meeting, or at the end of each grouped topic of discussion. The patient should be given the chance to agree or clarify any misunderstandings (Suzanne M. Kurtz, 2002)

\section{Professional qualities}

The next quality discussed is professional qualities of the doctor (Peggy Wagner et al, 2007). Again this can and should also be applied to any employed staff that the doctor has which come into contact with patient such as the secretary (Peggy Wagner et al, 2007) Professional qualities allow for a good impression which help show that the doctor is well knowledge as well as maintaining trust as it helps the patient know that the doctor will not overcome any personal barriers (Jeanne M Farnan et al, 2013). It also helps build trust and establish good adherence to the doctor's recommendations (Lydia $S$ et al, 2008).

The components of professionalism include, knowing and adhering to professional boundaries in terms of what a doctor can and can't cross (Peggy Wagner et al, 2007). A good guide to this is the doctor's code of autonomy beneficent, non-maleficent as well as being ethical (Toni Suzuki et al, 2005). Also as mentioned previously the doctor's mannerism, body language, appearance, and good cultural awareness also plays a big part in establishing a good professionalism impression (Lydia S et al, 2008). Knowledge is also important and includes not just knowledge about medicine but about social interactions, the law and about the boundaries of a patient doctor relationship. It is also important to work with the patient and establish what they expect and working together to best achieve the patient's expectation through creating a treatment plan which considers the patient's needs, lifestyle and their chances of adhering to that plan, which will be elaborated on in the next point below (Donald $J$ et al, 2006). Also, the follow up arrangements and expectations also fall into this. An effective strategy is to set pre planned appointments before the patient leaves and have the secretary give the patient a reminder call before the appointment to remind the patient (Working Party of RCP, 2005). This should be used to follow up the patient and ensure that they are adhering to the treatment plan as well as addressing any complications that the patient might have (Peggy Wagner et al, 2007).

\section{Collaborative decision making}

Collaborative decision making is vital to ensure that you address the patient's needs, concerns and expectations (Lisa Maria et al, 2007). Knowing the patient's needs will help physicians understand if they are realistic or not and how to proceed (Donald J et al, 2006). Addressing any concerns will help the patient overcome any challenges and problems before they arise as well as improve adherence recommendations. Addressing unexpected expectations while achieving reasonable expectations will help patients trust the doctor and return for future appointments (Beth A Lown et al, 2009). These all work together to ensure the patient is satisfied with the treatment plan and uncover any problems if they are not so that they can be addressed and corrected (Jochanan Benbassat et al, 1998). In addition, the physical needs to consider the patient's past experience with adherence to a certain style of treatment regimen and any life factors that may affect their ability to adhere to any difficult regiment. If the treatment plan is not necessary then an alternative treatment plan should be agreed on by both parties which will help ensure that the patient has the best treatment possible according to their situation and lifestyles (Lisa Maria et al, 2007).

Each of the points addressed make up a small component of what builds a good patient doctor relationship, however collectively improving all aspects will yield the best results.

\section{Discussion}

Doctor patient relationship is an important and essential parts of the healthcare system. It is one of the key components that enable proper diagnosis and effective treatment, by ensuring trust and reliability from both sides. A patient walk into the hospital with the expectation that he/she will return cured and satisficed. It is a doctor's responsibility to uphold this expectation. In order for this to happen, 
a good doctor patient relationship must be established. Some major components of this relationship were discussed above. These components include first impressions, mannerism and traits of the doctor, commination skills, professional qualities and collaborative decision making. In order for a doctor to know the elements of a good doctor patient relationship, they must be given ample opportunities to cultivate these skills in medical school.

First impressions are often undermined and over looked. Recent studies have shown that things as insignificant as the doctor's dressing sense have a big impact on the patient's perception. For example, the doctor's attire can function as an effective tool of non-verbal communication in order to signal confidence, trust and empathy and establish a good patient-doctor relationship. (Heesu Chung et al, 2012) In another study, respondents overwhelmingly favor physicians in professional attire with a white coat. Wearing professional dress (ie, a white coat with more formal attire) while providing patient care by physicians may favorably influence trust and confidence-building in the medical encounter. (Shakaib $U$. Rehman et al, 2005) After getting through the first impression, another aspect that majorly effects the patients is the mannerism of the doctor. The physician's ability to remember them as a person and build up knowledge of their medical and personal preferences is one way that most patients said physicians maintained the comfortable relationship. (Nancy Pandhi et al, 2007) Previous research has reported that nonverbal elements of physician-patient communication influence medical outcomes such as patients' understanding, compliance, and saris/action with health care delivery. (Richard L. Street et al).

Communication is also one of the core skills that a doctor need. However almost nil training is provided for them to develop these skills. For example, in oncology, good communication with the patient is one of the most important aspects of treatment which a doctor could offer. It stabilizes the patient's mind and allows them enough trust and will power to fight against the disease. There have been studies conducted that show how ineffective communication brings complications in the patients. Inadequate communication may cause much distress for patients and their families, who often want considerably more information than is usually provided. Good communication can improve outcomes for patients and doctors, and deserves equal importance as developing clinical knowledge and procedural skill. The importance of good communication is so critical that Australian guidelines list effective communication as part of the required conduct for all doctors. Despite all the technological advances of recent decades, caring, compassionate, healing doctors remain the best therapeutic tool in medicine. The ability of a doctor to provide comfort through their presence and their words is a fundamental component of good medical care. (Warnecke E, 2014).

Involvement of the patient in decision making, regards treatment regimens and other matters that concern the patient is one of the basic rights of a patient and the fundamental duty of a doctor. Studies show that having a personal doctor-patient relationship was highly valued by patients and GPs, in particular for more serious, psychological and family issues. $77-88 \%$ of patients and $80-98 \%$ of GPs valued a personal relationship more than a convenient appointment. (K E Kearley et al, 2001).

\section{Conclusion}

There are a number of conflicting and varied information about what makes up a good patient doctor relationship. The varied information is in some way accurate however they are not a comprehensive overview of all of the factors and components which make up an effective patient doctor relationship.

This article discussed many points, summarizing them into five main focal areas; First impressions, mannerisms, communication skills, professionalism qualities, and collaborative decision making. They all help in their own way to improve the patient doctor relationship, however as evident in some overlapping, they do not work in isolation, but rather together in an intricate network which if all elements are well executed then that would produce the best patient doctor relationship. As in if a doctor was to implement one of these key points, they would improve their patient doctor relationship, however improving all aspects would have a significant impact.

This research and evaluation were written to be used to help guide a physician to evaluate their own practice and help identify areas of weakness which they could improve. 
Although this article was written to be a comprehensive overall guide on the subject, due to the vast nature and intricacies of human interaction, not all aspects could be documented and there may be further improvements to this formula.

To evaluate if this proposed structure is effective or not in improving a doctor's patient doctor relationship, there needs to be further research on its implication and results. Hence this article is a theoretical model only and has yet to be proven practically.

\section{Limitation}

The limitation of this research is the limited journals that was used. It would have been better to have a larger sample of journals used. In addition, some of the journals did not have research showing the effects of implementing such techniques, hence a confirmative effect of those recommendation can't be proven.

In regards to the limitation of this article, the advice is from a combination of a number of different journals, however there isn't any research done on the effectiveness on implementing these suggestions, and research should be done to validate the recommendations set out in this article. There may be unforeseen issues that might arise in a real-world research of implementing these recommendations.

\section{References}

[1]."A Comfortable Relationship: A Patient-derived Dimension of Ongoing Care" Family Medicine, April 2007. [2].Arora, Raj PhD; Singer, Joseph PhD; Arora, Alisha MD "Influence of Key Variables on the Patients' Choice of a Physician" Quality Management in Health Care: July-August-September 2004 - Volume 13 - Issue 3 - p 166173.

[3].Ball LE, Barnes KA, Crossland L, Nicholson C, Jackson C. "Questionnaires that measure the quality of relationships between patients and primary care providers: a systematic review".

[4].Barbara M. Korsch, Ethel K. Gozzi, Vida Francis "GAPS IN DOCTOR-PATIENT COMMUNICATION" Pediatrics November 1968, VOLUME 42 / ISSUE 5.

[5].Beth A. Lown MD Janice L. Hanson PhD EdS William D. Clark MD "Mutual influence in shared decision making: a collaborative study of patients and physicians" Health Expectations 18 May 2009.

[6].Carol Teutsch, MD Patient-Doctor Communication, Research gate.

[7].Cathy Charles, Amiram Gafni, Tim Whelan "Decision-making in the physician-patient encounter: revisiting the shared treatment decision making model" Social Science and Medicine Vol 49, Issue 5, September 1999.

[8].David C. Dugdale MD Ronald Epstein MD Steven Z. Pantilat MD "Time and the Patient-Physician Relationship" Journal of General Internal Medicine 25 December 2001.

[9].Donald J.Kiesler, Stephen M. Auerbach "Optimal matches of patient preferences for information, decisionmaking and interpersonal behavior: Evidence, models and interventions" Patient Education and Counseling Volume 61, Issue 3, June 2006, Pages 319-341.

[10]. Emanuel EJ, Emanuel LL. "Four Models of the Physician-Patient Relationship" JAMA. 1992;267(16):22212226. doi:10.1001/jama.1992.03480160079038.

[11]. Gallagher TH, Levinson W. "A prescription for protecting the doctor-patient relationship."

[12]. Guseh JS, Brendel RW, Brendel DH "Medical professionalism in the age of online social networking" Journal of Medical Ethics 2009;35:584-586.

[13]. Heesu Chung, Hyeyeon Lee, Dong-Seon Chang, Ho-Sun Kim, Hyejung Lee, Hi-Joon Park, Younbyoung Chae "Doctor's attire influences perceived empathy in the patient-doctor relationship" Patient Education and Counseling Volume 89, Issue 3, December 2012.

[14]. Jeanne M. Farnan, MD, MHPE; Lois Snyder Sulmasy, JD; Brooke K. Worster, MD; Humayun J. Chaudhry, DO, MS, SM; Janelle A. Rhyne, MD, MA; Vineet M. Arora, MD, MAPP "Online Medical Professionalism: Patient and Public Relationships: Policy Statement From the American College of Physicians and the Federation of State Medical Boards" Annals of Internal Medicine 13 April, 2013.

[15]. Jennifer Fong Ha, MBBS (Hons) Dip Surg Anat and Nancy Longnecker, PhD "Doctor-Patient Communication: A Review". 
[16]. Jochanan Benbassat MD, Dina Pilpel PhD \& Meira Tidhar MSc (1998) "Patients' Preferences for Participation in Clinical Decision Making: A Review of Published Surveys", Behavioral Medicine, 24:2, 81-88, DOI: $10.1080 / 08964289809596384$.

[17]. K E Kearley, G K Freeman and A Heath "An exploration of the value of the personal doctor-patient relationship in general practice”. Br J Gen Pract 2001; 51 (470): 712-718.

[18]. Karen Sue Schaepe "Bad news and first impressions: Patient and family caregiver accounts of learning the cancer diagnosis” Social Science \& Medicine Volume 73, Issue 6, September 2011, Pages 912-921.

[19]. Kelley JM, Kraft-Todd G, Schapira L, Kossowsky J, Riess H (2014). "The influence of the patient-clinician relationship on healthcare outcomes: a systematic review and meta-analysis of randomized controlled trials". PLOS ONE. 9 (4): e94207.

[20]. Levinson W, Roter D. The effects of two continuing medical education programs on communication skills of practicing primary care physicians. J Gen Intern Med. 1993; 8:318-24. [PubMed].

[21]. Lisa Maria E. Frantsve, Robert D. Kerns; "Patient-Provider Interactions in the Management of Chronic Pain: Current Findings within the Context of Shared Medical Decision Making” Pain Medicine, Volume 8, Issue 1, 1 January 2007, Pages 25-35.

[22]. Lydia S. Dugdale and Mark Siegler and David T. Rubin. "Medical Professionalism and the Doctor-Patient Relationship." Perspectives in Biology and Medicine 51, no. 4 (2008): 547-553.

[23]. M Simpson, R Buckman, M Stewart, P Maguire, M Lipkin, D Novack, and J Till "Doctor-patient communication: the Toronto consensus statement." BMJ. 1991 Nov 30; 303(6814): 1385-1387.

[24]. Mary Klein Buller and David B. Buller "Physicians' Communication Style and Patient Satisfaction" Journal of Health and Social Behavior Vol. 28, No. 4 (Dec., 1987), pp. 375-388.

[25]. Mechanic D, Schlesinger M. The impact of managed care on patients' trust in medical care and their physicians. JAMA. 1996;275(21):1693-7. [PubMed].

[26]. Nadelson, T. (1971) 'Emotional Interactions of Patient and Staff: A Focus of Psychiatric Consultation', Psychiatry in Medicine, 2(3), pp. 240-246. doi: 10.2190/GPAW-0XRM-C4J4-KTT1.

[27]. Nancy Pandhi, MD, MPH; Barbara Bowers, RN, PhD; Fang-pei Chen, MSW, PhD.

[28]. Paul Haidet Joyce E Dains Debora A Paterniti Laura Hechtel Tai Chang Ellen Tseng John C Rogers Medical student attitudes toward the doctor-patient relationship.

[29]. Peggy Wagner Julia Hendrich Ginger Moseley Valera Hudson "Defining medical professionalism: a qualitative study" 20 February 2007.

[30]. Piyush Ranjan, Archana Kumari, and Avinash Chakrawarty "How can Doctors Improve their Communication Skills?” 2015 Mar 1. doi: 10.7860/JCDR/2015/12072.5712.

[31]. RICHARD L. STREET Jr. DAVID B. BULLER Patients' Characteristics Affecting Physician-Patient Nonverbal Communication Human Communication Reseearch September 1988.

[32]. Roger W.Squier "A model of empathic understanding and adherence to treatment regimens in practitionerpatient relationships” Social Science \& Medicine Volume 30, Issue 3, 1990, Pages 325-339.

[33]. Sadati AK, Tabei SZ, Lankarani KB. "A Qualitative Study on the Importance and Value of Doctor-Patient Relationship in Iran: Physicians' Views.”.

[34]. Shakaib U. Rehman MD, Paul J. Nietert PhD, Dennis W. Cope MD, Anne Osborne Kilpatrick DPA "What to wear today? Effect of doctor's attire on the trust and confidence of patients" The American Journal of Medicine Volume 118, Issue 11, November 2005, Pages 1279-1286.

[35]. Shakaib U. Rehman MD, Paul J. Nietert PhD, Dennis W. Cope MD, Anne Osborne Kilpatrick DPA "What to wear today? Effect of doctor's attire on the trust and confidence of patients" The American Journal of Medicine Volume 118, Issue 11, November 2005, Pages 1279-1286.

[36]. 36. Susan Dorr Goold, MD, MHSA, MA and Mack Lipkin, Jr., MD "The Doctor-Patient Relationship: Challenges, Opportunities, and Strategies".

[37]. Suzanne M. Kurtz "Doctor-Patient Communication: Principles and Practices” Volume 29, Issue S2 (A PeerReviewed Supplement to the Canadian Journal of Neurological Sciences) 2002 , pp. S23-S29.

[38]. Swenson, S.L., Buell, S., Zettler, P. et al. J GEN INTERN MED (2004) 19: 1069.

[39]. The Social Medicine Reader: edited by Gail Henderson, Nancy M. P. King, Ronald P. Strauss, Sue E. Estroff [40]. Toni Suzuki Laidlaw, David M Kaufman, Heather MacLeod, Sander Van Zanten, David Simpson, William Wrixon "Relationship of resident characteristics, attitudes, prior training and clinical knowledge to communication skills performance" 21 December 2005. 
[41]. Warnecke E "The art of communication”. Aust Fam Physician. 2014 Mar;43(3):156-8.

[42]. William Clark, MD, Mack Lipkin, MD, Howard Graman, MD, and Jeannette Shorey, MD "Improving Physicians' Relationships with Patients".

[43]. Woolf Steven H, Grol Richard, Hutchinson Allen, Eccles Martin, Grimshaw Jeremy. "Potential benefits, limitations, and harms of clinical guidelines" BMJ 1999.

[44]. Working Party of the Royal College of Physicians. "Doctors in society. Medical professionalism in a changing world” Clin Med (Lond). 2005 Nov-Dec;5(6 Suppl 1):S5-40. 


\title{
Occurrence, Molecular Characterisation and Antibiogram of Water Quality Indicator Bacteria (Pseudomonas Aeruginosa and Enterobacter Aerogenes) in Water Samples from Klang River
}

\author{
Article by Abisola Mercy Olowofeso, Suryadevara Nagaraja \\ MAHSA University Research Laboratory, Jalan SP 2, Bandar Saujana Putra, Malaysia
}

\begin{abstract}
Background and Objectives: Klang River is a $120 \mathrm{~km}$ long extremely polluted river with 11 major tributaries. The pollution is due to the areas where the water passes through. The aims of this research were to identify multidrug resistant Pseudomonas aeruginosa and Enterobacter aerogenes, phenotypically identify their resistance induced traits, and to determine the molecular characterisation of these strains.

Methods: In this research, 30 water samples were collected from different sites along Klang River, their physical properties and biological oxygen demand were estimated. The gram negative multidrug resistant (MDR) strains were isolated, Hodge test, Double Disk Synergy Test and Disk Potentiation Test were done to identify the cause of their resistance induced traits, and plasmid DNA profiling was carried out.

Results: One multidrug resistant (MDR) P. aeruginosa strain was isolated from the 30 samples, it was a non-carbapenemase and metallo- $\beta$-lactamase (MBL) producing strain. 9 E. aerogenes carbapenemase and MBL producing strains were identified, 6 of them were MDR, after extracting the bacteria plasmid DNA, it was confirmed that the bacteria were within the same range as that of control bacterium (marker).

Conclusion: Multidrug resistant $P$. aeruginosa and E. aerogenes were present in the water samples and they had similarly sized DNA fragments to control bacterium.
\end{abstract}

Keywords: Pseudomonas aeruginosa; Enterobacter aerogenes; multidrug resistance; metallo- $\beta$ lactamase.

\section{Introduction}

Enterobacter aerogenes are crucial hospital-acquired pathogens that cause infections such as bacteraemia; lower respiratory tract infections, skin and soft-tissue infections, UTIs, septic arthritis, and ocular infections ${ }^{(1)}$. They usually inhabit soil, water, dairy products and are in GIT of animals including humans. Healthy individuals are not frequently affected. The risk factors for infection with this nosocomial pathogen includes long hospital stay, recent invasive procedures and exposure to antibiotics, the presence of a central venous catheter. And the risk factors for infection with the multidrug-resistant strain includes the recent use of broad-spectrum antibiotic-aminoglycosides and prolonged ICU care ${ }^{(2)}$. Enterobacter aerogenes possess inducible beta-lactamases that are undetectable in vitro but are induce resistance during treatment ${ }^{(3)}$. In a study conducted by Thiolas et al., in 2005, the resistance mechanisms exhibited by the isolated Enterobacter aerogenes pathogens were characterised with alterations of the outer membrane that had caused a decrease in porin and lipopolysaccharide modifications and active efflux $\left({ }^{(4)}\right.$.

Currently, colistin, and polymyxin antibiotics are being substituted as alternative drugs against Gram-negative pathogens due to the resistance exhibited by these gram-negative bacteria to almost all antibiotics but the administration of colistin has been associated with neurotoxic and nephrotoxic effects hence application of alternatives such as biofield treatment which is the electromagnetic field that permeates and surrounds living organisms ${ }^{(5)}$. It is a technique that can alter the sensitivity of antimicrobials against E. aerogenes using results obtained from their genotype and phenotype studies (5).

Pseudomonas aeruginosa is a gram-negative opportunistic infection causing bacteria that affects both healthy individuals and immunocompromised patients or those with weakened immune system 
(burn and cancer patients, nosocomial infection- contaminated Automated Urine Analyzer) ${ }^{(6)}$. It is ubiquitous in nature and is found in soil, water, decaying vegetation and animals ${ }^{(7)}$, they possess a characteristic versatility that allows them adapt to a wide range of habitats and even in distilled water and the extremely hot temperatures of whirlpools ${ }^{(5)}$, there have been reports of infections such as folliculitis, conjunctivitis, and otitis externa ${ }^{(9)}$ associated with Pseudomonas aeruginosa in water hence prompting studies to be carried out. According to a study conducted by Fontes et al. in 2011, $P$. aeruginosa found in rivers are biofilm forming ones and can grow under unfavourable conditions such as low oxygen and hence colonise water systems making them serve as environmental reservoirs, chlorine is not $100 \%$ effective against their activities.

The most complicated and multidrug resistant Pseudomonas aeruginosa are the metallo- $\beta$ lactasmase (MBL) producing ones ${ }^{(11)}$ as they can render majority of the antibiotics used against them ineffective by hydrolysing their beta lactamase properties ${ }^{(12)}$. Patients on ampicillin are more susceptible to $P$. aeruginosa gastrointestinal infection due to the inhibition of the activities of normal intestinal flora, hence allowing bacteria to colonize ${ }^{(8) 13)}$, the antibiotics commonly used against $P$. aeruginosa are carbanapems as they can easily penetrate their outer membrane; however this membrane limits the penetration from small hydrophilic molecules and passage of large ones ${ }^{(14)}$. The increased resistance of P.aeruginosa to antibiotics damages tissue, increases hospital expenditure and prolongs hospitalisation stays. Sensitivity analysis showed that the risk of ingesting $P$. aeruginosa in drinking water is low but slightly higher in patients that take $P$. aeruginosa resistant antibiotics ${ }^{(8)(13)}$.

The Malaysian climate is characterised by uniform temperature, high humidity and sufficient rainfall. There are two main seasons, the southwest and northeast monsoon seasons. Altering climatic conditions changes the volume and quality of water hence affecting water usage practices, the intensity and incidence of rainfall alters quality of water in rivers (Klang river), hence the variation in volume of peak discharge. Temperature and flooding increase the risk of exposure to open sewage and inadequate sewage infrastructure increases the probability of infection ${ }^{(15)}$.

Antibiotics are usually used in the treatment of bacterial infections even in aquaculture industries; hence resistance to these drugs has given cause for concern as it affects consumers ${ }^{(16)}$. Water contaminated with this pathogen puts individuals at risk of gastro-enteric diseases ${ }^{(17)}$. Hospital wastewaters contain antimicrobial resistant bacteria about 8 times more than the domestic wastewater ${ }^{(18)}$. Effluents of industries influence pollution in water bodies as they change the physical, chemical and microbiological properties of water bodies ${ }^{(19)}$. Water bodies are sites of genetic exchange where environmental bacteria interact with those from humans and animals via horizontal gene transfer $(\mathrm{HGT})^{(20)}$.

\section{Materials and methods}

\section{Sample collection}

30 water samples were collected into $100 \mathrm{ml}$ sterile containers from these different water sites (Gombak, Batu, Kuyoh, Kerayong, Penchala, Ampang, Klang, and Damansara) that make the Malaysian Klang river, their physical properties (colour, odour, presence of turbidity and debris), temperature and $\mathrm{pH}$ were recorded, samples were also collected in dark amber bottles to determine the dissolved oxygen in them ${ }^{(21)}$, all were then kept in ice boxes until they were transported to the laboratory.

\section{Determination of dissolved oxygen}

To estimate dissolved oxygen of the water samples, the Winkler method was followed ${ }^{(22)}$.

\section{Bacteria isolation}

Each water sample was serially diluted from $10^{-1}$ to $10^{-3}$ using the serial dilution method. $10 \mu$ of each of these diluents were inoculated on Nutrient Agar (NA) via spread plate method (using less populated a glass L-rod) and incubated at $37^{\circ} \mathrm{C}$ for 16 hours, single isolated colonies were picked from less populated culture plates and each sample with two concentrations were inoculated on MacConkey Agar, commercially prepared Blood Agar, Eosin Methylene Blue (EMB) Agar for 24 hours ${ }^{(21)}$ and on Cetrimide Nalidixic Acid Agar (48 hours) ${ }^{(23)}$. 


\section{Characterization and identification}

The colonies on the Nutrient agar, Cetrimide Nalidixic Acid agar, EMB agar, Blood agar and MacConkey agar were observed for morphological characteristics. Pure colonies of EMB and Cetrimide Agars that had expected morphological appearance (or similar appearance) were used to perform identification test- Gram stain and standard microbiology biochemical tests (Indole, Methyl Red, Voges-Proskauer, Mannitol, Citrate, Urease and Triple sugar iron tests) ${ }^{(24)}$.

\section{Multidrug resistance testing}

After the biochemical tests, antibiotic susceptibility tests were carried out on the confirmed bacteria isolates using the Kirby-Bauer and the disc diffusion methods according to the Clinical and Laboratory Standards Institute guidelines ${ }^{(25)(26)}$.

Pure isolates of Enterobacter aerogenes and Pseudomonas aeruginosa were inoculated in nutrient broth and incubated overnight, after overnight incubation, a bacterial lawn was made across Mueller-

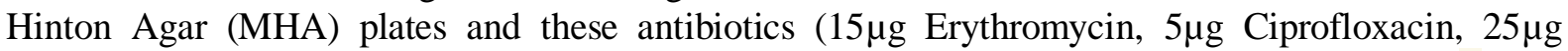

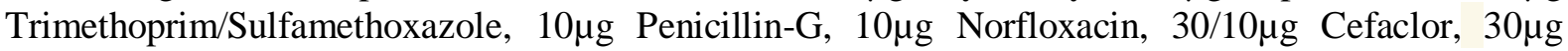

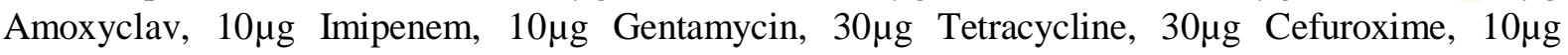
Meropenem) were placed on the surface of MHA plates and incubated at $37{ }^{\circ} \mathrm{C}$ for 18 hours (Jorgensen and Turnidge, 2015), the zone of inhibition around the discs were measured. Isolates that were resistant to three or more classes of antibiotics marked to be active against them were considered multidrug resistant strains.

\section{Phenotyping methods}

\section{Modified hodge test}

This is a test that detects bacteria that produce carbapenemases ${ }^{(28)}$. E. coli ATCC 25922 prepared according to the $0.5 \mathrm{McFarland}$ dilution standard was incubated overnight at $37^{\circ} \mathrm{C}$ and used to make a lawn culture on MHA (for each bacteria isolates). 10 $\mathrm{g}$ imipenem disc was placed at the centre of the each of the plates and the strains were streaked from the end of the disc to the edge of the plate in four different directions, plates were incubated at $37^{\circ} \mathrm{C}$. Carbapenemase production was indicated by a cloverleaf inhibition zone and strains negative for carbapenemase did not have a distorted zone of inhibition ${ }^{(29)}$.

\section{Imipenem-EDTA Double-disc synergy test (DDST)}

Overnight incubated isolates adjusted to the $0.5 \mathrm{McFarland}$ standard were used to make a lawn culture across MHA. 10 $\mu$ Imipenem and EDTA discs were placed on MHA 10mm apart and incubated overnight at $37^{\circ} \mathrm{C}$. An expanded growth inhibition zone between the discs indicated the strains were positive for MBL production and no synergistic zone of inhibition for the non-MBL producing strains ${ }^{(29)}$.

\section{Disk Potentiation Test (DPT)}

Overnight incubated isolates adjusted to the $0.5 \mathrm{McFarland}$ standard were used to make a lawn culture across MHA for each strain, two imipenem discs were placed on MHA, one of which was injected with $5 \mu 1$ of $0.5 \mathrm{M}$ EDTA solution, plates were then incubated overnight, strains with a wider zone of inhibition around EDTA with imipenem were considered MBL producing (Sowmya, 2015).

\section{Plasmid DNA profiling}

The procedure in the GenElute ${ }^{\mathrm{TM}}$ Plasmid Miniprep Kit was followed to extract the DNA from the bacteria isolates.

\section{Electrophoresis}

$50 \mathrm{ml}$ of $1.5 \%$ agarose gel was prepared by dissolving $0.75 \mathrm{~g}$ of agarose in $50 \mathrm{ml}$ of ready to use Tris-EDTA buffer solution and heating it till the solution became clear, after cooling to about $60^{\circ} \mathrm{C}$, $2 \mu \mathrm{l}$ of ethidium bromide was added and mixed well, gel was then poured in the gel tray, the well cutting comb was put in the gel, after it solidified at room temperature the comb was removed. $2 \mu 1$ of 
electrophoresis dye was added to $20 \mu$ of the solutions in the collection tubes (ones with elution solution) and added in the wells. The power cord was connected to the electrophoretic power supply properly. Electrophoresis was run at 120 volts and $90 \mathrm{~mA}$ current until the dye markers migrated a distance of about three-quarter of the gel, process was stopped and the gel was observed under a UV trans-illuminator.

\section{Results}

In this research, 30 water samples were collected along Klang River which extends over Gombak, Batu, Kuyoh, Kerayong, Penchala, Ampang, Klang and Damansara.

For Pseudomonas aeruginosa characterisation, 13-gram negative bacilli were isolated from water samples which were mostly slightly colourless and odourless, with a temperature of $30-32^{\circ} \mathrm{C}, \mathrm{pH}$ of 7.1 - 7.4 (Table 1). These water samples had the highest BOD value (Table 4.2) as compared to the ones with different physical properties. 6 of the 13-gram negative bacilli showed $P$. aeruginosa characterisation (Table 2) on selective Cetrimide agar, MAC and Blood agar. On Cetrimide agar, they showed a yellowish green fluorescence, on blood agar, beta haemolysis was demonstrated by greenish pigment and they were all non-lactose fermenting on MacConkey agar. P. aeruginosa isolation rate was at $3.33 \%$ (Table 3 ) as only one isolate indicated $P$. aeruginosa by being negative to Indole, Methyl Red, Voges-proskauer, Urease and positive to Mannitol, and Citrate tests, strain was motile and showed no hydrogen sulphide or gas production, alkaline slant and butt in TSI tests. The other 5 tested for bacteria that were not $P$. aeruginosa.

For Enterobacter aerogenes isolation, 17-gram negative bacilli were isolated from water samples which were mostly slightly colourless and odourless followed by the turbid and odourless ones, with a temperature of $30-35^{\circ} \mathrm{C}$ and $\mathrm{PH}$ of 6.7-7.2 (Table 1), 6 of the 9 gram negative bacilli showed $E$. aerogenes characterisation on selective EMB agar, MAC and Blood agar. On EMB agar, large pink or purplish mucoid colonies were seen, on blood agar, gamma haemolysis was demonstrated by the medium greyish white colonies and they were all lactose fermenting on MacConkey agar (pink colour). $30 \%$ of water sample isolates were further confirmed by their biochemical tests results by being negative to Indole, Methyl Red, Urease and positive to Voges-Proskauer, Mannitol, and Citrate tests, the strain was motile and showed no hydrogen sulphide or gas production, yellow slant and butt in TSI tests. The other 5 tested for bacteria that were not E. aerogenes.

\section{Multidrug resistant testing}

Table 2 shows the antibiotics that were used against the single strain of $P$. aeruginosa isolated from Klang River and it was highly susceptible to Norfloxacin followed by Meropenem, Cefuroxime, Imipenem, Ciprofloxacin, and Clavulanic acid. It showed resistance to Erythromycin, Trimethoprimsulfamethoxazole, Penicilin-G, Amoxyclav, and Tetracycline (Figure 1).

Table 3 shows the antibiotics that were tested against each of the strains isolated from Klang River. There are 6 multidrug resistant strains with E17 and E18 showing highest resistance (Figure 2) with most of them showing general resistance to Erythromycin, Trimethoprim-sulfamethoxazol, and Penicillin-G.

E14 showed resistance towards Erythromycin, Penicillin, Tetracycline and Cefuroxime, it showed high susceptibility to Clavulanic acid followed by Amoxyclav, Imipenem and Gentamicin, i.e. resistant to 4 of the 8 antibiotics it was tested against (Figure 3).

E17 showed resistance to Erythromycin, Trimethoprim-sulfamethoxazol, Clavulanic acid, Tetracycline and Cefuroxime, it showed high susceptibility to Norfloxacin followed by Imipenem, and Cefuroxime, i.e. resistant to 5 of the 8 antibiotics it was tested against (Figure 4).

E18 showed resistance to Erythromycin, Trimethoprim-sulfamethoxazol, Penicillin-G, Norfloxacin, and Cefuroxime, it showed similar high susceptibility to Clavulanic acid, Amoxyclav followed by Imipenem, i.e. resistant to 5 of the 8 antibiotics it was tested against (Figure 5).

E23 showed resistance to Erythromycin and Penicillin-G, it was highly susceptible to Meropenem, followed by Norfloxacin, Tetracycline, Amoxyclav and Gentamicin. This was resistant to 2 of 8 antibiotics; it is not a multidrug resistant (MDR) strain (Figure 6). 
E24 showed resistance to Erythromycin, Trimethoprim-sulfamethoxazol, Penicillin-G, and Tetracycline, it was highly susceptible to Ciprofloxacin followed by Imipenem, Cefuroxime, and Amoxyclav, i.e. resistant to 4 of the 8 antibiotics it was tested against (Figure 7).

E27 showed resistance to Erythromycin, Trimethoprim-sulfamethoxazol and Penicillin-G, showing high susceptibility to Ciprofloxacin followed by Imipenem, Meropenem, Clavulanic and Genatamicin, it was resistant to 3 of the 8 antibiotics it was tested against (Figure 8).

E30 showed resistance to Erythromycin, Penicillin-G, Tetracycline and Meropenem, it was highly susceptible to Cefuroxime followed by Norfloxacin, Ciprofloxacin and Clavulanic acid, i.e. resistant to 4 of the 8 antibiotics it was tested against (Figure 9).

E11 showed resistance to Erythromycin and Penicillin-G, it was highly susceptible to Amoxyclav followed by Norfloxacin, Cefuroxime, Ciprofloxacin, Meropenem and Clavulanic acid, this is not a MDR strain as it only showed resitance to 2 antibiotics (Figure 10).

E26 showed resistance to only Trimethoprim-sulfamethoxazol, and high susceptibility to Imipenem followed by Amoxyclav, Ciprofloxacin, Norfloxacin, Calvulanic acid, Gentamicin and Cefuroxime (Figure 11). This not a MDR strain.

\section{Modified hodge test}

The $P$. aeruginosa strain was tested for carbapenemase production and it tested negative as no clover or zone of inhibition was formed around the carbapenem (imipenem) disc used (Fig. 1).

The E14 strain tested negative for carbapenemase production by the lack of a zone of inhibition around the carbapenem (imipenem) disc used, however E17, E23, E 18, E24, E27 and E30 tested positive for carbapenemase production and was represented by the clover or zone of inhibition around the imipenem discs (Table 4).

\section{Imipenem-EDTA double-disc synergy test (DDST)}

The $P$. aeruginosa strain was tested with Imipenem and $10 \mu$ EDTA discs and it was MBL positive. All the 6 strains of E. aerogenes were tested and were MBL positive, this was indicated by the expanded growth/inhibition zone between the discs (Table 4).

\section{Disk potentiation test (DPT)}

The wider zone of inhibition around the Imipenem disc impregnated with EDTA than the plain Imipenem confirmed P20, E14, E17, E23, E 18, E24, E27 and E30 were MBL producing strains (Table 4).

\section{Electrophoresis}

Plasmid DNA was extracted and electrophoresed. Plasmid DNA of the bacteria was within the same range as of control bacteria (Figure 12).

\section{Discussion}

The need for safe and healthy water supplies has created a cause for public health concern about the rising pollution in water bodies (Klang River), there is now pressure on appropriate authorities to carry out due action to reduce the rate of pollution of this water bodies, hence the studies of micro flora found in them- pathogens, and faecal organisms ${ }^{(30)} .15$ of the water samples were slightly clear and odourless with mean $\mathrm{pH}$, Temperature, Dissolved oxygen and BOD of $7.06,30.87^{\circ} \mathrm{C}, 6.23 \mathrm{mg} / \mathrm{L}$, and $3.93 \mathrm{mg} / \mathrm{L}$ respectively. The normal BOD value range for moderately polluted rivers is $2-8 \mathrm{mg} / \mathrm{L}$, hence these water sites were moderately polluted hence higher dissolved oxygen levels that will permit growth of bacteria. Most of the gram-negative bacilli were isolated from these samples.

Two samples had debris in them but were odourless with mean $\mathrm{pH}$, Temperature, Dissolved oxygen and BOD of $7.10,30.50^{\circ} \mathrm{C}, 5.95 \mathrm{mg} / \mathrm{L}$ and $2.77 \mathrm{mg} / \mathrm{L}$ respectively. These samples had the lowest BOD value that still indicated that water was moderately polluted but with enough dissolved oxygen for bacteria and aquatic life to thrive.

Nine of the water samples were turbid and odourless with mean $\mathrm{pH}$, Temperature, Dissolved oxygen and BOD of $7.02,33.33^{\circ} \mathrm{C}, 7.56 \mathrm{mg} / \mathrm{L}, 3.28 \mathrm{mg} / \mathrm{L}$ respectively. BOD value indicates water was moderately polluted and still had enough dissolved oxygen for bacteria and aquatic life to thrive. 
Carbapenems are usually used against MDR strains P20 was susceptible to the carbapenemsImipenem and Meropenem used. E14, E17, E23, E 18, E24, E27 and E30 were resistant to imipenem and all but E30 were resistant to Meropenem. In a study conducted in India to detect the genes encoding carbapenem resistance among Enterobacter species, $53.84 \%$ of the isolates showed reduced susceptibility to Imipenem. $17.14 \%$ of these isolates were confirmed to be Enterobacter aerogenes ${ }^{(31)}$, although the susceptibility range was reduced just like that of E14, E17, E23, E18, E24, E27 and E30, most of the strains still showed resistance to Imipenem and Meropenem. 15 $\mu \mathrm{g}$ Erythromycin,

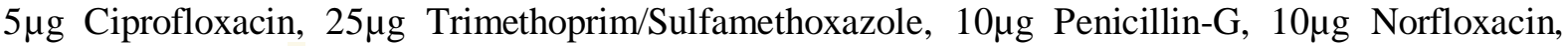

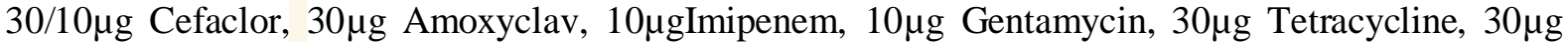
Cefuroxime, and $10 \mu \mathrm{g}$ Meropenem were used against P. aeruginosa and it exhibited high resistance to 5 of these 12. In a study conducted by Adesoji et al., 2015, P. aeruginosa was noted to be more resistant to older generation antibiotics (Trimethoprim/Sulfamethoxazole, Tetracycline) than the new generation ones (Nalidic acid, Gentamicin, and Kanamycin) and this older generation antibiotic resitance was exhibited in this $P$. aeruginosa isolation study. MDR rate of $P$. aeruginosa isolated from clinical samples in Iran, Nepal and Malaysia were $100 \%, 20.69 \%$ and $19.6 \%$ respectively ${ }^{(32)}$.

A study of $P$. aeruginosa isolated from river water and clinical smaples show resitance to cotrimoxazole than they do Gentamicin and Tetracycine, however isolates from river water alone show higher sensitivity to Ciprofloxacin ${ }^{(33)}$.

Phenotyping methods are dependent on the ability of metal chelators - EDTA and thiol-based compounds to inhibit MBL activity ${ }^{(34)}$. EDTA-(DDST and CPT) are used to detect MBL producing strains, CPT is more sensitive than DDST while Modified Hodge test can only detect if a strain is carbapenemase producing one as metal dependence of carbapenemase is not confirmed because EDTA is not used, ${ }^{(35)}$,These tests are cheap to perform, easy and give reliable and ideal results ${ }^{(36)}$.In this study, the P20 and E14 were not carbapenemase producing strains but were MBL producing ones. The other 5 of the 6 strains (83.33\%) were both MBL and carbapenemase producing strains.

Conclusively, multi-drug resistant Pseudomonas aeruginosa and Enterobacter aerogenes were present in water samples from Klang River, most of the E. aerogenes were carbapenemase producing while the single $P$. aeruginosa was not. All the strains of the two bacteria were MBL producing ones, this increased contamination and presence of MBL producing strains can be associated with the industries, hospitals, and increased pollution around the places Klang River passes through.

Multidrug resistant bacteria in water systems contribute to the wide-scale transfer of resistance genes in the environment thereby posing health hazard to humans and animals. Untreated water sources are a major threat to the public health and frequent antibiotic abuse has induced increased antibiotic resistance ${ }^{(16)}$.

Integrated antibiotic resistant surveillance system, promotion of controlled use of antibiotics and holistic one health approach are recommended in both the clinical and agricultural settings to prevent and control multidrug resistant bacteria in areas the Klang River passes ${ }^{(7)}$. Some of the effluents in the river water are from hospitals, the infection control measure applied in Recife Brazil can also be applied (identifying blaSPM-1 genes and disseminate clones to different hospitals ${ }^{(38)}$. Results of Hodge test can be made more ideal or improved by the addition of zinc sulphate to the Mueller Hinton $\operatorname{agar}^{(39)}$.

The band size was along the same size as that of the marker DNA. 16S rRNA sequencing can be done to further identify and confirm the strain of bacteria isolates.

\section{Significance of study}

This study highlighted the presence of MDR isolates of $P$. aeruginosa and E. aerogenes in water samples from Klang River and this is associated with the high rates of pollution from the disposal of household, industrial and hospital wastes around and into the water bodies increasing the risk of infection and prolonged hospitalisation from lack of response to empirical therapy, increased cost of health care and possibly complications in poorly managed situations. 


\section{Limitations of study}

$16 \mathrm{~S}$ rRNA sequencing can be done to further identify and confirm the strain of bacteria isolates.

Table 1. Physical properties, $\mathrm{pH}$, Temperature, DO and BOD value of water samples

\begin{tabular}{|c|c|c|c|c|c|}
\hline Sample & Physical properties & $\mathrm{pH}$ & $\begin{array}{l}\text { Temperature } \\
\left({ }^{\circ} \mathrm{C}\right)\end{array}$ & Dissolved Oxygen $(\mathrm{mg} / \mathrm{L})$ & $\begin{array}{l}\text { BOD value } \\
(\mathrm{mg} / \mathrm{L})\end{array}$ \\
\hline 1 & Slightly clear, odourless & 6.5 & 30 & 3.13 & 2.95 \\
\hline 2 & Slightly clear, odourless & 6.5 & 31 & 2.50 & 2.00 \\
\hline 3 & Slightly clear, odourless & 6.6 & 30 & 2.20 & 1.87 \\
\hline 4 & Debris present, odourless & 7.1 & 30 & 5.43 & 2.33 \\
\hline 5 & Debris present, odourless & 7.1 & 31 & 6.47 & 3.20 \\
\hline 6 & Slightly clear, odourless & 7.2 & 31 & 5.97 & 3.00 \\
\hline 7 & Slightly clear, odourless & 7.0 & 30 & 7.20 & 4.85 \\
\hline 8 & Slightly clear, odourless & 6.8 & 31 & 8.07 & 5.00 \\
\hline 9 & Clear, odourless & 6.8 & 30 & 6.43 & 2.50 \\
\hline 10 & Clear, punget smell & 6.7 & 32 & 7.10 & 4.60 \\
\hline 11 & Slightly clear, pungent smell & 6.7 & 33 & 7.27 & 4.60 \\
\hline 12 & Slightly clear, pungent smell & 6.8 & 32 & 6.93 & 3.85 \\
\hline 13 & Turbid, odourless & 6.4 & 33 & 8.90 & 3.90 \\
\hline 14 & Turbid, odourless & 6.7 & 34 & 6.10 & 2.45 \\
\hline 15 & Turbid, odourless & 6.9 & 34 & 6.17 & 2.30 \\
\hline 16 & Turbid, odourless & 7.0 & 33 & 6.90 & 2.85 \\
\hline 17 & Slightly clear, odourless & 7.4 & 32 & 9.35 & 4.50 \\
\hline 18 & Slightly clear, odourless & 7.2 & 32 & 4.23 & 2.75 \\
\hline 19 & Slightly clear, odourless & 7.4 & 31 & 5.33 & 3.72 \\
\hline 20 & Slightly clear, odourless & 7.4 & 32 & 9.70 & 6.20 \\
\hline 21 & Slightly clear, odourless & 7.4 & 31 & 10.30 & 7.56 \\
\hline 22 & Slightly clear, odourless & 7.1 & 32 & 7.50 & 4.10 \\
\hline 23 & Slightly clear, odourless & 7.1 & 30 & 5.50 & 3.30 \\
\hline 24 & Slightly clear, odourless & 7.1 & 30 & 6.70 & 3.70 \\
\hline 25 & Slightly clear, odourless & 7.2 & 30 & 5.70 & 3.43 \\
\hline 26 & Turbid, odourless & 7.2 & 32 & 6.80 & 2.50 \\
\hline 27 & Turbid, odourless & 7.2 & 35 & 8.30 & 3.50 \\
\hline 28 & Turbid, odourless & 7.4 & 33 & 9.30 & 5.10 \\
\hline 29 & Turbid, odourless & 7.2 & 31 & 7.70 & 3.23 \\
\hline 30 & Turbid, odourless & 7.2 & 35 & 7.90 & 3.65 \\
\hline
\end{tabular}


DOI: $10.21522 /$ TIJBMS.2016.04.01.Art003

ISSN: $2519-500 \mathrm{X}$

Table 2. Antibiogram of Pseudomonas aeruginosa (P20) isolate

\begin{tabular}{|l|l|}
\hline Antibiotics & P20 \\
\hline $15 \mu \mathrm{g}$ Erythromycin & Resistant \\
\hline $5 \mu \mathrm{g}$ Ciprofloxacin & $14 \mathrm{~mm}$ \\
\hline $25 \mu \mathrm{g}$ Trimethoprim-sulfamethoxazole & Resistant \\
\hline $10 \mu \mathrm{g}$ Penicillin-G & Resistant \\
\hline $10 \mu \mathrm{g}$ Norfloxacin & $23 \mathrm{~mm}$ \\
\hline $30 / 10$ Clavulanic acid & $10 \mathrm{~mm}$ \\
\hline $30 \mu \mathrm{g}$ Amoxyclav & Resistant \\
\hline $10 \mu \mathrm{g}$ Imipenem & $18 \mathrm{~mm}$ \\
\hline $10 \mu \mathrm{g}$ Gentamicin & $9 \mathrm{~mm}$ \\
\hline $30 \mu \mathrm{g}$ Tetracycline & Resistant \\
\hline $30 \mu \mathrm{g}$ Cefuroxime & $18 \mathrm{~mm}$ \\
\hline $10 \mu \mathrm{g}$ Meropenem & $21 \mathrm{~mm}$ \\
\hline
\end{tabular}




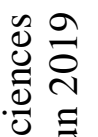

总

急

产

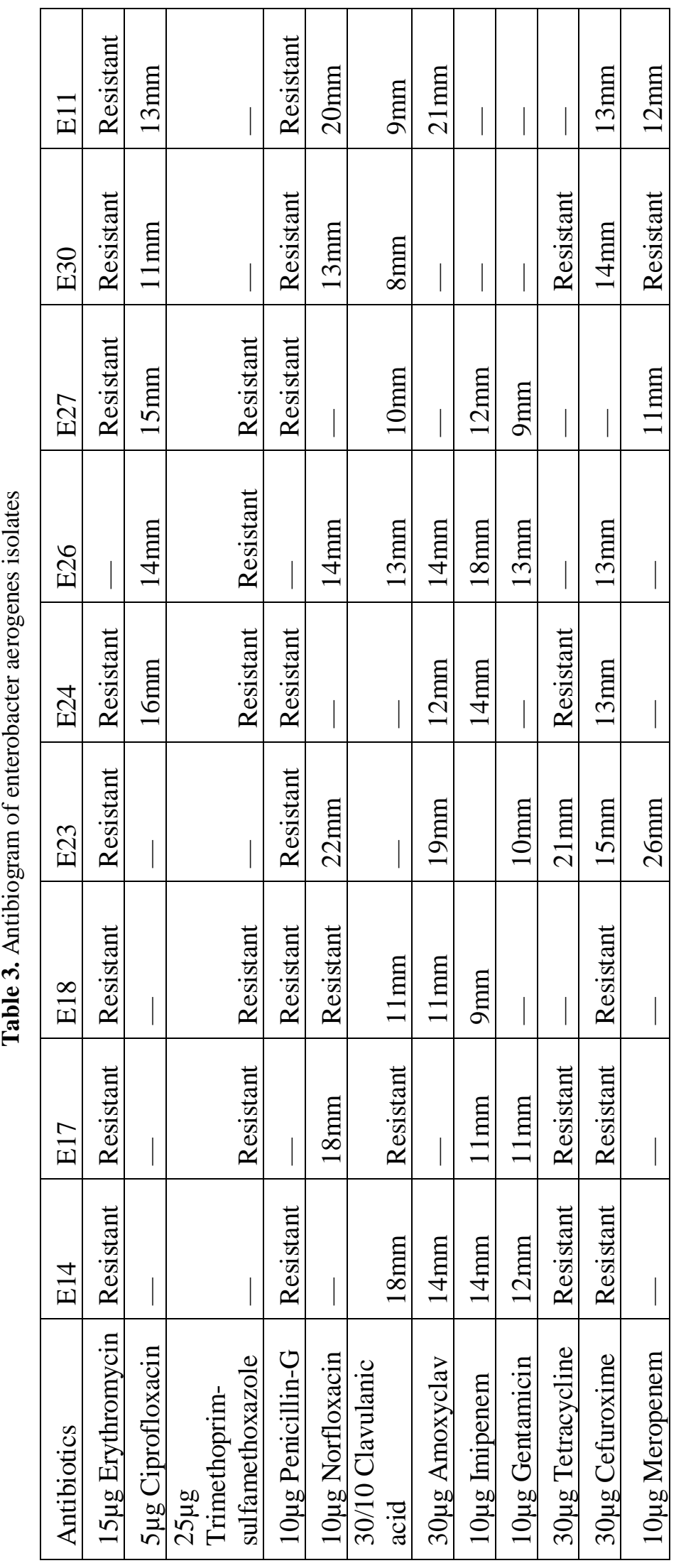


Table 4. Detection of carbapenemase, beta-lactamase and MBL producing gram negative E. aerogenes

\begin{tabular}{|l|l|l|l|l|l|l|l|}
\hline $\begin{array}{l}\text { Phenotypin } \\
\text { g tests }\end{array}$ & E14 & E17 & E23 & E18 & E24 & E27 & E30 \\
\hline Hodge Test & Negative & Positive & Positive & Positive & Positive & Positive & Positive \\
\hline DDST & Positive & Positive & Positive & Positive & Positive & Positive & Positive \\
\hline DPT & Positive & Positive & Positive & Positive & Positive & Positive & Positive \\
\hline
\end{tabular}

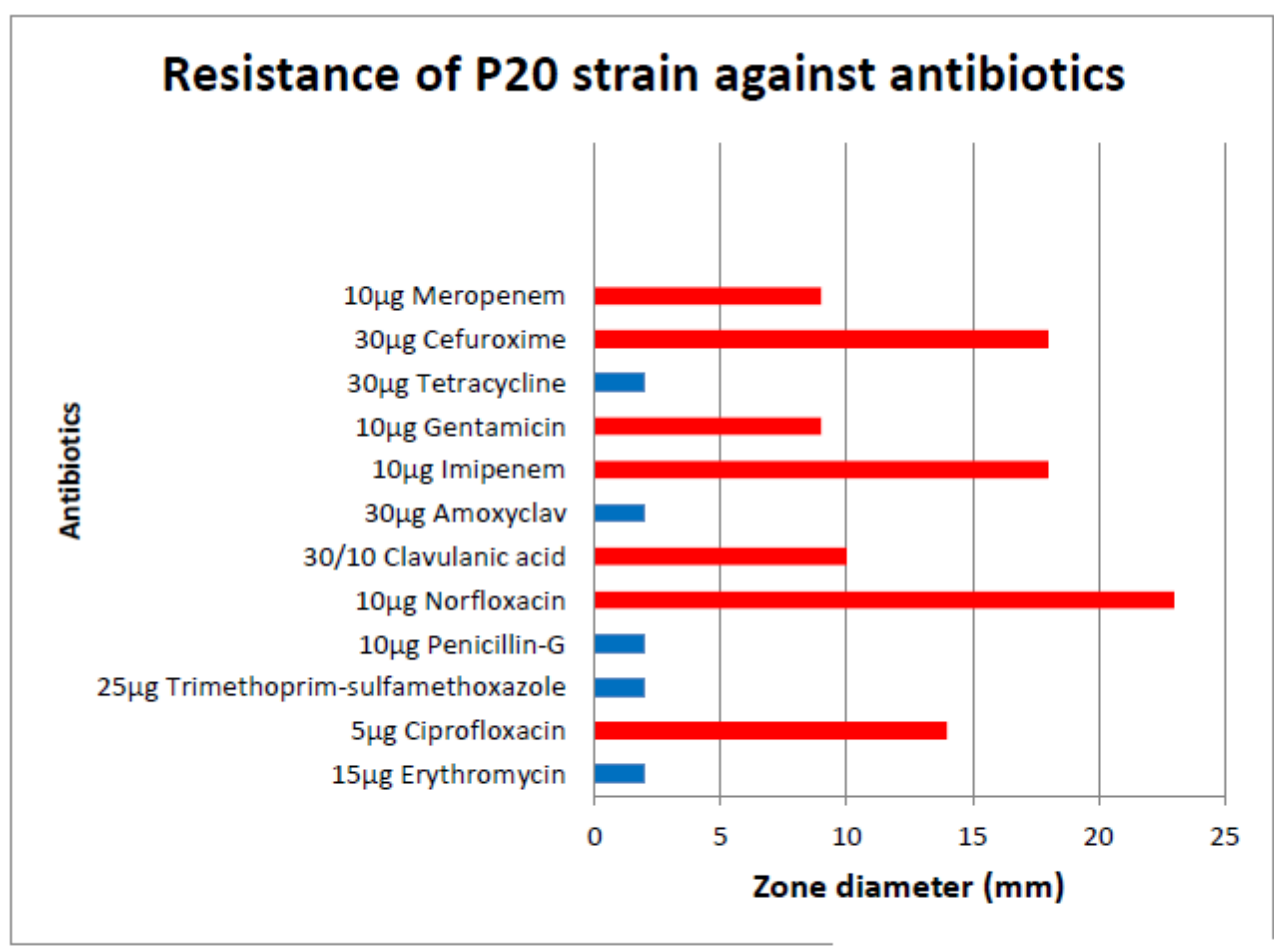

Resistance is represented by $2 \mathrm{~mm}$

Figure 1. Resistance of P20 strain against antibiotics

\section{E. aerogenes Resistance (\%)}

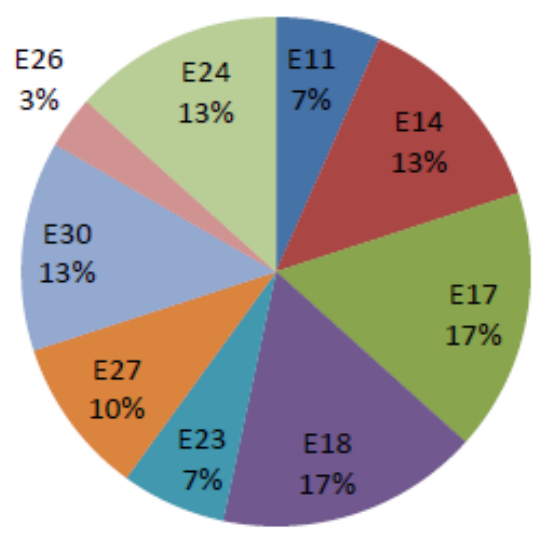

Figure 2. Rate of resistance of the different E. aerogenes strains to antibiotics 
DOI: $10.21522 /$ TIJBMS.2016.04.01.Art003

ISSN: $2519-500 \mathrm{X}$

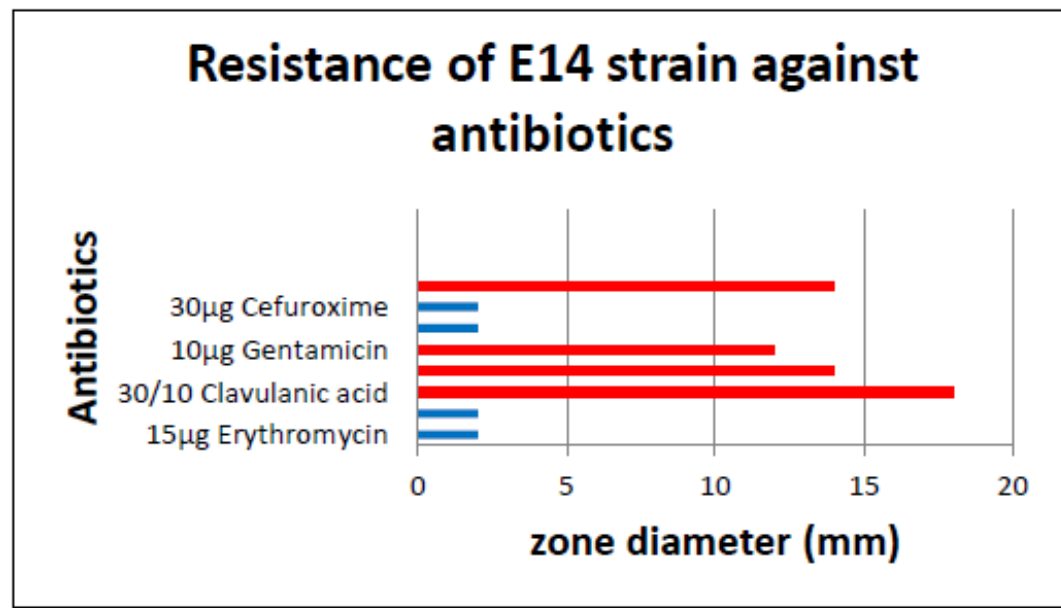

Resistance is represented by $2 \mathrm{~mm}$

Figure 3. Resistance of E14 strain against antibiotics

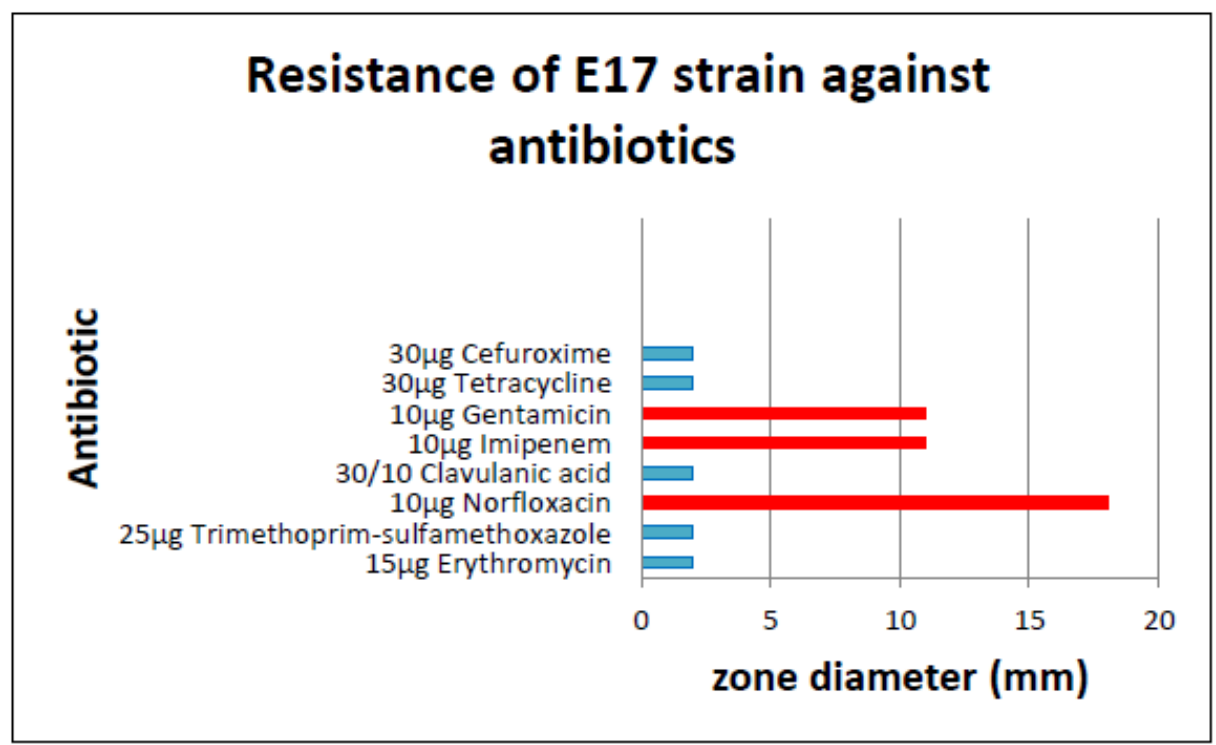

Resistance is represented by $2 \mathrm{~mm}$

Figure 4. Resistance of E17 strain against antibiotics 


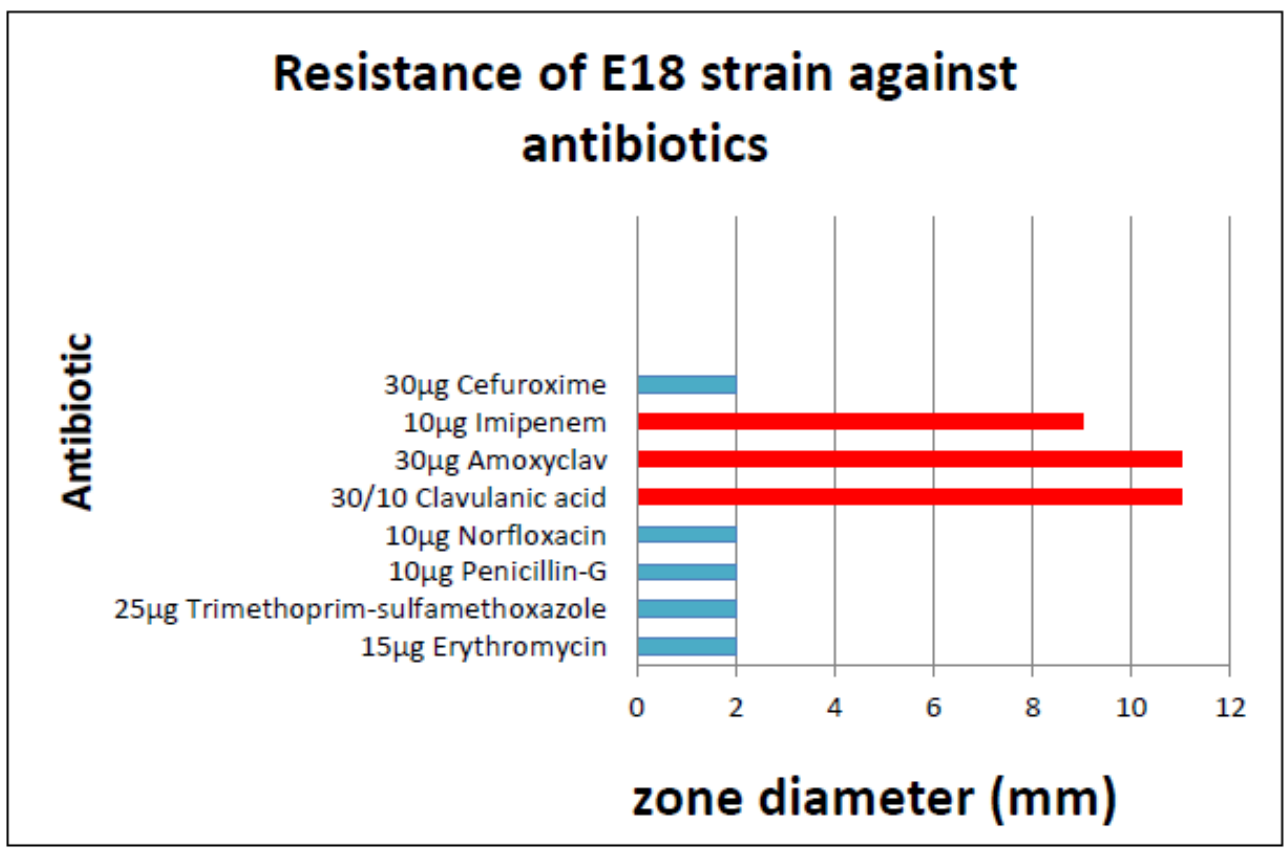

\section{Resistance is represented by $2 \mathrm{~mm}$}

Figure 5. Resistance of E18 strain against antibiotics

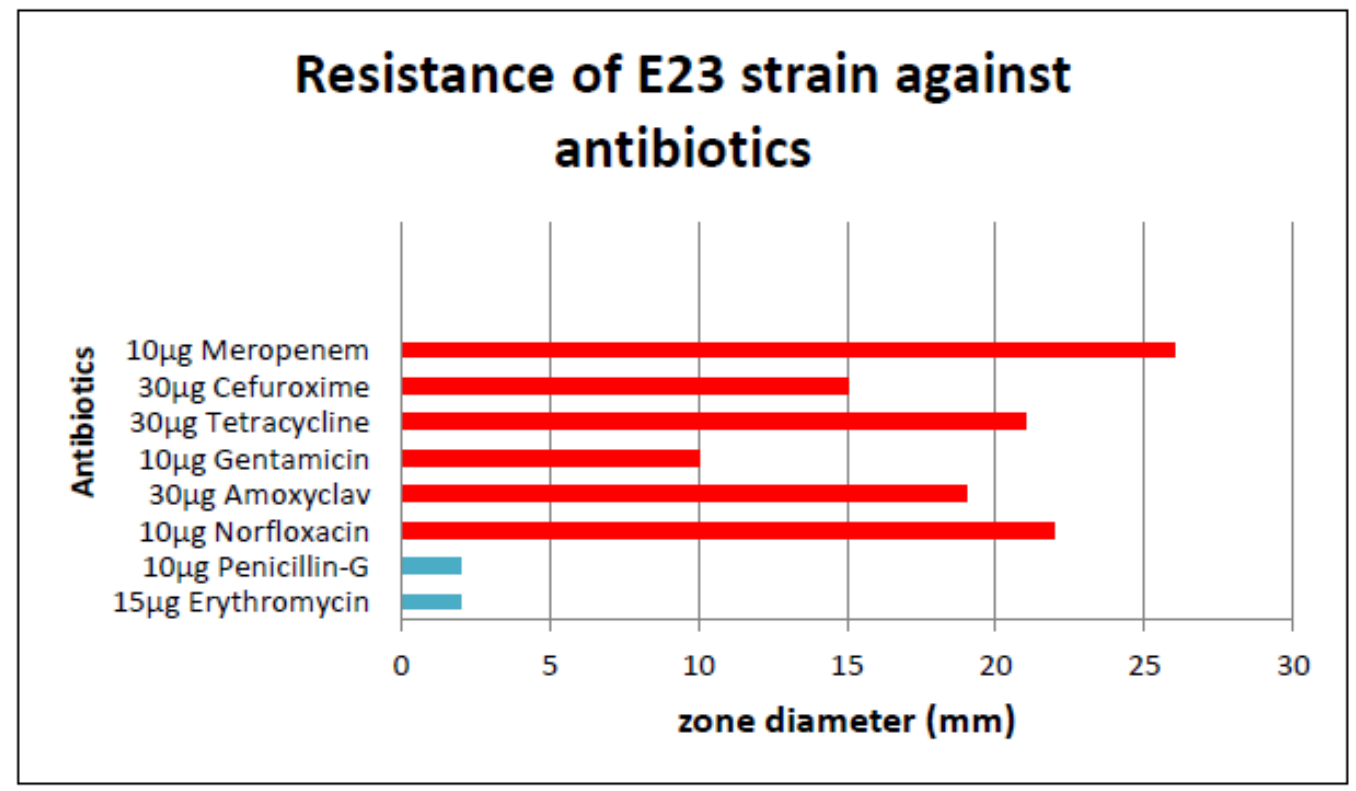

Resistance is represented by $2 \mathrm{~mm}$

Figure 6. Resistance of E23 strain against antibiotics 
DOI: $10.21522 /$ TIJBMS.2016.04.01.Art003

ISSN: $2519-500 \mathrm{X}$

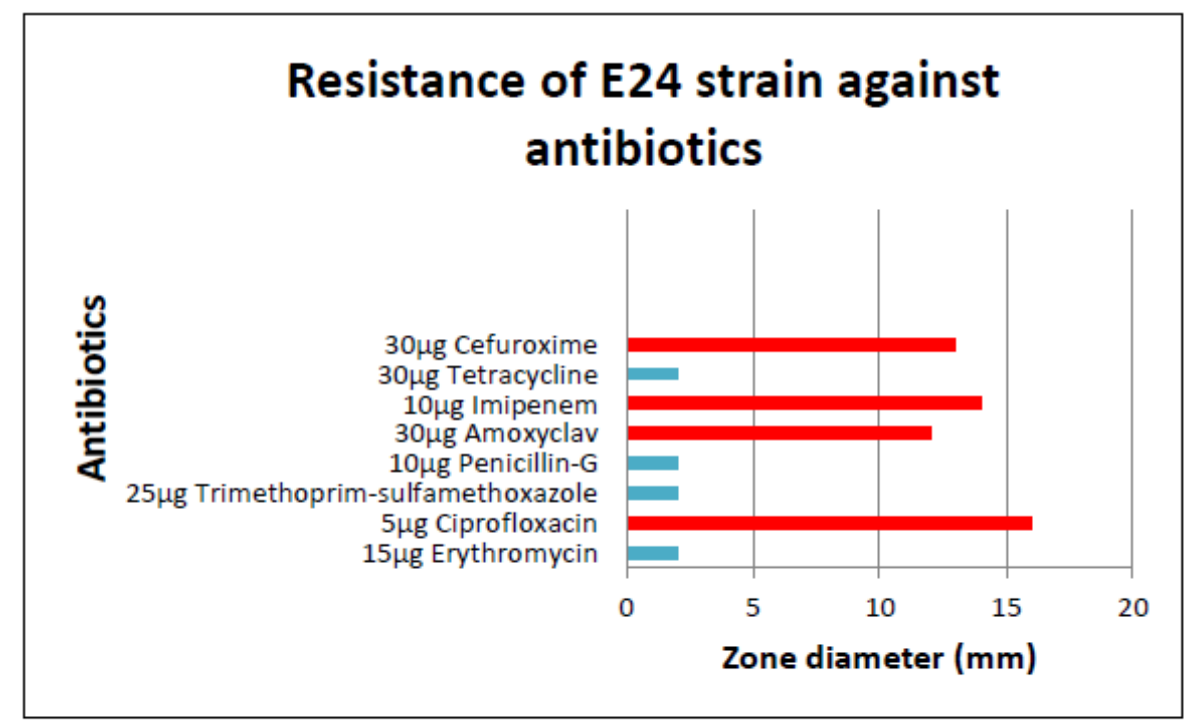

Resistance is represented by $2 \mathrm{~mm}$

Figure 7. Resistance of E24 strain against antibiotics

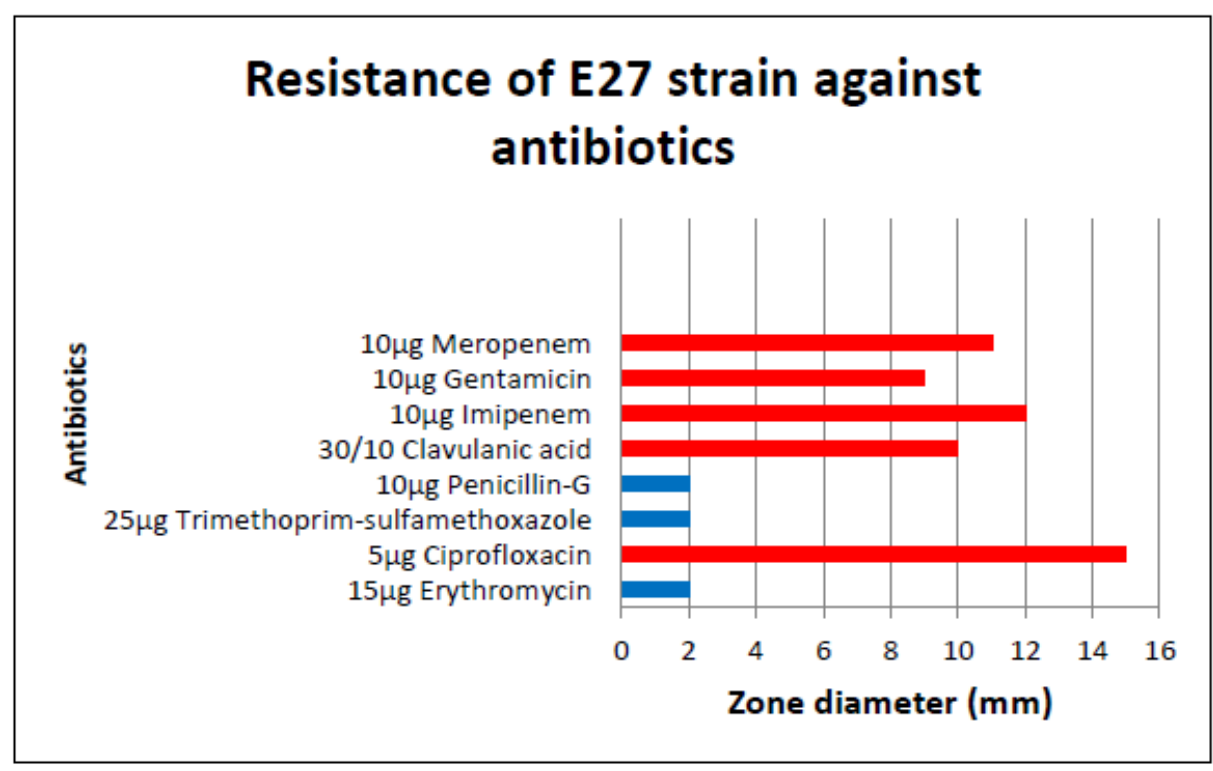

Resistance is represented by $2 \mathrm{~mm}$

Figure 8. Resistance of E27 strain against antibiotics 


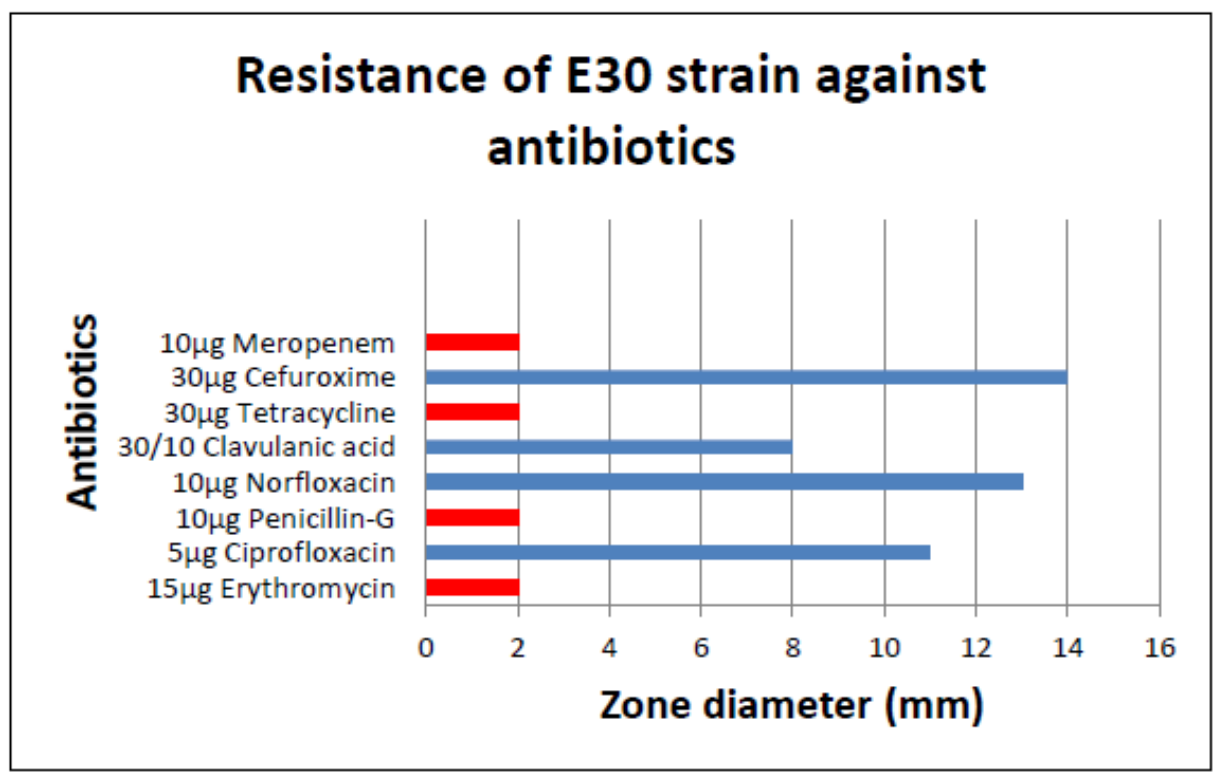

\section{Resistance is represented by $2 \mathrm{~mm}$}

Figure 9. Resistance of E30 strain against antibiotics

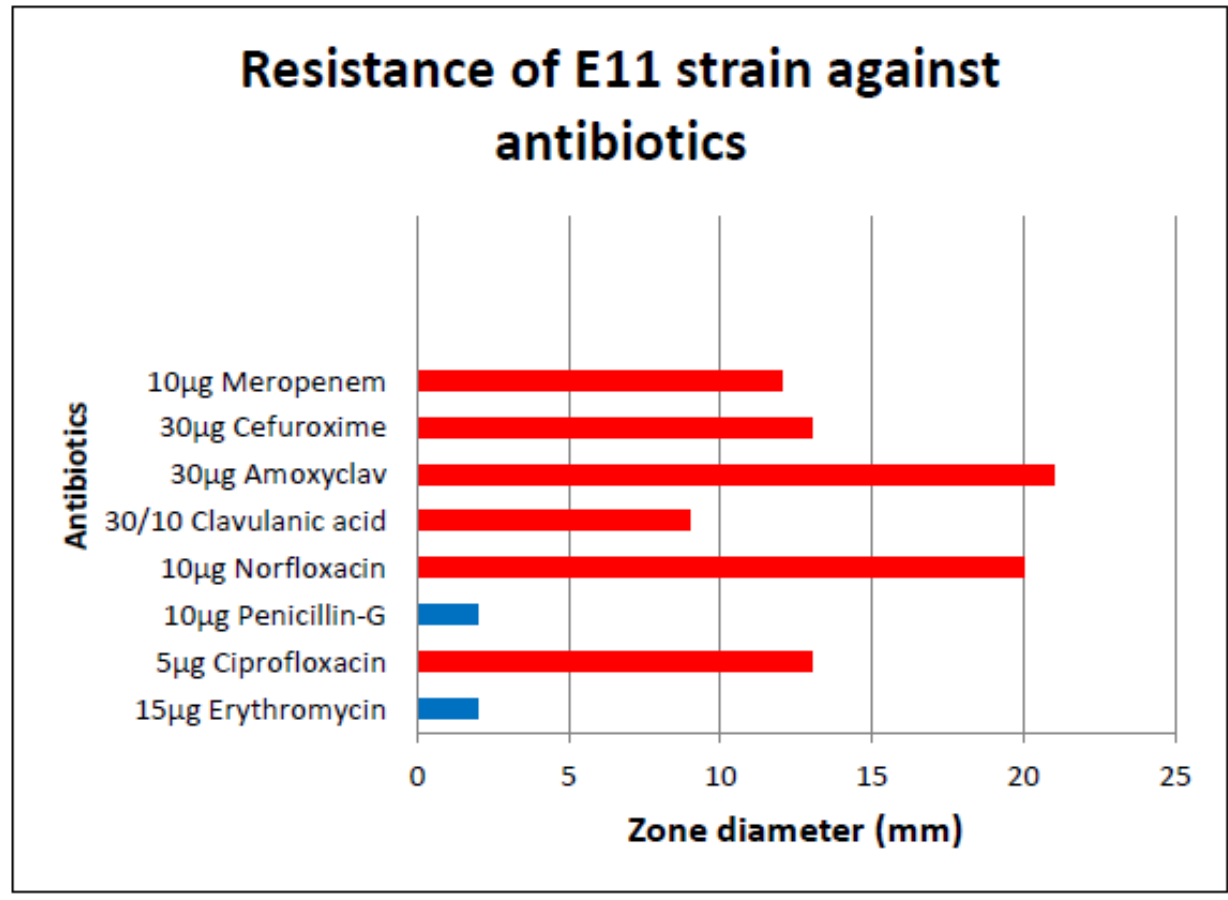

\section{Resistance is represented by $2 \mathrm{~mm}$}

Figure 10. Resistance of E11 strain against antibiotics\ 
DOI: $10.21522 /$ TIJBMS.2016.04.01.Art003

ISSN: 2519-500X

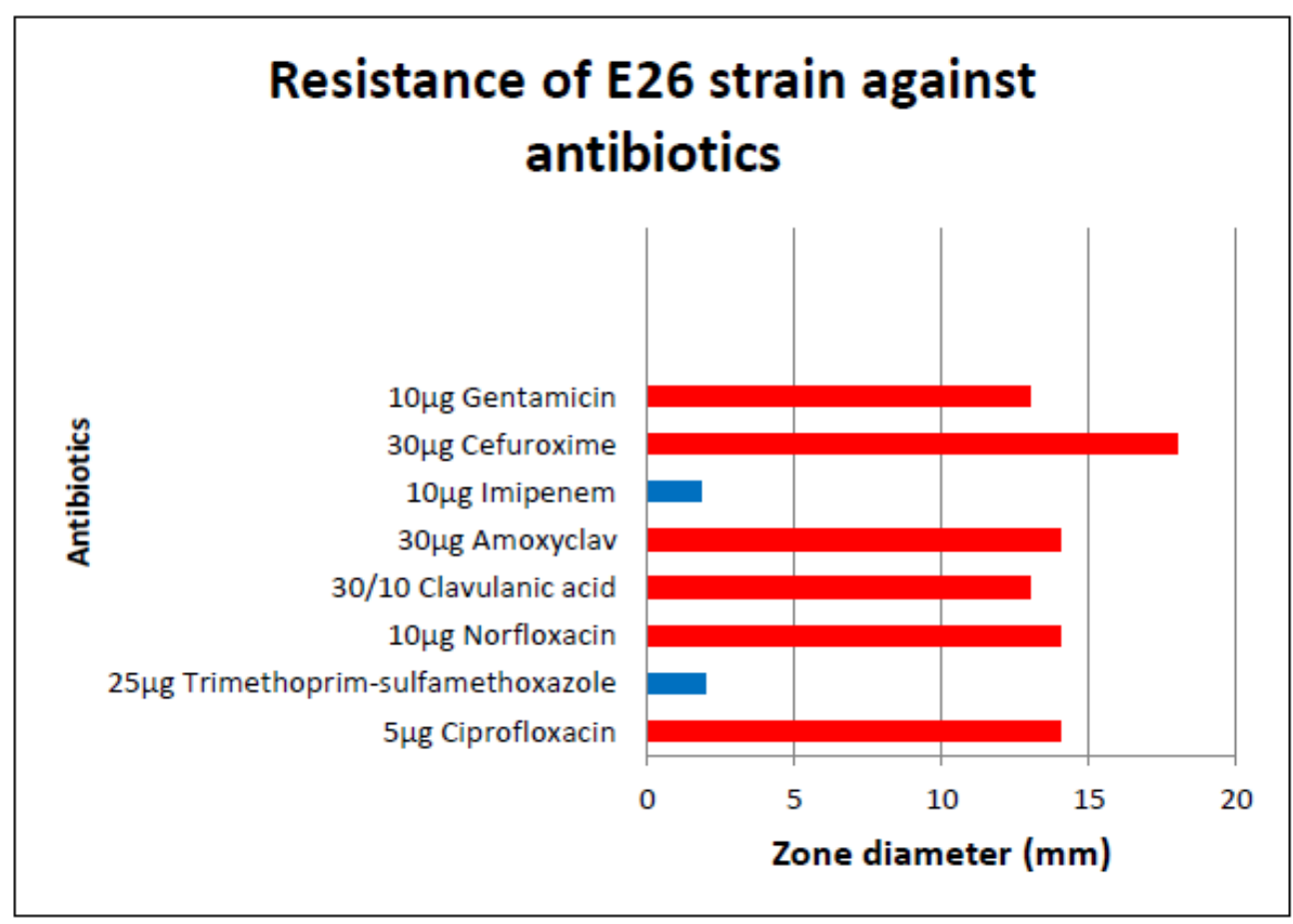

Resistance is represented by $2 \mathrm{~mm}$

Figure 11. Resistance of E26 strain against antibiotics

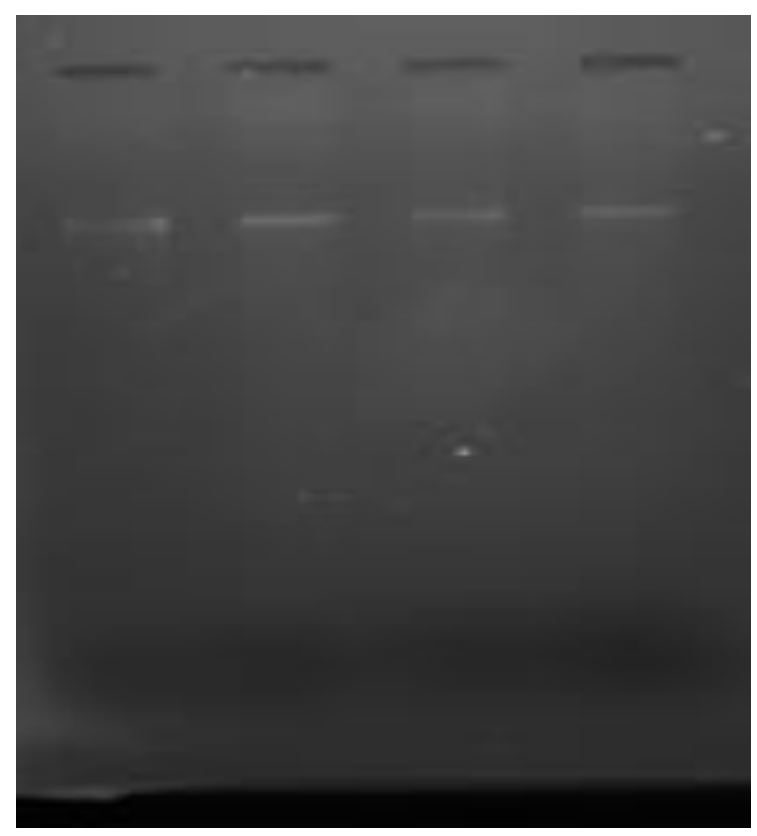

Figure 12. Plasmid DNA profiling

P E17 E18 P20

Lane P- control Pseudomonas aeruginosa ATCC 9027 (marker)

Lane E17-MDR Enterobacter aerogenes

Lane E18- MDR Enterobacter aerogenes

Lane P20- MDR Pseudomonas aeruginosa 


\section{References}

[1]. Lockhart, S., Abramson, M., Beekmann, S., Gallagher, G., Riedel, S., Diekema, D., Quinn, J. and Doern, G. (2007). Antimicrobial Resistance among Gram-Negative Bacilli Causing Infections in Intensive Care Unit Patients in the United States between 1993 and 2004. Journal of Clinical Microbiology, 45(10), pp.3352-3359.

[2]. Hidron, A., Edwards, J., Patel, J., Horan, T., Sievert, D., Pollock, D. and Fridkin, S. (2008). NHSN Annual Update: Antimicrobial-Resistant Pathogens Associated with Healthcare-Associated Infections: Annual Summary of Data Reported to the National Healthcare Safety Network at the Centers for Disease Control and Prevention, 2006-2007 •. Infection Control and Hospital Epidemiology, 29(11), pp.996-1011.

[3]. Thiolas, A., Bollet, C., La Scola, B., Raoult, D. and Pages, J. (2005). Successive Emergence of Enterobacter aerogenes Strains Resistant to Imipenem and Colistin in a Patient. Antimicrobial Agents and Chemotherapy, 49(4), pp.1354-1358.

[4]. Mallea, M., Chevalier, J., Bornet, C., Eyraud, A., Davin-Regli, A., Bollet, C. and Pages, J. (1998). Porin alteration and active efflux: two in vivo drug resistance strategies used by Enterobacter aerogenes. Microbiology, 144(11), pp.3003-3009.

[5]. Jana, S., Trivedi, M. and Branton, A. (2015). Characterization of Phenotype and Genotype of Biofield Treated Enterobacter aerogenes. Translational Medicine, 05(04).

[6]. Hallin, M., Deplano, A., Roisin, S., Boyart, V., De Ryck, R., Nonhoff, C., Byl, B., Glupczynski, Y. and Denis, O. (2012). Pseudo-Outbreak of Extremely Drug-Resistant Pseudomonas aeruginosa Urinary Tract Infections Due to Contamination of an Automated Urine Analyzer. Journal of Clinical Microbiology, 50(3), pp.580-582.

[7]. Adesoji, A., Ogunjobi, A. and Olatoye, I. (2015). Molecular characterization of selected multidrug resistant Pseudomonas from water distribution systems in southwestern Nigeria. Annals of Clinical Microbiology and Antimicrobials, 14(1).

[8]. Mena KD and Gerba CP (2009). Risk assessment of Pseudomonas aeruginosa in water. Reviews of Environmental Contamination and Toxicology, 201, pp.71-115.

[9]. Craun, G., Calderon, R. and Craun, M. (2005). Outbreaks associated with recreational water in the United States. International Journal of Environmental Health Research, 15(4), pp.243-262.

[10]. Fontes, L., Neves, P., Oliveira, S., Silva, K., Hachich, E., Sato, M. and Lincopan, N. (2011). Isolation of Pseudomonas aeruginosa Coproducing Metallo- -Lactamase SPM-1 and 16S rRNA Methylase RmtD1 in an Urban River. Antimicrobial Agents and Chemotherapy, 55(6), pp.3063-3064.

[11]. Mehul S Chaudhari Tanuja B Javadekar Govind Ninama Neelam Pandya Jivraj Damor (2011) A study of metallo-beta-lactatamase producing pseudomonas aeruginosa in clinical samples of S.S.G. hospital. Natl J Med Res, 1 (2), 60-63.

[12]. Pitout, J., Gregson, D., Poirel, L., McClure, J., Le, P. and Church, D. (2005). Detection of Pseudomonas aeruginosa Producing Metallo Lactamases in a Large Centralized Laboratory. Journal of Clinical Microbiology, 43(7), pp.3129-3135.

[13]. Mena KD and Gerba CP (2009). Risk assessment of Pseudomonas aeruginosa in water. Reviews of Environmental Contamination and Toxicology, 201, pp.71-115.

[14]. Ranjan, S., Sreenivasa Babu, P. and Banashankari, G. (2014). Comparison of epidemiological and antibiotic susceptibility pattern of metallo-beta-lactamase-positive and metallo-beta-lactamase-negative strains of pseudomonas aeruginosa. Journal of Laboratory Physicians, 6(2), p.109.

[15]. Corcoran, E., Nellemann, C., Baker, E., Bos, R., Osborn, D. and Savelli, H. (2010). Sick water? The central role of wastewater management in sustainable development. 1st ed. Arendal: UNEP/GRID-Arendal.

[16]. Ventola, C. L. (2015). The Antibiotic Resistance Crisis: Part 1: Causes and Threats. Pharmacy and Therapeutics, Pharmacy and Therapeutics, 40(4), 277-283.

[17]. Fawell, J. (2003). Contaminants in drinking water. British Medical Bulletin, 68(1), pp.199-208.

[18]. Artemova, T., Gerardin, Y., Dudley, C., Vega, N. and Gore, J. (2015). Isolated cell behavior drives the evolution of antibiotic resistance. Molecular Systems Biology, 11(7), pp.822-823.

[19]. Hussain, M. and Rao, T. (2013). Effect of Industrial Effluents on Surface Water Quality - A Case Study of Patancheru, Andhra Pradesh, India. Current World Environment Journal, 8(3), pp.445-454.

[20]. Coutinho, F., Silveira, C., Pinto, L., Salloto, G., Cardoso, A., Martins, O., Vieira, R. and Clementino, M. (2014). Antibiotic Resistance is Widespread in Urban Aquatic Environments of Rio de Janeiro, Brazil. Microbial Ecology, 68(3), pp.441-452. 
[21]. Okokwo Iheanyi, Damilola, Adejoye Oluseyi; Adeola, Ogunnusi Tolulope; A, Enobong; B, Shittu Olufunke. (2008). Microbiological and physicochemical analysis of different water samples used for domestic purposes in Abeokuta and Ojota, Lagos State, Nigeria. African Journal of Biotechnology, pp. 617-621.

[22]. Carpenter, J. (1965). THE CHESAPEAKE BAY INSTITUTE TECHNIQUE FOR THE WINKLER DISSOLVED OXYGEN METHOD. Limnology and Oceanography, 10(1), pp.141-143.

[23]. Slekovec, C., Plantin, J., Cholley, P., Thouverez, M., Talon, D., Bertrand, X. and Hocquet, D. (2012). Tracking Down Antibiotic-Resistant Pseudomonas aeruginosa Isolates in a Wastewater Network. PLoS ONE, 7(12), p.e49300.

[24]. Cappuccino, J. and Sherman, N. (2007). Microbiology: A Laboratory Manual. 8th ed.

[25]. CLSI Institute 2011

[26]. Bashir D, Thokar MA, Fomda BA, Bashir G, Zahoor D, Ahmad S, Toboli AS (2011). Detection of metallo-beta-lactamase (MBL) producing Pseudomonas aeruginosa at a tertiary care hospital in Kashmir. Afr. J. Microbiol. Res. 5(2):164-172.

[27]. Jorgensen, J. and Turnidge, J. (2015). Susceptibility Test Methods: Dilution and Disk Diffusion Methods*. Manual of Clinical Microbiology, 11th Edition, pp.1253-1273.

[28]. Amjad, A., Mirza, I., Abbasi, S., Farwa, U., Malik, N., \& Zia, F. (2011). Modified Hodge test: A simple and effective test for detection of carbapenemase production. Iranian Journal of Microbiology, 3(4), pp.189193.

[29]. Sowmya, G., Shivappa, Ranjitha Shankaregowda, Raghavendra Rao M, Rajeshwari K G, Madhuri Kulkarni (2015). Detection of Metallo-beta lactamase production in clinical isolates of Nonfermentative Gram negative bacilli. IOSR Journal of Dental and Medical Sciences (IOSR-JDMS), pp. 43-48.

[30]. Canhoto, O. and Magan, N. (2005). Electronic nose technology for the detection of microbial and chemical contamination of potable water. Sensors and Actuators B: Chemical, 106(1), pp.3-6.

[31]. Khajuria, A., Praharaj, A., Kumar, M. and Grover, N. (2014). Carbapenem Resistance among Enterobacter Species in a Tertiary Care Hospital in Central India. Chemotherapy Research and Practice, 2014, pp.1-6.

[32]. Nasreen, M., Sarker, A., Malek, M., Ansaruzzaman, M. and Rahman, M. (2015). Prevalence and Resistance Pattern of Pseudomonas aeruginosa isolated from Surface Water. Advances in Microbiology, 05(01), pp.74-81.

[33]. Bhalerao DS, Roushani S, Kinikar AG, Akhter I. (2010). Study of Metallo-beta lactamase producing Pseudomonas aeruginosa in Pravara Rural Hospital. Pravara Med Rev; 2(3).

[34]. Manoharan, A., Chatterjee, S., Mathai, D. and SARI Study Group (2010). Detection and characterization of metallo beta lactamases producing Pseudomonas aeruginosa. Indian Journal of Medical Microbiology, 28(3), p.241.

[35]. Kali, A. (2013). Detection of metallo-beta-lactamase producing Pseudomonas aeruginosa in intensive care units. Australasian Medical Journal, 6(12), pp.686-693.

[36]. Qu TT1, Zhang JL, Wang J, Tao J, Yu YS, Chen YG, Zhou JY, Li LJ. (2009). Evaluation of phenotypic tests for detection of metallo-beta-lactamase-producing Pseudomonas aeruginosa strains in China. J Clin Microbiol 47(4): pp.1136-1142.

[37]. Jácome, P., Alves, L., Cabral, A., Lopes, A. and Maciel, M. (2012). Phenotypic and molecular characterization of antimicrobial resistance and virulence factors in Pseudomonas aeruginosa clinical isolates from Recife, State of Pernambuco, Brazil. Revista da Sociedade Brasileira de Medicina Tropical, 45(6), pp.707712.

[38]. Lee, K., Lim, Y., Yong, D., Yum, J. and Chong, Y. (2003). Evaluation of the Hodge Test and the Imipenem-EDTA Double-Disk Synergy Test for Differentiating Metallo- -Lactamase-Producing Isolates of Pseudomonas spp. and Acinetobacter spp. Journal of Clinical Microbiology, 41(10), pp.4623-4629.

[39]. Ataee R. A., Tavana A. m., Hosseini S. M. J., Moridi K., and Zadegan M. G. (2012). A Method for Antibiotic Suseptibility Testing: Applicable and Accurate. Jundishapur J Microbiol. 5(1), pp. 341-345.I

[40]. Cox, B. (2003). A review of dissolved oxygen modelling techniques for lowland rivers. The Science of The Total Environment, 314-316, pp.303-334.

[41]. Diene, S., Merhej, V., Henry, M., El Filali, A., Roux, V., Robert, C., Azza, S., Gavory, F., Barbe, V., La Scola, B., Raoult, D. and Rolain, J. (2012). The Rhizome of the Multidrug-Resistant Enterobacter aerogenes Genome Reveals How New "Killer Bugs" Are Created because of a Sympatric Lifestyle. Molecular Biology and Evolution, 30(2), pp.369-383.37. 


\title{
Tranexamic Acid: Implementing a Clinical Guideline for its use in a Moderate Resource Setting
}

\author{
Article by Hemchand Jhagru \\ Department of Pre-Clinical Sciences, College of Medicine, Texila American University, \\ Guyana, South America
}

\begin{abstract}
Background: Guyana, located on the northern South American Mainland is a moderate resource, developing country with high rates of traumatic hemorrhage. There is a shortage of blood products available for use in the emergency department of Georgetown Public Hospital, the main tertiary public hospital. Tranexamic acid (TXA) is an antifibrinolytic that inhibits both plasminogen activation and plasmin activity, thus preventing clot breakdown. CRASH-2, a large randomized, multicenter double blind, placebo-controlled clinical trial, that showed that TXA reduces mortality and blood product use in acute trauma in a moderate resource setting. Currently TXA is not available for use in the public health system in Guyana.

Methods: A literature review was conducted using Google Scholar and PubMed, and by analyzing review articles from the Cochrane Database, European Guidelines, NICE Guidelines. Sources were analyzed to determine pharmacology, feasibility and utility of TXA in moderate resource emergency medicine settings such as Guyana. Steps were taken to bring TXA for use in the public health system in Guyana.

Results: Meetings with stakeholders. Cost analysis. A protocol for initial utilization. Plan for data collection and future expansion.

Conclusions: Tranexamic acid is a safe and inexpensive drug that should be incorporated into trauma clinical guidelines for the resuscitation of the bleeding patient at Georgetown Public Hospital. Implementing a clinical guideline for the use of tranexamic acid in trauma at GPHC will improve mortality due to bleeding and reduce the use of blood products.
\end{abstract}

Keywords: Tranexamic acid; Acute trauma; Moderate resource setting.

\section{Introduction}

Guyana is a low middle-income developing country located on the northern mainland of South America. It has cultural, historical and political ties with the Caribbean Community. Guyana is bordered by the Atlantic Ocean to the north, Brazil to the south-west, Suriname to the east and Venezuela to the west $t^{1}$. Guyana has an area of $215,000 \mathrm{~km}^{2}$ with approximately 750,000 inhabitants ${ }^{2}$.

Georgetown, the capital city, has the only public tertiary health care facility in the country, Georgetown Public Hospital Cooperation (GPHC). Georgetown Public Hospital Corporation is the main referral center in Guyana. According to data obtained from the records department of GPHC, the Accident \& Emergency department treats approximately 3800 patients per month of which motor vehicle accidents account for approximately $4.5 \%$ of visits and assaults $6.3 \%$ of visits.

\section{Epidemiology and pathophysiology of traumatic hemorrhage}

Injuries from trauma result in the death of more than five million people worldwide every year ${ }^{3}$. Uncontrolled post-traumatic bleeding is the leading cause of potentially preventable death, accounting for up to $30 \%$ of the mortality among these patients ${ }^{4,5}$. Major surgery and trauma have similar effects on the hemostatic pathway. Physiologic pathways of clot breakdown (fibrinolysis) can progress to hyperfibrinolysis- which significantly increases mortality $(70-100 \%)^{6}$.

Antifibrinolytic agents such as tranexamic acid is proven to reduce blood loss in patients with both normal and exaggerated fibrinolytic responses in surgery, without increasing the risk of postoperative complications ${ }^{7}$. About $25 \%$ patients with severe traumatic injury will have an abnormality in the coagulation system. This entity, called acute coagulopathy of trauma, is associated with 
increased morbidity, mortality and need for transfusion ${ }^{8}$. Blood is a scarce and expensive resource in low income countries. Furthermore, the risk of transfusion-related infections is more prevalent in low resource, developing countries ${ }^{9}$.

\section{Acute coagulopathy of trauma}

The presence of coagulopathy in trauma is a reflection of the severity of injury and correlates with mortality ${ }^{10}$. Trauma-induced coagulopathy is different from disseminated intravascular coagulation (DIC). DIC is characterized by generalized intravascular micro coagulation with subsequent factor consumption whereas in acute traumatic coagulopathy, there is a bleeding-related loss of coagulation factors and platelets ${ }^{11}$.

Coagulopathy in trauma is caused by a loss of clotting factors and platelets by bleeding, and dilutional coagulopathy after administration of fluids to maintain blood pressure ${ }^{12}$. Also, activation of the fibrinolytic system and subsequently hyperfibrinolysis, hypothermia, acidosis, and hypoperfusion (due to hypotension and shock) directly affect fibrinogen polymerization and coagulopathy ${ }^{13,14}$. The prevention of shock and acidosis due to hypovolemia and hypoperfusion are important to prevent coagulopathy. Acidosis causes impaired enzyme activity, depleted fibrinogen levels and platelet counts, prolonged clotting time, and increased bleeding time ${ }^{15}$. Hypoperfusion leads to decreased oxygen delivery, increased lactate production, and metabolic acidosis ${ }^{16}$. Decreased endogenous heat production exacerbates hypothermia caused by environmental exposure and injudicious administration of cold resuscitation fluids and blood. This causes clinically significant reduction in platelet function and aggregation ${ }^{17}$. Below $34^{0} \mathrm{C}$, each drop-in temperature by $1^{\circ} \mathrm{C}$ is associated with a $10 \%$ drop in platelet function ${ }^{18}$

\section{Pathogenesis of hyperfibrinolysis}

Fibrinolysis occurs through the proteolytic effects of plasmin, which is activated from plasminogen by tissue plasminogen activator (t-PA). Once formed, plasmin cleaves fibrin into small protein fragments. Negative control of the fibrinolytic system comes from direct inhibition of plasmin by plasminogen activator inhibitor 1 (PAI-1) and thrombin activatable fibrinolysis inhibitor (TAFI), which block the conversion of plasminogen to plasmin, thus inhibiting fibrinolysis ${ }^{19}$. The activation of protein $\mathrm{C}$ results in a proteolytic deactivation of clotting factors Va and VIIIa and enhanced fibrinolysis through a decrease in PAI-1(normally inhibits t-PA), which results in an increase in t-PA activity and increased fibrinolysis ${ }^{20}$.

\section{Methodology}

Using online databases Google Scholar and PubMed, a primary literature search was done for articles published between January 2004 - August 2016 with key words 'tranexamic acid', 'trauma', 'pharmacology', 'history', 'CRASH 2 trial and analysis', 'MATTERS trial'. Review articles from Cochrane database, European Guidelines, and NICE Guidelines were obtained. Pertinent information on pharmacology of TXA and clinical application of TXA in trauma was abstracted.

\section{Pharmacology of tranexamic acid}

Tranexamic acid is an antifibrinolytic that inhibits both plasminogen activation and plasmin activity, thus preventing clot break-down rather than promoting new clot formation ${ }^{21}$. The process of fibrin breakdown begins when plasminogen, a glycoprotein pro-enzyme produced by the liver, binds to strands of fibrin. The plasminogen molecule is folded into loops called kringles. Plasminogen binds to fibrin via lysine binding sites at the ends of these loops. Tranexamic acid acts by occupying the lysine-binding sites on plasminogen, thereby blocking the binding site of lysine residues on fibrin. This reduces plasminogen activation to plasmin. Similarly, blockade of lysine-binding sites on circulating plasmin prevents binding to fibrin and thus prevents clot break- down ${ }^{22}$.

Tranexamic acid does not affect platelet count or aggregation or coagulation parameters. It is excreted largely unchanged in urine and has a half-life of about 2 hours in circulation. Dosing should be adjusted for renal impairment, but no adjustment is needed for hepatic impairment ${ }^{23}$. TXA crosses the placenta but is safe during pregnancy. (24) Tranexamic acid is supplied in ampules of $1000 \mathrm{mg}$ in $10 \mathrm{ml}$ water for injection. It is stored at room temperature ${ }^{25}$. 


\section{Applications of tranexamic acid}

In the 1970s to 1990s, tranexamic acid was used to control bleeding in a number of clinical settings including dental extraction in patients with hemophilia, menstrual bleeding, in pediatric urinary tract surgery, ruptured intracranial aneurysms, oral and dental surgery, gynecologic surgery, treatment of hereditary angioneurotic edema, upper gastrointestinal hemorrhage and traumatic hyphema ${ }^{26}$. Tranexamic acid has been proven to reduce blood loss and need for transfusion in cardiopulmonary bypass, liver transplantation and hip or knee arthroplasty ${ }^{27,28}$.

A systematic review by Henry et al in 2011, showed that tranexamic acid reduced the need for transfusions in elective surgery by $30 \%$ and the need for further surgery to control bleeding by $50 \%{ }^{29}$. Concerns regarding risk of thrombosis with use of tranexamic acid have not been substantiated in clinical trials ${ }^{30}$.

\section{Tranexamic acid in traumatic hemorrhage: the CRASH-2 trial}

The Clinical Randomization of an Antifibrinolytic in Significant Hemorrhage 2 (CRASH-2) Trial was a large international randomized, double blinded, multicenter placebo-controlled clinical trial of the effects of the early administration of tranexamic acid on death, vascular occlusive events, and blood transfusion in trauma patients with significant hemorrhage. This study was undertaken in 274 hospitals in 40 countries and enrolled 20,211 patients with, or at risk of, significant bleeding. The patients were randomly assigned to either tranexamic acid (loading dose $1 \mathrm{~g}$ over $10 \mathrm{~min}$ followed by infusion of $1 \mathrm{~g}$ over $8 \mathrm{~h}$ ) or placebo ${ }^{31}$. This study was published in the Lancet in 2010.

The inclusion criteria were as follows:

1. Adult trauma patients with or at risk of significant haemorrhage

2. Systolic blood pressure (SBP) less than $90 \mathrm{~mm} \mathrm{Hg}$

3. Heart rate of more than 110 beats per minute

4. Presentation within 8 hours of injury

\section{Benefits of TXA in CRASH-2}

The Primary Outcome measured all-cause 28-day mortality and was 1,463 (14.5\%) in the tranexamic acid group and 1,613 (16.0\%) in placebo patients (absolute risk reduction 1.5\%, RR 0.91, NNT 67, $\mathrm{p}=0.0035)^{31}$. This $1.5 \%$ absolute risk reduction means that one would have to treat 67 trauma patients with TXA to prevent one from dying of any cause (number needed to treat $=1 /$ absolute risk reduction) ${ }^{26}$. The authors also reported a reduction of death as a result of bleeding of $15 \%$ ( RR $0.85, \mathrm{p}$ 0.0077) ${ }^{32}$. Secondary outcomes measured vascular occlusive events (myocardial infarction, stroke, pulmonary embolism [PE] and deep vein thrombosis [DVT], receipt of blood transfusion, and units of blood products transfused. No significant difference in blood transfusions (about $50 \%$ in both groups) or thrombo-embolic events (1.7\% in TXA, $2.0 \%$ in placebo group) were found ${ }^{31}$.

An exploratory analysis of the effect of tranexamic acid on mortality due to bleeding according to time to treatment, severity of hemorrhage (assessed by systolic blood pressure, Glasgow coma score) and type of injury were assessed ${ }^{32}$. It was published in the Lancet in 2011 by CRASH-2 collaborators. This assessment indicated that the effect of TXA varied by time to treatment. Treatment within one hour of injury was associated with a $32 \%$ relative reduction in risk of death due to bleeding (RR 0.68 , $\mathrm{P}<0.0001)$ and treatment between one and three hours after injury was associated with a $21 \%$ reduction $(\mathrm{RR} 0.79, \mathrm{P}=0.03)$. Treatment with TXA after three hours of injury was associated with a $44 \%$ relative increase in risk of death due to bleeding when compared to the placebo group. (RR 1.44, $\mathrm{P}=0.004)^{32}$. Patients receiving tranexamic acid within 3 hours received less blood transfusion than those in the control group (mean difference $-0.21, \mathrm{P}=0.04)^{33}$. There was no statistically significant difference in risk for stroke, pulmonary embolism, deep vein thrombosis and surgical intervention between the groups. The authors of CRASH-2 concluded that tranexamic acid should be given as early as possible to bleeding trauma patients ${ }^{32}$. For trauma patients given TXA more than 3 hours after injury, tranexamic acid is less effective at controlling bleeding and could be harmful ${ }^{33}$.

\section{Matters study}

The MATTERs study is a retrospective observational study comparing tranexamic acid to no 
tranexamic acid in combat casualty patients. Results showed that the TXA group had lower mortality than the group not given TXA (17.4\% vs. $23.9 \%)$. This benefit was greatest in polytrauma patients $(14.4 \%$ vs. $28.1 \%)$ where tranexamic acid was also independently associated with survival and less coagulopathy $(\mathrm{p}=0.003)^{34}$.

\section{Quality of evidence}

CRASH-2 was done in different healthcare settings around the world and involved a large and diverse study population. Most of the 274 study sites in CRASH-2 were in low-income and middleincome countries, where other treatments directed at coagulopathy, such as fresh frozen plasma, platelets, and cryoprecipitate, are not as readily available. This shows that the results are generalizable across settings. The CRASH-2 was a clinical, randomized, double-blinded, placebo- controlled trial with intention-to-treat analysis. The FDA considers this type of study to be the highest level of evidence in clinical studies ${ }^{26}$. The intention to treat approach of CRASH-2 demonstrated that the drug effect is still observed in real world settings even if the drug was subsequently changed or discontinued in a proportion of patients. Also, over $99 \%$ of patients were followed up so there was minimal bias due to attrition ${ }^{33}$.

\section{Cost effectiveness}

A quotation of the cost of TXA was requested from International Pharmaceutical Agency (IPA), which is one of the main retailing pharmaceutical companies in Guyana. They submitted an invoice which estimated that an ampule of tranexamic acid would cost \$300 Guyana dollars. This would amount to \$ 3 USD per patient.

\section{Ongoing studies}

There are a number of ongoing studies evaluating the possible use of TXA in gastrointestinal bleed (HALT-IT), postpartum hemorrhage (WOMAN) and traumatic brain injury (CRASH-3) ${ }^{36}$. Tranexamic acid has been adapted into the treatment protocol of Emergency Medical Services (EMS) in countries such as Australia where the acutely injured patient may be more than 3 hours away from a health facility capable of providing trauma care ${ }^{37,38}$. This is important since the greatest effect on mortality is within the first hour of traumatic bleeding ${ }^{32}$.

\section{WHO list of essential drugs}

The world health Organization (WHO) reviewed the evidence for the use of TXA from CRASH-2 and related studies, and listed TXA on the List of Essential Drugs due to its mortality reduction in traumatic hemorrhage ${ }^{39}$.

\section{Development of ED Clinical Practice Guideline for TXA at GPHC}

Based on the enrollment procedures, inclusion and exclusion criteria of CRASH-2, a simplified clinical practice guideline was developed to indicate which patients with significant hemorrhage should receive TXA at GPHC. The guideline was designed to advise clinicians treating acutely injured patients with bleeding (Figure 1). Significant hemorrhage was defined as the attending physician's clinical gestalt that there is a likelihood that patient would need a blood transfusion and would therefore need to be grouped and crossed match.

\section{Implementation of TXA at GPHC}

Tranexamic acid as an adjunct in the treatment of the bleeding trauma patient was proposed to the Director of Residency of emergency medicine, Dr N. Forget and to the Head of Department of emergency medicine at GPHC, Dr Z. Bux in April 2016.

A comprehensive review of the literature on tranexamic acid was done over the following months and a clinical guideline for the use of TXA in acute trauma was formulated. (figure 1). This clinical guideline was presented to Dr Forget and Dr Bux in October 2016 and meetings were scheduled with various stakeholders such as the Pharmacy Committee, the Blood Bank and the Management Committee of GPHC.

A presentation of the clinical guideline to the Department of General Surgery and Orthopedics, 
who are responsible for definitive management of severe traumatic injury at GPHC was done in November 2016. And during the months of January and February 2017, the Management Committee of GPHC, the Director of the Blood Bank and the representatives of the Pharmacy Committee were presented to the benefits and lifesaving attributes of TXA.

The clinical guideline formulated for the use of TXA in acute trauma was approved and endorsed by the hospital leadership other stakeholders aforementioned. Thus, the process of adding tranexamic acid to the national formulary of medications started and is ongoing. The Pharmacy Committee is currently in the process of purchasing the medication so that it can be stocked for use in the emergency department.

Many of the physicians in the emergency department of GPHC are not familiar with the use of tranexamic acid in trauma. Ongoing provider education and supervision where the shift supervisor of the emergency department ensures that the clinical guideline is adhered to and that presenting trauma patients who meet the inclusion criteria are given the medication appropriately.

Nurses will be taught the pharmacokinetics of tranexamic acid and how to administer it according to the clinical guidelines in the following months.

A donation of 10 vials of TXA from a NGO (Non-Government Organization) was given to the emergency department and TXA has already been administered to two patients with favourable outcomes.

Continuous monitoring and assessment of the use of TXA in the emergency department is an ongoing task. The trauma registry is in the process of implementation and installation. The use of TXA will be one of the parameters that will be monitored by the trauma registry as well as primary outcome (mortality) and the use of blood products. In the meantime, monitoring and assessment is done by completion of a data collection sheet (see annex) by the shift supervisor and the patient's primary outcome (mortality) and secondary outcome (use of blood products) are monitored with visits to the admitting ward.

\section{Plans for TXA in the Near Future at GPHC}

The Obstetrics and Gynecology department of GPHC has asked about the process of implementing a guideline for the management of postpartum hemorrhage and as a drug given before cesarean section to minimize bleeding. Tranexamic acid would be very useful in our setting when used as an adjunct for GI bleeds as these patients face the same constraint as in trauma, with inadequate supply of necessary blood products. There is also scope for its use in ENT and in orthopedics for joint replacement surgeries which are often complicated by bleeding and then secondarily infection.

In Guyana, there are numerous regional hospitals and health posts in the forested and hinterland regions where access to tertiary and definitive health can often be delayed. The use of TXA by doctors and nurses in these hospitals would decrease bleeding and improve mortality and morbidity. TXA can also be used in pre-hospital settings by EMS when evacuating patients. The clinical guideline can be followed by online medical direction. These are the areas that tranexamic acid will expand to in the coming months and years as it's use become more popular and the relevant departments and services are educated to its safety and usefulness.

\section{Conclusions}

TXA is an important antifibrinolytic agent with demonstrated ability to cost-effectively improve mortality and reduce need for blood products in the acutely bleeding trauma patient. The clinical practice guideline proposed here shows that use of TXA in the GPHC emergency department is a feasible and practical way to save lives in trauma management. There is also great scope for the incorporation of TXA into clinical guidelines in other areas of medicine where acute bleeding is a problem and for EMS and Regional Hospitals to use tranexamic acid in acute hemorrhage. 
DOI: 10.21522/TIJBMS.2016.04.01.Art004

ISSN: $2519-500 \mathrm{X}$

Figure 1

CLINICAL GUIDELINE FOR THE USE OF TRANEXAMIC ACID

IN THE EMERGENCY DEPARTMENT OF GPHC

Inclusion Criteria

1. Age $>16$ yrs

2. Systolic $\mathrm{BP}<90 \mathrm{mmHg}$

3. Pulse $>110$

4. Bleeding or at risk of ' significant' hemorrhage

Presents within $3 \mathrm{hrs}$ of injury

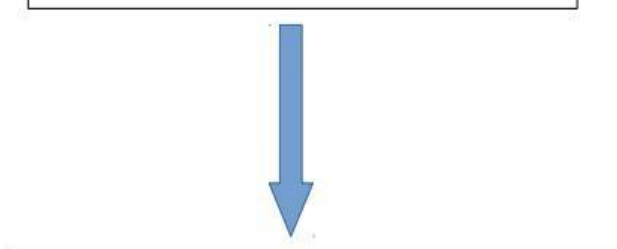

Exclusion Criteria

1. Known allergy

YES DO NOT

2. Active tromboembolic event (stroke, DVT,PE, DIC)

NO

Administer Tranexamic acid $1 \mathrm{~g}$ in $100 \mathrm{mls}$ of N/S over $10 \mathrm{~min}$ then

Tranexamic acid $1 \mathrm{~g}$ in $1000 \mathrm{mls}$ of N/S over $8 \mathrm{hrs}$ 


\section{Annex}

\section{Data Collection form for the use of Tranexamic ACID}

\begin{tabular}{|l|l|l|l|l|l|l|l|l|}
\hline Name of Patient & $\begin{array}{l}\text { Date } \\
\text { Seen }\end{array}$ & Diagnosis & \multicolumn{2}{|l|}{ Vital Signs } & Disposition & $\begin{array}{l}\text { Primary outcome } \\
\text { (mortality) }\end{array}$ & $\begin{array}{l}\text { Secondary outcome } \\
\text { (blood products given) }\end{array}$ \\
\cline { 4 - 8 } & & & BP & Pulse & & & In ER & In ward \\
\hline & & & & & & & & \\
\hline & & & & & & & & \\
\hline & & & & & & & & \\
\hline & & & & & & & & \\
\hline & & & & & & & & \\
\hline
\end{tabular}

\section{References}

[1]. Health in the Americas, 2012 Edition: Country Volume N' Pan American Health Organization, 2012. Available from: http://www.paho.org/saludenlasamericas/index.php?option=com_docman\&task=doc_view\&gi $\mathrm{d}=133 \&$ Itemid $=$

[2]. Guyana, Bureau of Statistics. Population \& Housing Census 2012. Available from: http://www.statisticsguyana.gov. gy/census.html

[3]. Murray CJ, Lopez AD: Alternative projections of mortality and disability by cause 1990-2020: Global Burden of Disease Study. Lancet 1997, 349:1498-1504.

[4]. Kauvar DS, Lefering R, Wade CE. Impact of hemorrhage on trauma outcome: an overview of epidemiology, clinical presentations, and therapeutic considerations. J Trauma. 2006;60: S3-S11.

[5]. World Health Organisation: World Health Statistics 2009: Cause-specific mortality and morbidity. [http://www.who.int/whosis/whostat/ EN_WHS09_Table2.pdf].

[6]. Kashuk JL, Moore EE, Sawyer M, Wohlauer M, Pezold M, Barnett C, Biffl WL, Burlew CC, Johnson JL, Sauaia A. Primary fibrinolysis is integral in the pathogenesis of the acute coagulopathy of trauma. Ann Surg. 2010; 252:434Y442; discussion 443Y444.

[7]. Lawson JH, Murphy MP. Challenges for providing effective hemostasis in surgery and trauma. Seminars in Hematology 2004;41(1 Suppl 1):55-64.

[8]. Brohi K, Singh J, Heron M, Coats T. Acute traumatic coagulopathy. J Trauma. 2003; 54:1127- 1130.

[9]. Sihler KC, Napolitano LM: Complications of massive transfusion. Chest 137:209-220, 2010.

[10]. MacLeod JB, Lynn M, McKenney MG, Cohn SM, Murtha M. Early coagulopathy predicts mortality in trauma. J Trauma 2003; 55: 39-44.

[11]. Fries D, Streif W, Haas T, Kuhbacher G. Dilutional coagulopathy, an underestimated problem? Anasthesiol Intensivmed Notfallmed Schmerzther 2004; 39: 745-50.

[12]. Gruen RL, Brohi K, Schreiber M, et al. Haemorrhage control in severely injured patients. Lancet. 2012; 380:1099-1108.

[13]. Hess John R, Brohi Karim, Dutton Richard P, et al. The coagulopathy of trauma: a review of mechanisms. J Trauma. 2008; 65:748e754.

[14]. Brohi K, Cohen MJ, Ganter MT, et al. Acute coagulopathy of trauma: hypoperfusion induces systemic anticoagulation and hyperfibrinolysis. J Trauma 2008; 64: 1211-17.

[15]. Lynn M, Jeroukhimov I, Klein Y, Martinowitz U. Updates in the management of severe coagulopathy in trauma patients. Intensive Care Med 2002; 28(Suppl. 2): S241-7.

[16]. Jansen JO, Scarpelini S, Pinto R, Tien HC, Callum J. Hypoperfusion in severely injured patients is associated with reduced coagulation factor activity. J Trauma. 2011 Nov;71(5 suppl 1): S435eS440.

[17]. Wolberg AS, Meng ZH, Monroe 3rd DM, Hoffman M. A systematic evaluation of the effect of temperature on coagulation enzyme activity and platelet function. J Trauma. 2004 June;56(6):1221e1228.

[18]. Tsuei BJ, Kearney PA. Hypothermia in the trauma patient. Injury. 2004 Jan;35(1):7e15. 
[19]. Medcalf RL. Fibrinolysis, inflammation, and regulation of the plasminogen activating system. J Thromb Haemost. 2007;5(Suppl 1):132Y142.

[20]. Davidson CJ, Tuddenham EG, McVey JH. 450 million years of hemostasis. J Thromb Haemost. 2003; 1:1487Y1494.

[21]. McCormack PL. Tranexamic acid: a review of its use in the treatment of hyperfibrinolysis. Drugs. 2012; 72:585Y617.

[22]. Lucas M, Fretto L, McKee P. The binding of human plasminogen to fibrin and fibrinogen. J Biol Chem 1983; 258: 4249-56.

[23]. http://www.drugbank.ca/drugs/DB00302.

[24]. http://www.ncbi.nlm.nih.gov/pubmed/3321402.

[25]. Pfizer. Cyklokapron (tranexamic acid) injection package insert. 2008. Available at: www.pfizer.com/products/rx/prescription.jsp. In.

[26]. Andrew P. Cap, MD, PhD, David G. Baer, PhD, Jean A. Orman, MPH, ScD, James Aden, PhD, Kathy Ryan, PhD, and Lorne H. Blackbourne, MD. Tranexamic Acid for Trauma Patients: A Critical Review of the Literature. DOI 101097TA0b013e31822114af.

[27]. Karski JM, Teasdale SJ, Norman P, et al. Prevention of bleeding after cardiopulmonary bypass with highdose tranexamic acid. Double-blind, randomized clinical trial. J Thorac Cardiovasc Surg. 1995; 110:835-842.

[28]. Eubanks JD. Antifibrinolytics in major orthopaedic surgery. J Am Acad Orthop Surg. 2010; 18:132-138.

[29]. Henry DA, Moxey AJ, Carless PA, O'Connell D, Henderson KM, Fergusson D, et al. Anti- fibrinolytic use for minimising perioperative allogeneic blood transfusion. Cochrane Database of Systematic Reviews 2011, Issue 1. [DOI: 10.1002/14651858.CD001886.pub2].

[30]. Colman R, ed. Hemostasis and Thrombosis Basic Principles and Clinical Practice. 5th ed. Philadelphia, PA: Lippincott Williams \& Wilkins; 2006.

[31]. CRASH-2 trial collaborators, Shakur H, Roberts I, Bautista R, Caballero J, Coats T, Dewan Y, El-Sayed $\mathrm{H}$, Gogichaishvili T, Gupta S, et al. Effects of tranexamic acid on death, vascular occlusive events, and blood transfusion in trauma patients with significant haemorrhage (CRASH-2): a randomised, placebo-controlled trial. Lancet. 2010; 376:23.

[32]. CRASH-2 collaborators, Roberts I, Shakur H, Afolabi A, Brohi K, Coats T, et al. The importance of early treatment with tranexamic acid in bleeding trauma patients: an exploratory analysis of the CRASH-2 randomised controlled trial. Lancet 2011;377(9771):1096-101.

[33]. Ker K, Roberts I, Shakur H, Coats TJ. Antifibrinolytic drugs for acute traumatic injury. Cochrane Database of Systematic Reviews 2015, Issue 5. Art. No.: CD004896. DOI:

[34]. 10.1002/14651858.CD004896.pub4.

[35]. Morrison JJ, Dubose JJ, Rasmussen TE, Midwinter MJ. Military Application of Tranexamic Acid in Trauma Emergency Resuscitation (MATTERs) Study. Arch Surg. 2012; 147:113Y119.

[36]. Guerriero C, Cairns J, Perel P, Shakur H, Roberts I: Cost-effectiveness analysis of administering tranexamic acid to bleeding trauma patients using evidence from the CRASH-2 trial. PLoS One 2011, 6: e18987.

[37]. http://epmonthly.com/article/its-time-to-embrace-txa-for-traumatic-bleeds/.

[38]. Erik Nelson Vu, CCP, MD, FRCPC, DAvMed,1,2,3 Rob S. Schlamp, CCP,1 Robert T. Wand, CCP,1 Geoff A. Kleine-Deters, CCP, RN,1. Prehospital Use of Tranexamic Acid for Hemorrhagic Shock in Primary and Secondary Air Medical Evacuation. 1067-991X3600 Copyr 2013 Air Med J Assoc Httpdxdoiorg101016jamj201305001.

[39]. Brown JB, Neal MD, Guyette FX, Peitzman AB, Billiar TR, Zuckerbraun BS, et al. Design of the Study of Tranexamic Acid during Air Medical Prehospital Transport (STAAMP) Trial: Addressing the Knowledge Gaps. Prehosp Emerg Care. 2015 Jan 2;19(1):79-86.

[40]. Summary of the report of the 18th meeting of the WHO Expert Committee on the Selection and Use of Essential Medicines, 18th Meeting, Accra, Ghana March 21Y25, 2011. Available a Accessed November 10, 2012. 


\title{
Characterization of Selected Medicinal Plants of Mamanwa Tribe in Caraga, Philippines
}

\author{
Article by Levitah C. Mapatac \\ Caraga State University, Philippines \\ E-mail:lcmapatac@gmail.com
}

\begin{abstract}
Mamanwa indigenous people (IP) mostly lived in Caraga region, Philippines. Most of them depended on the traditional method of herbal plants for medication. This study aims to determine the bioactive compounds present in the fifteen ethnomedicinal plants extract through IR spectrophotometric analysis for the presence of the different functional group in the plant extract. The presence of the peaks forms IR spectroscopy for the stretching of $\mathrm{O}-\mathrm{H} / \mathrm{N}-\mathrm{H}, \mathrm{C}-\mathrm{H}, \mathrm{C}-\mathrm{O}$ and $\mathrm{C}-\mathrm{Cl} / \mathrm{C}-\mathrm{S}, \mathrm{S}-\mathrm{H}, \mathrm{N}=\mathrm{O}$ and $\mathrm{C}=\mathrm{O}$ for the functional groups alcohols, carboxylic acids, alkanes, alkenes, halogens, amide, aromatic compounds, ethers, amino acids, lactones, nitro compounds, acid anhydrides and aldehydes that makes this possible potential antibiotics and medicine.
\end{abstract}

Keywords: Mamanwa IP, functional groups, ethnomedicine \& IR spectrophotometric analysis.

\section{Introduction}

Herbal medicine involves the use of plants for medicinal purposes. The term "herb" includes leaves, stems, flowers, fruits, seeds, roots, rhizomes, and bark. There can be little doubt that the use of plants for healing purposes is the most ancient form of medicine known. The quest for plants with medicinal properties continues to receive attention as scientists are in need of plants, particularly of ethnobotanical significance for a complete range of biological activities, which ranges from antibiotic to anticancer substance. Several plants and herb species used traditionally have potential antimicrobial and antiviral properties (Shelef, 1983; Zaika, 1988) and this has raised the optimism of scientists about the future of phyto-antimicrobial agents. (Das, Mujib \& De,1999).

In the Philippines, an emphasis has been placed on indigenous plants to produce safe, efficacious, and affordable drugs for primary health care. The impacts of these new technologies have been tremendous especially on the development of potential drugs especially with the presence of indigenous tribes in Mindanao specifically the Manobo and the Mamanwa which is the focus of the study.

The Mamanwas lives in the northeastern provinces of Surigao and Agusan del Norte and they rely on the subsistence economy which was a hand- to- mouth existence. Mostly of the Mamanwas are food gatherers who move from one place to another depending upon the supply of food found in the place.

Due to hardship, the Mamanwa tend to used herbal medicine for their health and medicinal needs, especially for child care. The biggest tribes of Mamanwa were found in Cantugas, Mainit, Surigao del Norte having eighty-eight families and each family has minimum children of seven and a maximum of fifteen children in the family. Most of the herbal medicines are often used for the cure of stomach-ache, bloody diarrhea, wounds, scabies, insect bites, itchiness, burns, scalds, eyesores, fever, headache, skin diseases, asthma, sore throat, cough, colds, incontinence, kidney stones, constipation, snake bite, dyspepsia, mouth ulcers, tongue blisters and inflammation.

The study has envisioned in providing scientific evidence on the use of the study plants traditionally utilized as herbal medicines by the Mamanwa's for child health care. The researcher selected fifteen (15) herbal plants namely; the albahaka (Ocimum basilicum), alibangbang ( Bauhinia monandra), Angelika (Bryophyllum pinnatum), elepante (Elephantopus Scaber Linn.), Gabon (Plectranthi Amboinici Folium), hilbas (Artemisia vulgaris Linn), kalabo ( Origanum vulgare), lunas (Lunasia amara Blanco), makulibhag (Rabelaisa philippinensis), sawan-sawan (Blumea balsamifera), sinawsinaw (Peperomia pellucide), tagbak (Alpinia elegans $K$.), talawatawa (Musseanda philippic), tawatawa ( Euphorbia hirta Linn) and togup (Artocarpus altilis) through the process of phytochemical analysis and antimicrobial assay. Plant samples were further subjected to an IR spectroscopy for the 
characterization of the fifteen plant ethanolic and methanolic extract for the identification of its functional group present in the sampled medicinal plants.

\section{Methodology}

\section{Research setting}

This study had employed the descriptive survey and experimental designs. A descriptive survey was used in the identification of the most commonly used medicinal plants by Mamanwa in Caraga and questionnaire about the common perceptions how it was used and traditional method applied to the medicinal plant used by the Mamanwa in Caraga and interview from the local herbolaria and the local people. And the researcher did an IR spectroscopy for the identification of the functional group present in the selected plant extracts. The study was conducted at the three Mamanwa tribes in Caraga namely; Mamanwa tribe in Santiago, Agusan del Norte, Mamanwa tribe in Cantugas, Mainit, Surigao del Norte and Mamanwa tribe in Kitcharao, Surigao del Norte. Mainit is a fourth class municipality in the province of Surigao del Norte, Philippines. It is situated on the north shore of Lake Mainit in the northeastern part of Mindanao. Mainit got its name from the hot sulfuric spring which flows to the river the "Mapaso Hot Spring". Mapaso literally is "hot". Santiago is a fourth class municipality in the province of Agusan del Norte, the Philippines comprising of nine barangays wherein the Mamanwa tribe resides in barangay Curva. Kitcharao is a fourth-class municipality in the province of Surigao del Norte wherein the Mamanwa tribe resides in barangay Mahayahay with almost one hundred fifty families. And laboratory analysis was done at Caraga State University Diagnostic Laboratory for the Antimicrobial Bioassay and the Phytochemical Screening of the fifteen herbal plants used by the Mamanwa people as herbal medicine.

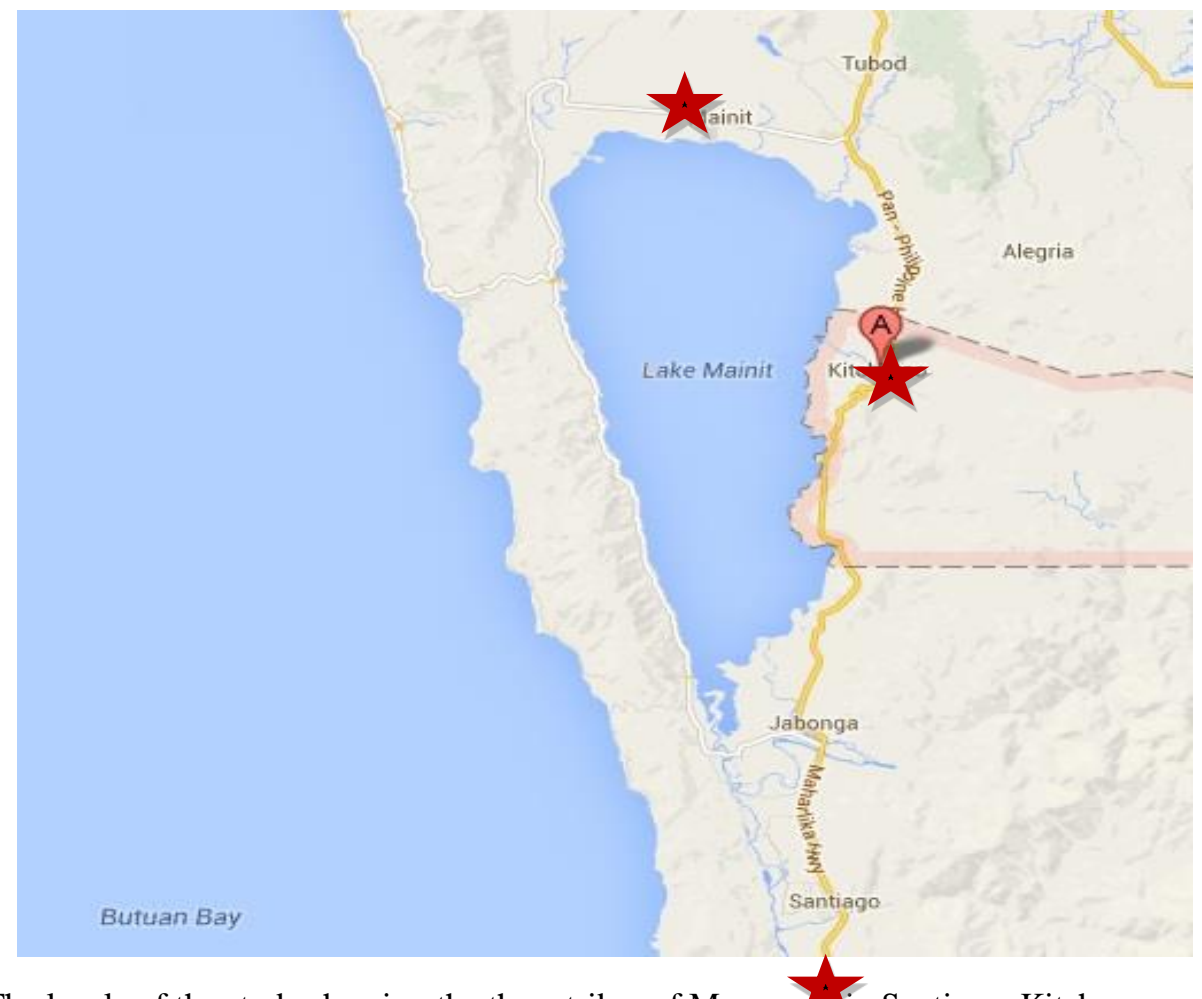

Figure 1. The locale of the study showing the three tribes of Mamanwin Santiago, Kitcharao, and Cantugas, Maiinit Surigao del Norte

The gathering of plant samples comes from the key informants (known as herbolaria) in the area who had helped in the identification of the medicinal plant that was used for child and maternal health care. The researcher also took pictures to give more concrete evidence of the medicinal plants. The analysis for the identification of the functional group of the sampled plants was done in the Mindanao University of Science and Technology Chemistry Laboratory by IR Spectroscopy. 


\section{Collection of plant materials}

Fresh plant leaves and barks were collected at Cantugas, Mainit, Surigao del Norte, Kitcharao, Surigao del Sur and Santiago, Agusan del Norte where the Mamanwa tribes were residing. The plant samples were constantly used for the cure of minor to major diseases by an eighty-eight-year-old herbolaria Nanay Felisa Hubasan and the local people of the Mamanwa tribe.

\section{Data collection methods}

A total of one hundred respondents were being interviewed from the three Mamanwa tribes in Caraga, forty from the Mamanwa tribe in Cantugas, Mainit, thirty Mamanwa people in Santiago and thirty Mamanwa respondents in Kitcharao on the use of herbal plants and its efficacy and their perceptions about the medicinal plants. On the part of their sociocultural beliefs, the Datu of the tribe was consulted on their cultural practices especially in their beliefs on spirits and god's in the application of the medicinal plants.

Fresh plants leave and bark was cut into smaller pieces and weighed about 100g in an Erlenmeyer flask and mixed with $80 \%$ ethanol solution and submerge the plant materials and was kept soaked for 48 hours. The extracts were then filtered using Whatman \#2 filter paper with gentle suction. The flask and plant material were rinsed with fresh portions of alcohol. Washing and plant material and was transferred to the funnel, combining the washing of the first filtrate. Gentle suction was applied to complete the collection of the plant extract; then the plant residue was discarded. The filtrate plant extract was concentrated over a steam bath at a temperature below $50^{\circ} \mathrm{C}$ to about $20 \mathrm{ml}$. The concentration of the stock plant extract was recorded as grams of dried plant material per $\mathrm{mL}$ of the extract that was obtained. The extract was stored in cold $\left(0-5^{\circ} \mathrm{C}\right)$ and labeled properly with the name of the plant, concentration of the plant and the date of extraction.

\section{Results and discussion}

Commonly Used Ethnomedicinal Plants Use by the Mamanwa in Caraga

From the result of the survey among the one hundred respondents of the three Mamanwa tribe from Mamanwa tribe of Cantugas, Mainit, Surigao del Norte, Mamanwa tribe of Kitcharao, Surigao del Norte and the Mamanwa tribe of Santiago, Agusan del Norte. Knowledge on the herbal medicine was passed down from one generation to the next generation according to the old herbolaria known as Nanay Felisa Hubasan, the oldest herbolaria of the Mamanwa tribe of Cantugas, Mainit, Surigao del Norte. The fifteen herbal plants of the study were from the survey coming out from the common list of herbal plants used by the respondents in their community for the child and maternal health care. Most of the herbal plant used by the respondents were used either by " lina'ga" or decoction especially for cure for stomach pain, dysentery, and fever, another method was a crude way of just smashing the leaves or plant part and squeeze its plant juice in the wounds or the inflamed part of the body as an anti-inflammatory agent or as relieving pain in a toothache or boils.

About fifteen different herbal plants namely: the albahaka (Ocimum basilicum), alibangbang (Bauhinia monandra), Angelika (Bryophyllum pinnatum), elepante (Elephantopus Scaber Linn.), Gabon (Plectranthi Amboinici Folium), hilbas (Artemisia vulgaris Linn), kalabo (Origanum vulgare), lunas (Lunasia amara Blanco), makulibhag (Rabelaisa philippinensis), sawan-sawan (Blumea balsamifera), sinaw-sinaw (Peperomia pellucide), tagbak (Alpinia elegans K.), talawatawa (Musseanda philipicca), tawa-tawa ( Euphorbia hirta Linn) and togup (Artocarpus altilis) were obtained from the Mamanwa tribe in Cantugas, Mainit, Surigao del Norte. Table 1 shows the different herbal plants with its specific use by the Mamanwa according to the tribal herbolaria (Nanay Felisa Hubasan) who is known for her indigenous knowledge on herbal plants and people of the tribe. Most of the parts of the herbal plant used are the leaves, stem, bark, roots and the tubers wherein the common way of preparation is decoction, smashing, cutting and chopping into smaller pieces, extracting the juice, and applied directly to the affected area. Most of the medicinal plant samples were used by the tribe people for a child and maternal health care especially for stomached pain, diarrhea cure, for curing of wounds, for anti-inflammatory, lowering of fever, cough, and colds, lowering of blood pressure and for mothers with a menstrual problem. 
Table 1. List of Plants recorded with medicinal values among the mamanwa tribe

\begin{tabular}{|c|c|c|}
\hline \multicolumn{3}{|c|}{ Scientific Name Local Name Medicinal Used of the Mamanwa } \\
\hline $\begin{array}{l}\text { Bauhinia } \\
\text { monandra }\end{array}$ & $\begin{array}{l}\text { Alibang } \\
\text { bang }\end{array}$ & $\begin{array}{l}\text { The chop boiled leaves and roots will serve as a decoction in curing } \\
\text { stomach-ache, bloody diarrhea, and purging. }\end{array}$ \\
\hline $\begin{array}{l}\text { Bryophyll } \\
\text { um } \\
\text { pinnatum }\end{array}$ & Angelika & $\begin{array}{l}\text { Chop leaves and roots applied to wounds will speed up its healing } \\
\text { process, it has also anti-inflammatory effect to boils, and chop leaves } \\
\text { relieve a toothache. }\end{array}$ \\
\hline $\begin{array}{l}\text { Elephanto } \\
\text { pus Scaber } \\
\text { Linn }\end{array}$ & Elepante & $\begin{array}{l}\text { Smash roots applied to burns and scalds reduce infection, boiled root } \\
\text { decoction lowers body heat. And dewdrops collected from the flower } \\
\text { can be used as eye drops. }\end{array}$ \\
\hline $\begin{array}{l}\text { Plectranth } \\
i\end{array}$ & Gabon & $\begin{array}{l}\text { Leaves of this plant are especially used to treat children if they are not } \\
\text { feeling well. The roots and leaves are boiled as decoction are taken to }\end{array}$ \\
\hline Amboinici & & treat flu or another sickness in children. A few leaves and slices of \\
\hline Folium & & $\begin{array}{l}\text { roots placed in warm water is used to bathe children to provide relief } \\
\text { from illness, especially for newly giving birth mothers. }\end{array}$ \\
\hline $\begin{array}{l}\text { Artemia } \\
\text { vulgaris } \\
\text { Linn }\end{array}$ & Hilbas & $\begin{array}{l}\text { Leaf poultice is a cure for a headache, skin diseases, asthma, and } \\
\text { dyspepsia. Its juice is used externally for scabies, eczema, herpes. } \\
\text { Infusion leaves will induce menstruation, as an abortifacient and } \\
\text { uterine stimulant. }\end{array}$ \\
\hline $\begin{array}{l}\text { Origanum } \\
\text { vulgare }\end{array}$ & Kalabo & $\begin{array}{l}\text { Juice obtained from smashed green leaves can be applied to the throat } \\
\text { or taken to cure a sore throat and relieves a cough and cold especially } \\
\text { for children. }\end{array}$ \\
\hline $\begin{array}{l}\text { Lunasia } \\
\text { amara }\end{array}$ & Lunas & $\begin{array}{l}\text { To treat rashes or wounds, poultice from barks are applied on affected } \\
\text { areas. }\end{array}$ \\
\hline Blanco & & $\begin{array}{l}\text { The whole plant or only the leaves are boiled and the decoction is taken } \\
\text { to treat high blood pressure. The bark, when mixed with coconut oil, } \\
\text { cures snake bites, insect bites and skin diseases. }\end{array}$ \\
\hline $\begin{array}{l}\text { Rabelaisa } \\
\text { philippine } \\
\text { nsis }\end{array}$ & $\begin{array}{l}\text { Makulib } \\
\text { hag }\end{array}$ & $\begin{array}{l}\text { During the confinement period, the boiled roots as decoction are taken } \\
\text { to cure birth wound and clean the uterus. Roots are boiled as a } \\
\text { decoction and could be taken as a contraceptive. The bark is boiled and } \\
\text { the decoction is drunk for abortion. }\end{array}$ \\
\hline $\begin{array}{l}\text { Blumea } \\
\text { balsimefir } \\
\text { a }\end{array}$ & $\begin{array}{l}\text { Sawan- } \\
\text { sawan }\end{array}$ & $\begin{array}{l}\text { The leaves and stems are soaked in warm water and used for bathing } \\
\text { children with fever, epilepsy (sawan), pale complexion and several } \\
\text { other serious illnesses. }\end{array}$ \\
\hline $\begin{array}{l}\text { Peperomia } \\
\text { pellucide }\end{array}$ & $\begin{array}{l}\text { Sinaw- } \\
\text { sinaw }\end{array}$ & $\begin{array}{l}\text { Boil the leaves as like tea and drink } 3 \text { or more times a day a good as } \\
\text { diuretic agent and effective in dissolving kidney stones. }\end{array}$ \\
\hline $\begin{array}{l}\text { Alpinia } \\
\text { elegans } K \text {. }\end{array}$ & Tagbak & $\begin{array}{l}\text { Raw or boiled tuber is taken to treat kidney problems and constipation. } \\
\text { Smashed tubers are mixed and applied on the patient's head to cure } \\
\text { fever. The young shoots (red or white in color) are minced into a paste } \\
\text { which is then mixed with some water. The paste is then applied on the } \\
\text { forehead to treat a headache. }\end{array}$ \\
\hline $\begin{array}{l}\text { Mussaend } \\
\text { a philipica }\end{array}$ & $\begin{array}{l}\text { Talawat } \\
\text { awa }\end{array}$ & $\begin{array}{l}\text { The decoction of the leaves and bark will cure dysentery and emollient. } \\
\text { The latex of the bark will cure snake bites and insect bites. }\end{array}$ \\
\hline $\begin{array}{l}\text { Euphorbia } \\
\text { hirta Linn }\end{array}$ & $\begin{array}{l}\text { Tawa- } \\
\text { tawa }\end{array}$ & $\begin{array}{l}\text { The roots are boiled and the water is then used for bathing to treat high } \\
\text { fever especially when the patient starts shivering. } \\
\text { Droplets of water/sap from freshly cut stems are used for eye irritation. } \\
\text { Juices gathered from smashing the stem are taken to reduce body heat. }\end{array}$ \\
\hline $\begin{array}{l}\text { Artocarpu } \\
\text { s altilis }\end{array}$ & Togup & $\begin{array}{l}\text { The bark is boiled and the decoction drunk to cure stomach-ache, treat } \\
\text { mouth ulcers and tongue blisters. }\end{array}$ \\
\hline
\end{tabular}

Further, these herbal plants were used by the tribal people either by mixing one plant with another plant. For instance, sawan-sawan, kalabo, and Gabon were mixed by boiling or decoction process and 
this will be used for treating hard cough with fever and cold wherein herbal plant mixture is more effective in the cure of a certain sickness or disease.

\section{Functional groups present in the crude extracts}

The IR spectra were used to identify the functional group of the active components based on the peak value in the region of infrared radiation. The plant ethanolic extracts were passed into the Spectrophotometer and the functional groups of the components were separated based on its peak ratio and identified through its fingerprint region.

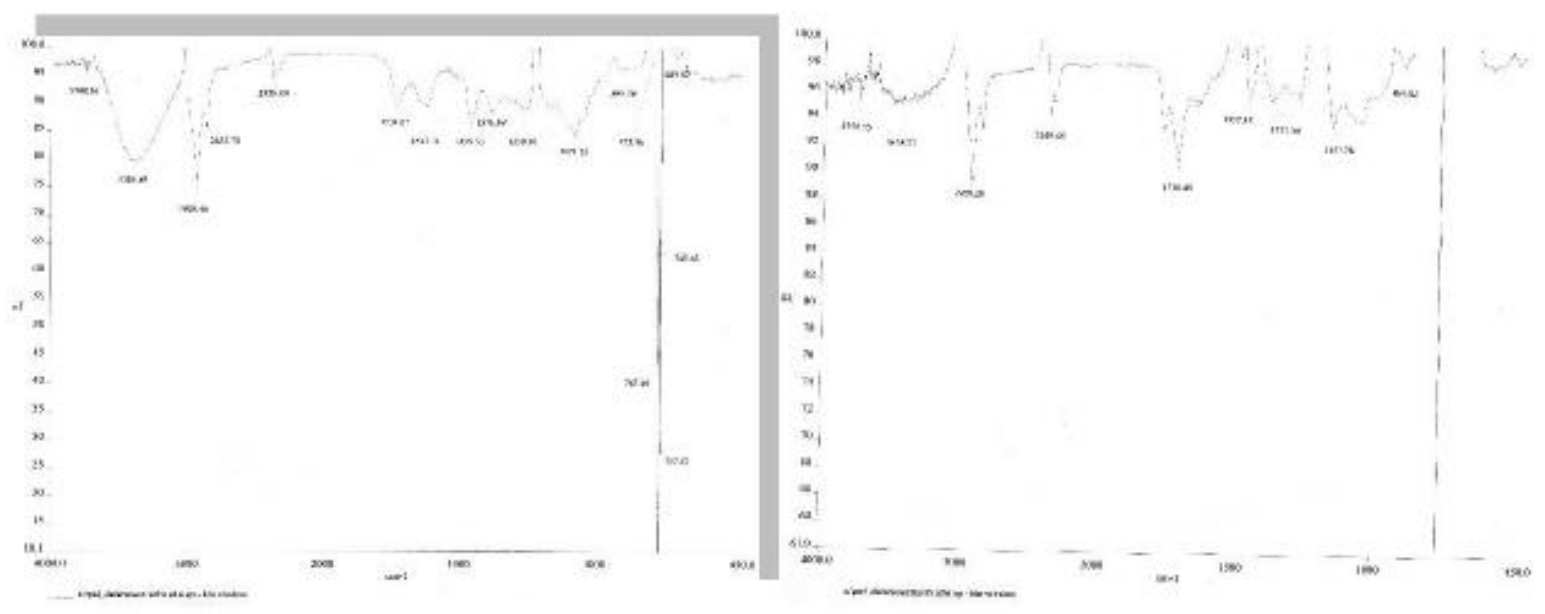

Figure 2a and 2b. The IR spectrum of the crude extract from the albahaka \& alibangbang leaves

Figure 2a of albahaka leaves extract shows that there are different functional groups peaks with different intensity. The broad peak observed at $3386.89 \mathrm{~cm}^{-1}$ assigned to -COOH carboxylic acids and $1071.53 \mathrm{~cm}^{-1}$ assigned to $\mathrm{C}-\mathrm{F}$ of halogen groups. The medium peak observed at $1731.64 \mathrm{~cm}-1$ attributed to $\mathrm{C}=\mathrm{O}$ stretching of ketones groups and $1617.1 \mathrm{~cm}-1$ with $\mathrm{C}=\mathrm{C}$ from alkenes group. The small peaks observed at 2358 and $2855.73 \mathrm{~cm}^{-1}$ correspond to the $\mathrm{N}-\mathrm{H}$ group and $\mathrm{O}-\mathrm{H}$ stretching carboxylic acid groups. The strong peak observed at $2929.48 \mathrm{~cm}^{-1}$ assigned to $\mathrm{O}-\mathrm{H}$ stretching of the amide. This reveals the presence of various chemical constituent with ethanolic extract in alibangbang leaves extract (figure $2 b$ ). The broad peak is represented by $3438.5 \mathrm{~cm}^{-1}$ for N-H stretching from amide group, $1377.08 \mathrm{~cm}-1$ for C-O stretching of alcohol group and $1151.78 \mathrm{~cm}^{-1}$ for C-F halogen group. For strong peaks, it represents $2929.78 \mathrm{~cm}^{-1}$ for O-H of alcohol $1716.46 \mathrm{~cm}-1$ for $\mathrm{C}-\mathrm{O}$ of lactones and $2355.69 \mathrm{~cm}^{-1}$ for $\mathrm{N}-$ $\mathrm{H}$ stretching for the carboxylic acid group.

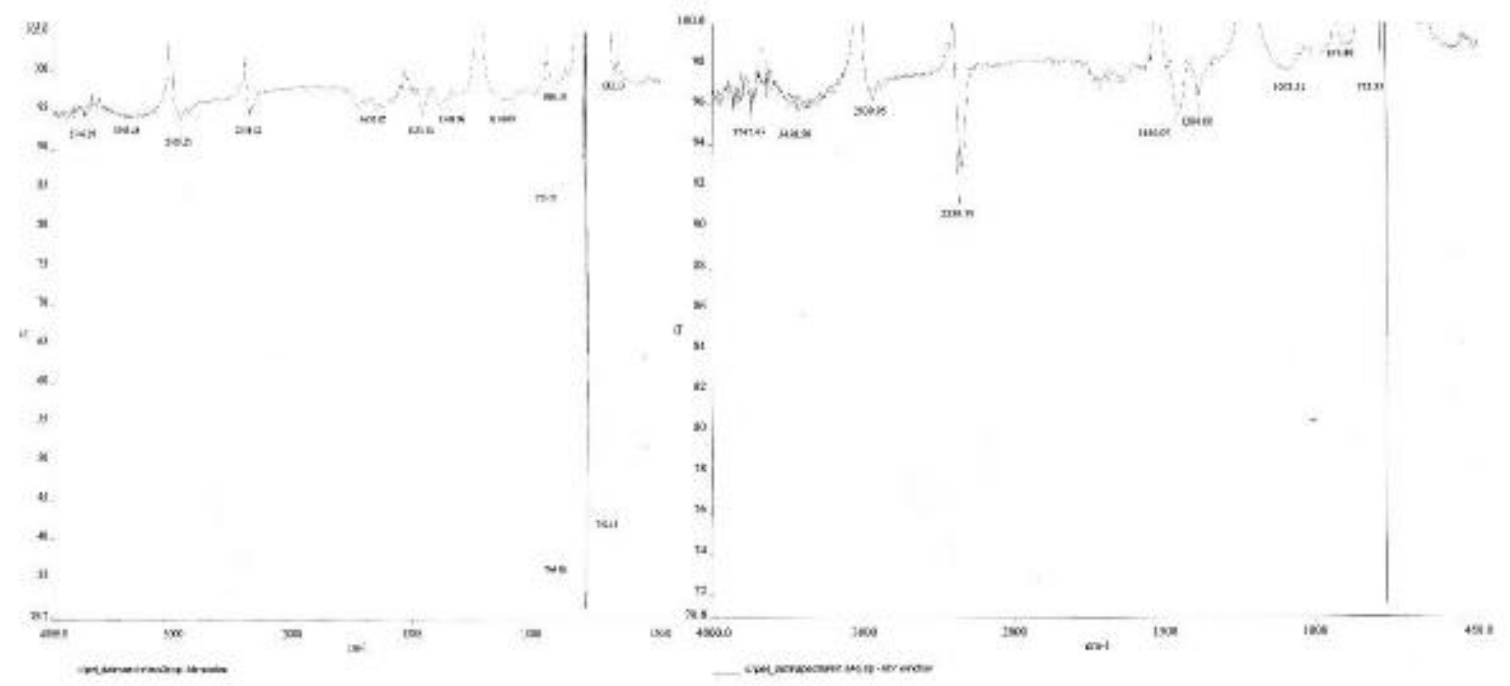

Figure 3a and 3b. The IR spectrum of the crude extract from the Angelika \& elepante leaves 
The absorption spectra of Angelika leaves extract(fig.3a) conforms to a broadband spectrum of $3746.29 \mathrm{~cm}^{-1}$ for $\mathrm{O}-\mathrm{H}$ stretching, $3385.85 \mathrm{~cm}^{-1}$ for $\mathrm{N}-\mathrm{H}$ stretching, $1652.87 \mathrm{~cm}^{-1}$ for C-H stretching and 1114. $09 \mathrm{~cm}^{-1}$ for $-\mathrm{C}-\mathrm{F}$ stretching represented by functional groups of alcohol, amide, aldehyde and halogen groups. Small peaks with a spectrum of $2938.25 \mathrm{~cm}^{-1}$ for O-H stretching, $2358.42 \mathrm{~cm}^{-1}$ for N$\mathrm{H}$ stretching and $1456.16 \mathrm{~cm}^{-1}$ for $-\mathrm{C}-\mathrm{H}$ stretching from the functional groups of amide, carboxylic acid, an alkene. The dominant band of the elepante leaves extract (fig. $3 \mathrm{~b}$ ) was observed at $2939.95 \mathrm{~cm}^{-}$ ${ }^{1}$ with O-H stretching, $2359.19 \mathrm{~cm}-1 \mathrm{~N}-\mathrm{H}$ stretching, $1456.07 \mathrm{~cm}^{-1}$ with C-H stretching and 1384.60 $\mathrm{cm}^{-1}$ with C-O stretching which represents the amide, carboxylic acid, alkenes, and alcohol. The band at $1073.31 \mathrm{~cm}^{-1}$ and $878.89 \mathrm{~cm}^{-1}$ was due to the halogen compound. The band at $773.35 \mathrm{~cm}^{-1}$ stretching of $\mathrm{C}-\mathrm{H}$ that shows aromatic compounds.

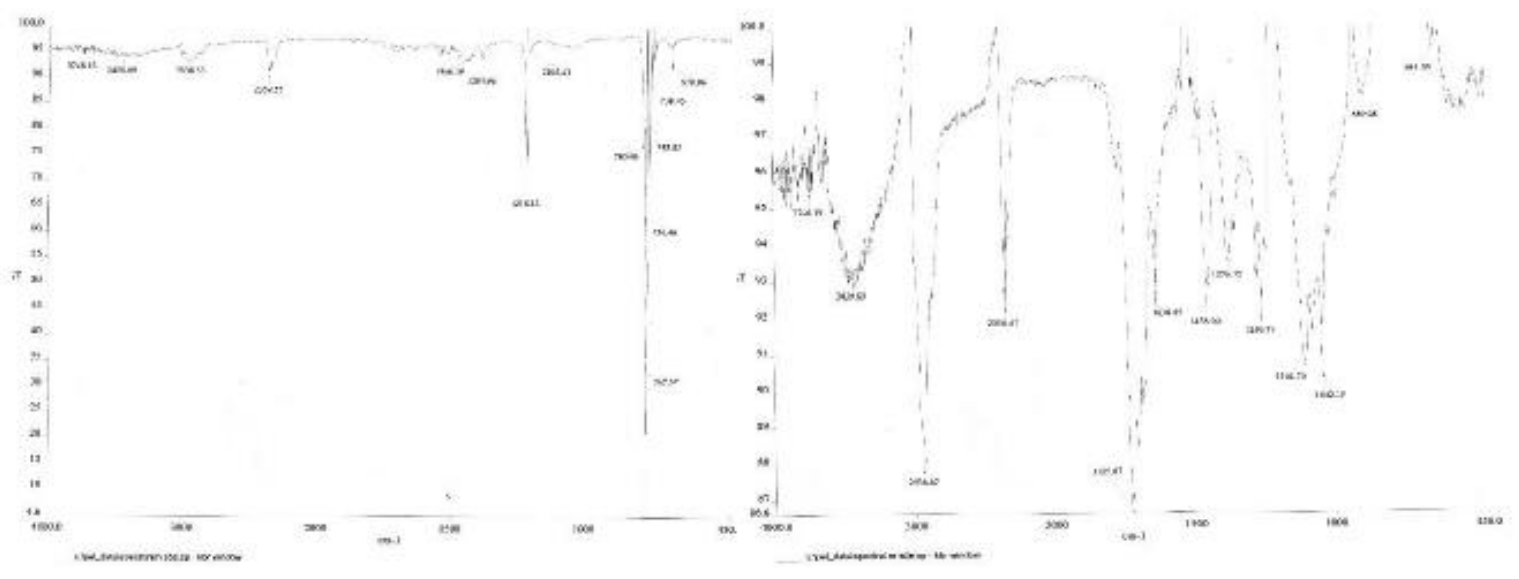

Figure $4 \mathbf{a}$ and $\mathbf{4 b}$. The IR spectrum of the crude extract from the Gabon \& hilbas leaves

Figure $4 \mathrm{a}$ shows a very strong absorption of Gabon leaves extract band between 1218.13 and 1205.4 $\mathrm{cm}^{-}{ }^{1}$ indicates the presence of nitro compounds derivatives. The vibration of $\mathrm{NH} 3$ shows the presence of a primary amine. The C-H stretching group of bands of $780.69 \mathrm{~cm}^{-1}, 767.37 \mathrm{~cm}^{-1}, 756.46 \mathrm{~cm}^{-1}, 749.82$ $\mathrm{cm}^{-1}$ and $738.76 \mathrm{~cm}^{-1}$ shows functional groups of aromatic compounds. The bands observed at near $670.06 \mathrm{~cm}^{-1}$ represent the C-Cl group in halogen. While different bands occurring at $3748.12 \mathrm{~cm}^{-1}$ for $\mathrm{O}-\mathrm{H}$ stretching of alcohol, bands between $3450.09 \mathrm{~cm}^{-1}$ and 2938.53 for stretching's of N-H/O-H which indicates the presence of amides. Further bands of $2359.57 \mathrm{~cm}^{-1}$ for $-\mathrm{COOH}$ stretching for carboxylic acids and finally $1384.96 \mathrm{~cm}^{-1}$ for stretching of C-H for alkenes group.

Figure $4 \mathrm{~b}$ of hilbas leaves extract displays more intense bands occurring at $2936.67 \mathrm{~cm}^{-}, 3439.89$ $\mathrm{cm}^{-}{ }^{-}, 2358.87 \mathrm{~cm}^{-}{ }^{1}, 1725.07 \mathrm{~cm}^{-}{ }^{1}$ corresponding to $\mathrm{O}-\mathrm{H} / \mathrm{N}-\mathrm{H} / \mathrm{N}-\mathrm{H}, \mathrm{C}=\mathrm{O}$ stretching/ bending vibrations respectively indicate the presence of amide, amino acids, and ketones. The very strong absorption band of $3746.19 \mathrm{~cm}^{-1}$ may be due to the presence of bonded $\mathrm{O}-\mathrm{H}$ stretching of alcohol. The very strong absorption around bands of $1638.05 \mathrm{~cm}^{-}{ }^{1}, 1376.75 \mathrm{~cm}^{-}{ }^{1}$ and $1259.77 \mathrm{~cm}^{-1}$ in ethanol extract with $\mathrm{N}=\mathrm{O}$ stretching/ bending vibrations for nitro compounds. The very strong absorption band observed between 1104.70-1042.15 cm- ${ }^{1}$ region indicates the presence of ether. It also illustrates a band of $885.68 \mathrm{~cm}^{-1}$ and $641.05 \mathrm{~cm}^{-1}$ for stretching of the $\mathrm{C}-\mathrm{Cl}$ band coming from the halogen group. 


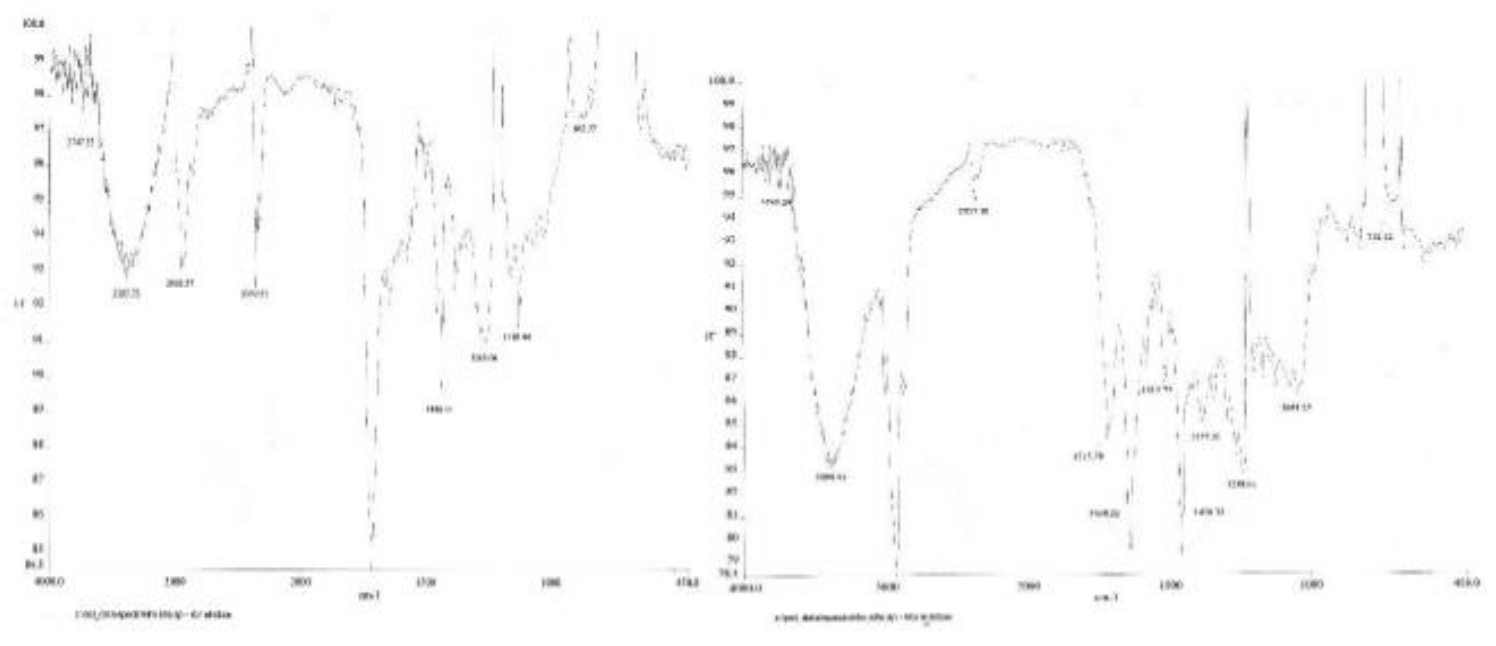

Figure 5a and 5b. The IR spectrum of the crude extract from the kalaboleaves and lunas bark.

The strong peak of (fig.5a) represents a band between $2952.37 \mathrm{~cm}^{-1}$ and $1436.61 \mathrm{~cm}^{-1}$ with C-H stretching of alkanes group and $2359.27 \mathrm{~cm}^{-}{ }^{1}$ from the N-H stretching of an amino acid group. The broad bands of $3747.32 \mathrm{~cm}^{-1}$ (O-H stretching), $3385.73 \mathrm{~cm}^{-1}\left(\mathrm{~N}-\mathrm{H}\right.$ stretching), $1263.06 \mathrm{~cm}^{-}{ }^{-1} \mathrm{~N}=\mathrm{O}$ stretching), $1130.44 \mathrm{~cm}^{-1}$ (C-O stretching) and $862.32 \mathrm{~cm}^{-1}$ (C-Cl stretching) represented by alcohol, amide, nitro compounds, ethers and halogen groups.

The strong peak of lunas bark (fig.5b) ethanolic extract appears at the band of $3384.43 \mathrm{~cm}^{-1}(\mathrm{~N}-\mathrm{H}$ stretching), $1638.22 \mathrm{~cm}^{-1}$ (C-H stretching), $1456.61 \mathrm{~cm}^{-1}$ (C-H stretching) and $1238.61 \mathrm{~cm}^{-1}(\mathrm{~N}=\mathrm{O}$ stretching) which were associated with groups of amide, aldehyde, alkene and nitro compounds. The broadband absorbance peaks of lunas bark also were having frequencies between $2357.10 \mathrm{~cm}^{-1}$ and $1238.61 \mathrm{~cm}^{-1}$ represented by the $\mathrm{N}=\mathrm{O}$ stretching of nitro compounds. Broader band absorbances of $3749.29 \mathrm{~cm}^{-1}$ (O-H stretching), $2357.10 \mathrm{~cm}^{-1}$ (N-H stretching), $1715.70 \mathrm{~cm}^{-1}$ (C=O stretching), 1377.31 $\mathrm{cm}^{-1}$ (C-Cl stretching), $1043.25 \mathrm{~cm}^{-1}$ (C-O stretching) and 712.12 $\mathrm{cm}^{-1}(\mathrm{C}=\mathrm{O}$ stretching $)$ associated with different functional groups of alcohol, amino acid, lactones, halogen, ethers and aromatic compounds.

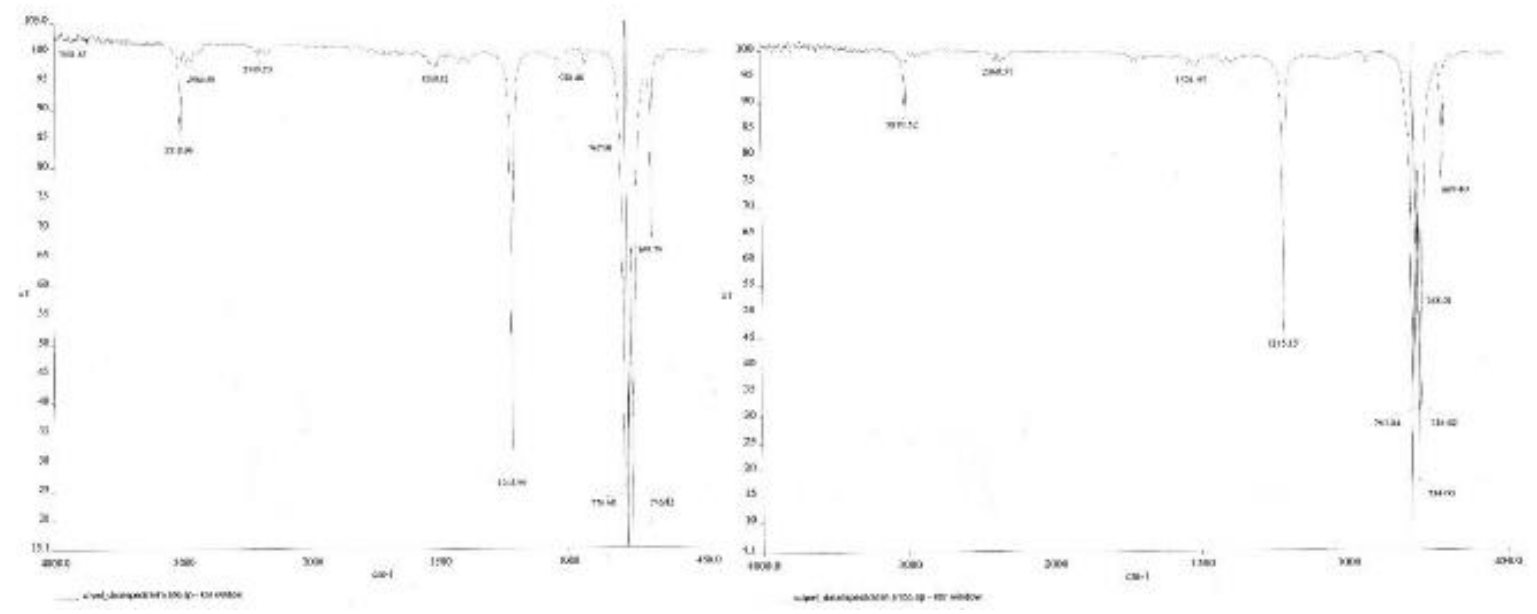

Figure 6a and 6b. The IR spectrum of the crude extract from the makulibhag bark and sawan-sawan leaves

The very strong absorption peak observed with makulibhag bark extract (fig.6a) around $1215.98 \mathrm{~cm}^{-}$ ${ }^{1}$ (C-O stretching) may be due to the presence of ethers, absorption peaks of $776.68 \mathrm{~cm}^{-1}, 746.82 \mathrm{~cm}^{-1}$ and $669.70 \mathrm{~cm}^{-1}$ associated with $\mathrm{C}-\mathrm{Cl}$ stretching of halogen groups. The small absorption peaks of different frequencies of $3851.87 \mathrm{~cm}^{-1}$ (O-H stretching) for the presence of alcohol, $3018.96 \mathrm{~cm}^{-1}$ to $1508.16 \mathrm{~cm}^{-1}$ (O-H stretching) for amide group, $2399.70 \mathrm{~cm}-1$ (N-H stretching) for the presence of amino acid and 928.48 (C-O stretching) for the functional group of ethers. The strong absorption bands of sawan-sawan leaves extract (fig.6b) with wave numbers of 3019.52 in C-H stretching for the presence of alkanes, 2360.57 in N-H stretching with an amino acid group and 1521.95 
in $\mathrm{N}=\mathrm{O}$ stretching with nitro compounds groups. Weak absorption bands represented by different frequencies of $1215.15 \mathrm{~cm}^{-1}$ ( $\mathrm{N}=\mathrm{O}$ stretching) for nitro compounds, peaks associated with 745.62/ $758.01 / 669.49 \mathrm{~cm}-1$ with $\mathrm{C}-\mathrm{Cl}$ stretching for the presence of halogen compounds, $763.84 \mathrm{~cm}-1$ with $\mathrm{C}-\mathrm{H}$ stretching of aromatic compounds and finally $754 \mathrm{~cm}-1$ with $\mathrm{C}-\mathrm{O}$ stretching with ether compound in the ethanolic extract of sawan-sawan.

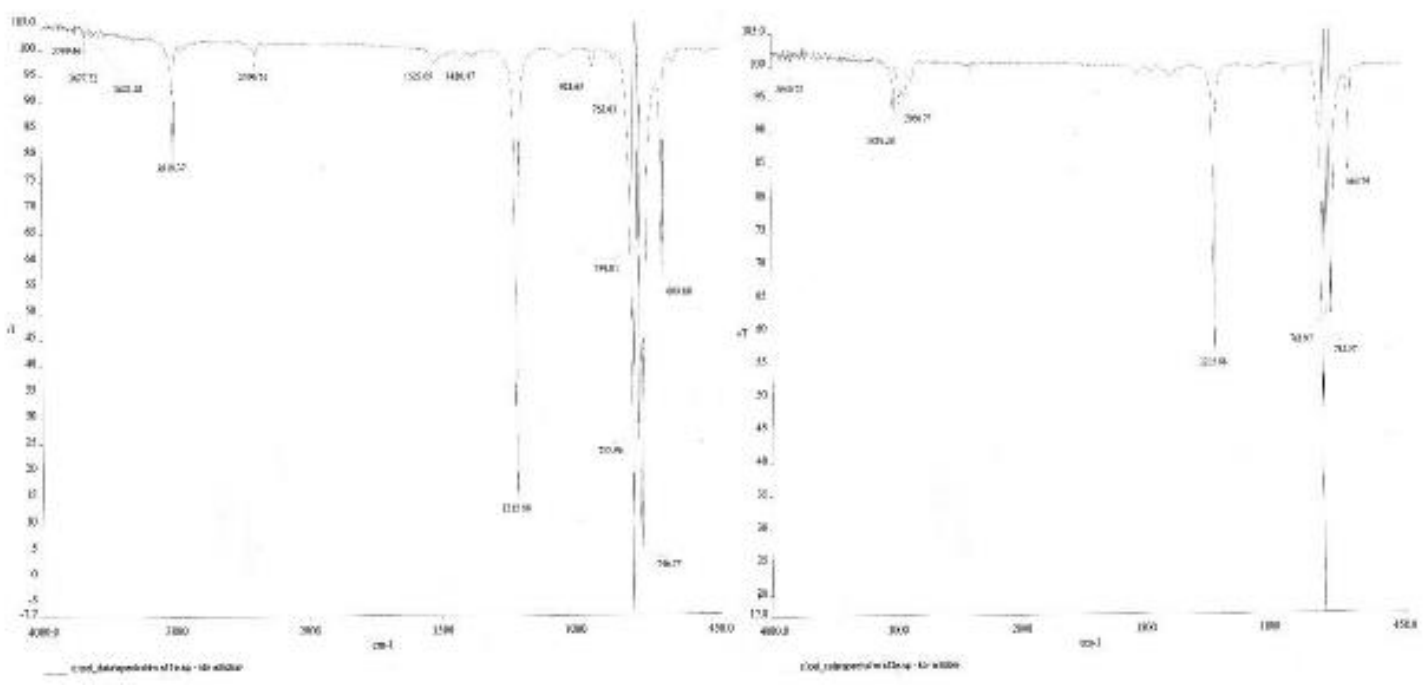

Figure 7a and 7b. The IR spectrum of the crude extract from the sinaw-sinaw leaves and tagbak tubers

Figure $7 \mathrm{a}$ above shows the absorbance bands of sinaw-sinaw ethanolic leaves extract with strong peaks of 3019.37 and $1420.47 \mathrm{~cm}^{-1}$ ( C-H stretching) for alkane groups, 1215.86 and $1522.05 \mathrm{~cm}^{-1}$ ( $\mathrm{N}=\mathrm{O}$ stretching) for nitro compounds, 759.81, 755.96 and755.96 $\mathrm{cm}^{-1}$ (C-H stretching) for aromatic compounds and $669.68 \mathrm{~cm}^{-1}$ ( $\mathrm{C}-\mathrm{Cl}$ stretching ) for halogen group. For weak peaks of sinaw-sinaw ethanolic extract with spectra of $3799.46,3677.72$ and3622.28 cm- ${ }^{-1}$ ( C-H stretching) represented with alcohol compounds, $2399.74 \mathrm{~cm}^{-1}$ ( N-H stretching) for amino acids and finally $928.65 \mathrm{~cm}^{-1}$ ( C-O stretching) for ether group of compounds.The IR absorbance of tagbak ethanolic extract(fig.7b) with prominent peaks of $1215.88 \mathrm{~cm}^{-1}$ ( C-H stretching) for alkane group, $2360.57 \mathrm{~cm}^{-1}, 743.57 \mathrm{~cm}^{-1}$ and $669.74 \mathrm{~cm}^{-1}$ ( C-Cl stretching) for halogen compounds. Short waves spectrum of $3850.73 \mathrm{~cm}^{-1}$ ( O-H stretching) for alcohol, $3010.20 \mathrm{~cm}^{-1}$ (O-H stretching) for amide compound and $2966.77 \mathrm{~cm}^{-1}$ (C-H stretching) for alkane compounds.

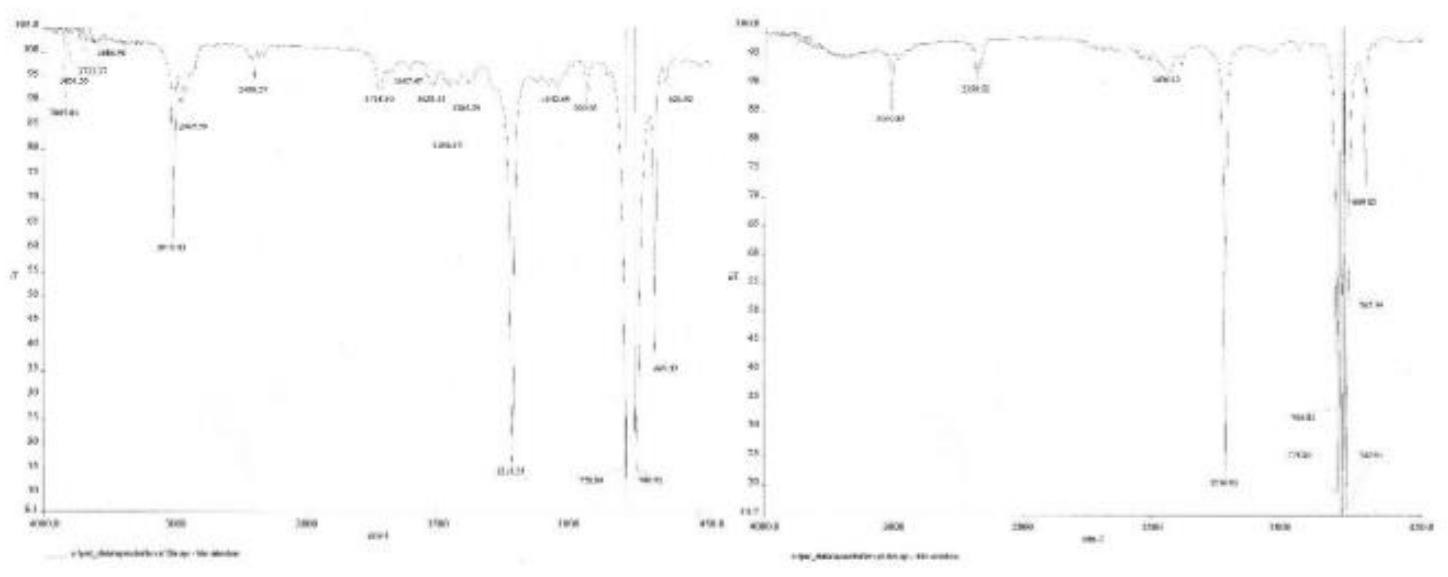

Figure 8a and 8b. The IR spectrum of the crude extract from the talawa-tawa and tawa-tawa leaves

Talawa-tawa leaves extract (fig.8a) subjected to IR shows the strong absorbance of 3865.84/ $3851.55 / 3733.37$ and $3686.96 \mathrm{~cm}^{-1}$ for $\mathrm{O}-\mathrm{H}$ stretchings of an alcohol group, absorbance peaks of 3019.43 to $2967.23 \mathrm{~cm}^{-1}$ for O-H stretching of amide groups and strong peaks of 740.95, 669.32 and $626.92 \mathrm{~cm}^{-1}$ for $\mathrm{C}-\mathrm{Cl}$ stretchings for halogen compounds. Shortwave absorbances of $2400.23 \mathrm{~cm}-1$ ($\mathrm{COOH}$ stretching $)$ for carboxylic acids, $1718.10 \mathrm{~cm}^{-1}(\mathrm{C}=\mathrm{O}$ stretching $)$ for lactones, 16017.47 to 
$1456.13 \mathrm{~cm}^{-1}$ (C-H stretching) for alkenes compounds, 1520.11 to $1214.24 \mathrm{~cm}^{-1}$ ( $\mathrm{N}=\mathrm{O}$ stretching) for nitro compounds, 1042.59 to $928.03 \mathrm{~cm}^{-1}$ ( C-O stretching) for ethers and $778.84 \mathrm{~cm}-1$ ( C-H stretching) for the aromatic compound. The IR spectrum of the crude ethanolic extract of tawa-tawa shows(fig.8b) short peaks of $3019.35 \mathrm{~cm}^{-1}$ ( O-H stretching) represented by the amide group, $2359.52 \mathrm{~cm}^{-1}$ ( N-H stretching) for the carboxylic acid group, $1436.12 \mathrm{~cm}^{-1}$ ( C-H stretching) for alkenes and a short peak of $778.20 \mathrm{~cm}^{-1}$ ( C-H stretching) for aromatic compounds. For long peak absorbance associated with $1216.65 \mathrm{~cm}^{-1}$ ( $\mathrm{N}=\mathrm{O}$ stretching) for nitro compounds, and long peaks of $765.83 \mathrm{~cm}^{-1}, 762.14 \mathrm{~cm}^{-1}$, $743.14 \mathrm{~cm}^{-1}$ and $669.82 \mathrm{~cm}^{-1}$ ( $\mathrm{C}-\mathrm{Cl}$ stretching) for halogen group of compounds.

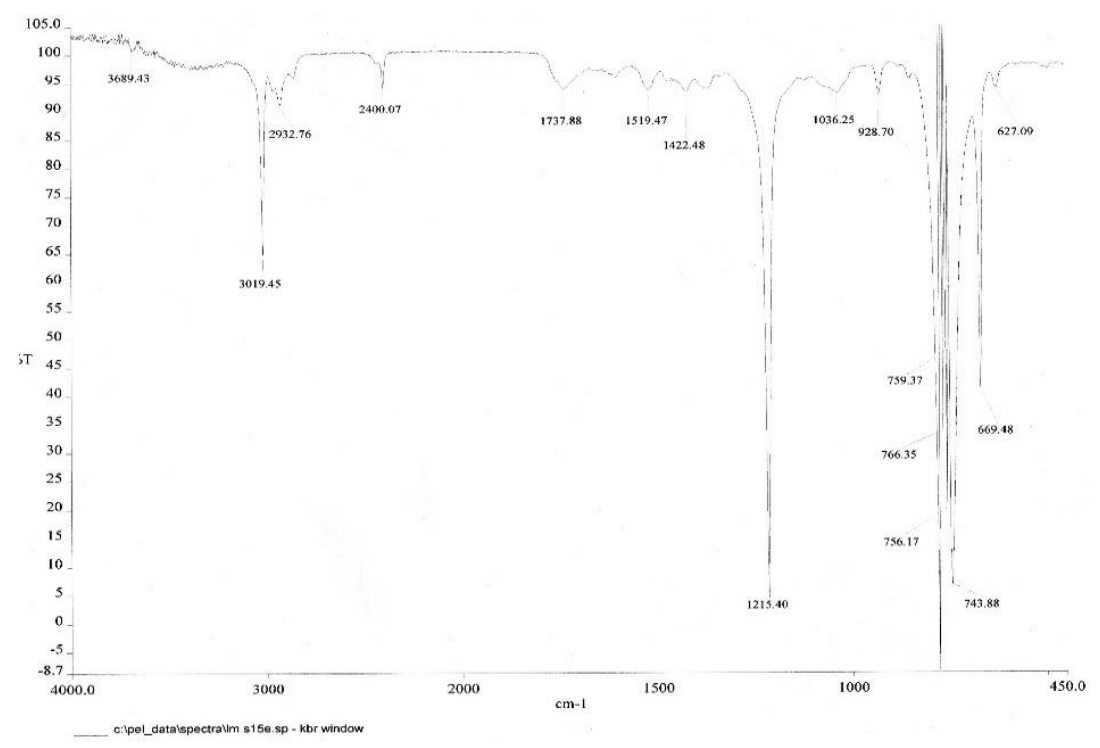

Figure 9.The IR spectrum of the crude extract from the togup bark

Finally the togup bark ethanolic extract (fig.9) has IR spectrum peaks of $3689.43 \mathrm{~cm}^{-1}$ ( O-H stretching) for alcohol, $3019.45 \mathrm{~cm}^{-1}$ ( C-H stretching) for alkane group, $2932.76 \mathrm{~cm}^{-1} / 1519.47 \mathrm{~cm}^{-1}$ (O$\mathrm{H} \& \mathrm{~N}-\mathrm{H}$ stretching) for amide groups, $2400 \mathrm{~cm}^{-1}$ ( N-H stretching) for amino acids, $1737.88 \mathrm{~cm}^{-1}(\mathrm{C}=\mathrm{O}$ stretching) for acid anhydride group, $1215.40 / 1036.25 \mathrm{~cm}^{-1}$ (C-O stretching) for ether functional group, $928.70 \mathrm{~cm}^{-1}$ (C-H stretching) for aromatic compounds and finally for 766.35/756.17/743.88/669.48 and 627.09 for $\mathrm{C}-\mathrm{Cl}$ stretching for the components of halogen group of compounds.

\section{Conclusions}

A study on the determination of the bioactive compounds present in the fifteen ethnomedicinal plants extracts through IR spectrophotometric analysis for the presence of the different functional group in plant extracts. It was found out that most of the plant samples has different amino acid groups, anhydride group, aromatic compounds, alcohol group, phenolic compounds, alkane, alkene and alkynes groups and many more important organic compounds. And this should undergo structural elucidation using combining simple biological assays with hyphenated HPLC analyses, such as LC/UV, LC/MS, and LC/NMR. Once a candidate plant has been chosen, a suitable isolation procedure can be employed for the isolation of the active principles to come up of a novel compounds which will be beneficial in the cure of certain diseases for children like asthma, cough and colds, fever, diarrhea, stomach pain, urinary tract infection, boils, antiseptic for wounds, skin disorders, snake bite, skin irritations and simple diseases that will help the lack of medicine in the Mamanwa tribe and even poor communities who will resort on the use of herbal medicinal plants. 
DOI: $10.21522 / \mathrm{TIJBMS} .2016 .04 .01 . A r t 005$

ISSN: $2519-500 \mathrm{X}$

\section{References}

[1]. Agte V.V, Tarwadi K. V., Mangle S. and Chiplonkar S. A. (2000). Potential of Indigenous Green Vegetables as Natural Sources of Fortification of Eight Micronutrients. J. Food Comp. Anal. 13: 885891. Retrieved from Asian scientific journals.com/publication/.../636.

[2]. Ajayi A.O. (2008). Antimicrobial Nature and Use of Some Medicinal Plants in Nigeria. African Journal of Biotechnology, 7(5): 595-599. Retrieved from

www.academicjournals.org/journal/.../BD329BE7.

[3]. Akerele, O. (1984). WHO Traditional Medicine Programmed: Progress and Perspective, WHO Chronicles. Social Science and Medicine, 38:78-81. Retrieved from www.europepmc.org/articles/.../bullwho00089-0002.pd.

[4]. Aruona O.L. (2003). Methodological Considerations for Characterizing Potential Antioxidant Actions of Bioactive Compounds in Plant Foods. Mutat. Res. 522(524)9-20. Retrieved from www.vkingpub.com/.../201409091140134338.pd.

[5]. Enzo A.P. (2007). Traditional Plants and Herbal Remedies Used in the Treatment of Diarrheal Disease: Mode of Action, Quality, Efficacy and Safety Considerations. In: Ahmad I, Aqil F, Owais M, editors. Modern Phytomedicine Turning Medicinal Plants into Drugs. WILEY-VCH Verlag Gmb H \& Co. KGaA, Weinheim, pp.248-260. Retrieved from www.onlinepharmacytech.info/.../JPST11-03-08.

[6]. Farmsworth N.R. and Morris R.W. (1976), Higher Plants- The Sleeping Giant of Drug Development. Am.J. Pharm. 147:46. Retrieved from www.phytojournal.com/vol1 Issue6/Issue.../3.pdf. [7]. Ivanova, D.D. Gerova, T. Chervenkov and T. Yankova, (2005), Polyphenols and Antioxidant Capacity of Bulgarian Medicinal Plants. J. Ethnopharmacol. 96:145-150. Retrieved from www.ncbi.nlm.nih.gov/pmc/articles/PMC3249785/.

[8]. Janovska, D., Kubikova, K., \& Kokoska, L. (2003). Screening for Antimicrobial Activity of some Medicinal Plants Species of Traditional Chinese Medicine. Czech J. Food Sci. 21(3): 107-110. Retrieved from www.ijpsdr.com/pdf/vol4-issue1/8.pdf.

[9]. L.G. Lirio., M.L. Hermano., M.Q. Fontanilla, (1998). Antibacterial Activity of Medicinal Plants from the Philippines. Pharmaceutical Biology, Vol. 36, Issues 5 pp.337-359. Retrieved from www.ijsrp.org/print-journal/ijsrp-mar-2015-print.pdf.

[10]. Mahasned, Adel M. (2002). Screening of Some Indigenous Qatari Medicinal Plants \& Antimicrobial Activity. Phytotherapy Research. 16: 752-753. Retrieved from www.strathprints.strath.ac.uk/view/divisions/12100.type.html.

[11].Mandal, V., Y. Mohan and S. Homalatha, (2007). Microwave-Assisted Extraction- An Innovative and Promising Extraction Tool for Medicinal Plant Research, Pharmacog. Rev., 1:7-18. Retrieved from www.ijpbs.net/vol-3/issue-4/Pharma/41.pdf

[12].Misra, A., (2009). Studies on Biochemical and Physiological Aspects in Relation to PhytoMedicinal Qualities and Efficacy of the Active Ingredients During the Handling, Cultivation, and Harvesting of the Medicinal Plants. J. Med. Plants Res. 3:1140-1146. Retrieved from www.academia.edu/.../ISOLATION_AND_CHAR..

[13].Morgan, K. (2002) Medicine of the Gods: Basic Principles of Ayurvedic Medicine [http://www.compulink.co.uk/ mandrake/Ayurveda.htm

[14].Oliveri C.S (2003) Nutraceuticals, Phytochemicals, and Antioxidants- What are they about? OSU Extension Fact Sheet. L and Cao t, HY 6-5050-98. Retrieved from

www.webmd.com/diet/guide/phytonutrients-faq.

[15].Oomah B. O and Mazza G (2000). Functional foods: In Francis F.J (editions) the Wiley Encyclopedia of Science and Technology $2^{\text {nd }}$ edition, Wiley, New York, USA. Pp 1178-1182. Retrieved from https://www.scribd.com/doc/82961984/Book-Antimicrobials-in-Food.

[16].Pacual M.F., Carretero M.F., Slowing K.V., Villar A. (2002). Simplified Screening by TLC of Lant Drugs. Pharmaceutical Biology, 40(2): 139-143. Retrieved from www.hindawi.com/ journals/ijac/2012/205101/.

[17].Panthi, M.P., \& Chaudhary, R.P. (2006). Antibacterial Activity of Some Selected Folklore Medicinal Plants from West Nepal. Scientific World. 4(4):16-21. Retrieved from www.ansfoundation.org/.../41/47-50.pdf. 
[18].Parekh, L., \& Chanda, S.V. (2007). In Vitro Antimicrobial Activity and Phytochemical Analysis of Some Indian Medicinal Plants. Turk J. Biol, 31:53-58. Retrieved from www.academicjournals. org/.../article1380187752

[19].Philippine Pharmacope.ia PP1 (2004). Retrieved from www.academicjournals.org/.../article1380187752.

[20].Prior R.L and Cao G (2000) Antioxidant Phytochemicals in Fruits and Vegetables-Diet and Health Implications. Horticultural Science 35(4)588-592. Retrieved from www.postharvest.ucdavis.edu/libraries/List.../Section_6.

[21].Shirkumar S. and T.K. Ravi, (2007). Approaches Towards Development and Promotion of Herbal Drugs, Phcog. Rev., 1:180-184. Retrieved from www.ijppsjournal.com/Vol4 Issue1/3173.pdf.

[22].Sigh A.P. (2006). Short Review: Distribution of Steroid like Compounds in Plant Flora. Pharmacognosy Magazine, 2(6):87-89. Retrieved from www.ijpbs.net/vol-3/issue-2/pharma /30.pdf.

[23].Soughari J.H, Elmahmood A. M, and Tyoyina I (2008). Antibacterial Activity of Leaf Extracts of Senna obtustolia L.J. of Pharmacy and Pharmacology, vol 2 1:7:13. Retrieved from www.ijirr.com/sites/default/files/issues/0501.pdf.

[24].Steimez K.A. and Potter J.D. (1996). Vegetables, Fruits, and Cancer Prevention: A Review. Journal American Diet Association, 96:1027-1039. Doi 10.1016/50002-8223 (96) 00273-8. Retrieved from www.andjrnl.org/article/S0002...8/references.

[25].Vital, P.G., \& Rivera, W.L., 2009. Antimicrobial Activity and Cytotoxicity of Chromolaena Odorata (1.f.) King and Robinson and Uncaria Perrottetii (A. Rich). Merr Extracts. Journal of Medicinal Plants Research,3(7):511-518. Retrieved from www.sciencedirect.com/... /S1995764511602022.

[26].Wijte A. (2005). Combating Arundo Donaz and Other Rhizomaous Aquatic and Estuarine Nuisance Grasses by Exploiting their Ecophysiological Characteristics. Research completion reports, California sea grant college program. Retrieved from www.ethnoleaflets .com/leaflets /cleroden.htm. 
Texila American University,

Lot 2442, Plantation Providence,

East Bank Demerara (EBD),

Guyana, South America.

\section{GLOBAL OFFICE}

Texila Education \& Management Services (P) Ltd,

Module 310, III floor,

TIDEL Park, ELCOT-SEZ,

Aerodrome Post, Coimbatore-641014,

Tamilnadu, India.

$\bowtie$ ejournal.assist@tau.edu.org

s texila.aco32

(Di) +918056580933 